CASSIA MASSUCATO NISHIJIMA HELENO

\title{
PREPARAÇÃO E CARACTERIZAÇÃO DE SENSORES DE AMÔNIA BASEADOS EM FILMES ULTRAFINOS DE POLIANILINA E POLIANILINA- FTALOCIANINAS
}

Dissertação apresentada à Escola Politécnica da Universidade de São Paulo para obtenção do Título de Mestre em Engenharia. 
CASSIA MASSUCATO NISHIJIMA HELENO

\section{PREPARAÇÃO E CARACTERIZAÇÃO DE SENSORES DE AMÔNIA BASEADOS EM FILMES ULTRAFINOS DE POLIANILINA E POLIANILINA- FTALOCIANINAS}

Dissertação apresentada à Escola Politécnica da Universidade de São Paulo para obtenção do Título de Mestre em Engenharia.

Área de concentração:

Microeletrônica

Orientador:

Prof. Dr. Ely Antônio Tadeu Dirani

SÃO PAULO

2007 
Este exemplar foi revisado e alterado em relação à versão original, sob responsabilidade única do autor e com a anuência de seu orientador.

São Paulo, de novembro de 2007.

Assinatura do autor

Assinatura do orientador

\section{FICHA CATALOGRÁFICA}

Heleno, Cassia Massucato Nishijima

Preparação e caracterização de sensores de amônia baseados em filmes ultrafinos de polianilina e polianilina-ftalocianinas / C.M.N. Heleno. -- ed.rev. -- São Paulo, 2007.

$78 \mathrm{p}$.

Dissertação (Mestrado) - Escola Politécnica da Universidade de São Paulo. Departamento de Engenharia de Sistemas Eletrônicos.

1.Polímeros condutores 2.Amônia 3.Filmes finos 4.Ftalocianinas I.Universidade de São Paulo. Escola Politécnica. Departamento de Engenharia de Sistemas Eletrônicos II.t. 
Aos meus amados Mario, Efigenia, Catarine, Evandro e Victor. 


\section{AGRADECIMENTOS}

Ao Deus Pai, Filho e Espírito Santo, por permitir que este trabalho tenha sido realizado.

Ao orientador e amigo Prof. Dr. Ely Antonio Tadeu Dirani pela paciência, pelos conselhos e constante incentivo.

A todos os colegas do GSMAT, entre eles Leonardo, Gerson, Emerson, Nadja, John Paul, João, Fábio, Adriana, Ênia e Mauricio, pelo apoio e companheirismo.

Aos professores Fernando Josapetti, Rodrigo Bianchi, Adnei Andrade, Roberto Onmori e Valtencir Zuccoloto, pela colaboração e inspiração.

Aos colaboradores do LME e IFSC: Jair, Teresa, Marcos, Henrique, Níbio e demais da Sala Limpa e oficina.

Ao meu marido, minha irmã, meus pais e meu filho pela compreensão, apoio, orações e incentivo.

Aos meus amigos da GE Motors, em especial a Antonio Mendes, pelo incentivo e apoio durante o período de conclusão do trabalho.

A CAPES, pelo apoio financeiro.

A todos que, direta ou indiretamente, colaboraram durante o desenvolvimento deste trabalho. 


\section{RESUMO}

O presente trabalho tem como objetivo o estudo e o desenvolvimento de dispositivos eletrônicos, para o monitoramento de gás de amônia, confeccionados com filmes ultrafinos de polianilina e ftalocianinas metálicas.

Foram fabricados três diferentes tipos de sistemas: polianilina/PVS, polianilina/ftalocianina de níquel e polianilina/ftalocianina de cobre, sendo a espessura dos filmes o parâmetro de análise. Foram preparadas amostras com 10, 20 e 40 bicamadas. Os filmes foram caracterizados por profilometria e espectroscopia de absorção na faixa da radiação do UV - visível. Observou-se um aumento linear da espessura dos filmes com o aumento do número de bicamadas depositadas.

Os dispositivos foram preparados a partir da deposição dos filmes ultrafinos de polianilina e ftalocianinas sobre substratos de vidro com eletrodos interdigitados de ouro evaporados termicamente.

Os dispositivos foram caracterizados eletricamente por medidas de variação da resistência elétrica, em regime de corrente contínua e alternada, para diferentes concentrações de amônia. Também foi analisado o efeito da temperatura e da umidade relativa do ar na sensibilidade dos dispositivos.

Todas as estruturas apresentaram uma dependência direta do valor da resistência elétrica com a concentração de amônia. Os dispositivos baseados em filmes de polianilina e ftalocianina de níquel apresentaram a menor variação do valor de resistência elétrica com a umidade relativa do ar. Esta característica é bastante desejável já que os ambientes nos quais se pretende utilizar este tipo de dispositivo para de monitoramento do gás de amônia, pode sofrer grandes variações no valor da umidade relativa do ar, como é o caso de granjas em geral. 


\begin{abstract}
The aim of this work is the study and development of electronic devices for ammonia gas monitoring based on polyaniline and metal phthalocyanines ultrathin films.

It was produced three different systems: polyaniline/PVS, polyaniline/nickel phthalocyanine of and polyaniline/copper phthalocyanine and the analysis parameter of the films is the thickness. Samples were prepared with 10, 20 and 40 bilayers. The films were characterized by profilometry and spectroscopy of absorption of radiation in the range of UV-visible. There was a linear increase the thickness of the films with the increase in the number of deposited bilayers. The devices were prepared from the deposition of polyaniline and ftalocianines ultrathin films on glass substrates with interdigited electrodes of gold evaporated thermally.

The devices were prepared from the polyaniline and phthalocyanine deposition of ultrathin films over glass substrates with gold interdigited electrodes. The devices were characterized electrically by measures of variation of electrical resistance, under the direct current and alternating, for different concentrations of ammonia. It was also examined the effect of temperature and relative humidity of the air in the sensitivity of the devices.

All structures had a direct dependence of the value of the electrical resistance with the ammonia concentration. Devices based on films of polyaniline and nickel phthalocyanine of had the slightest variation in the amount of electrical resistance with the relative humidity. This feature is desirable because the environments in which it intends to use this type of device for tracking of ammonia gas, may undergo major changes in the value of the relative humidity of the air, such as poultry houses in general.
\end{abstract}




\section{SUMÁRIO}

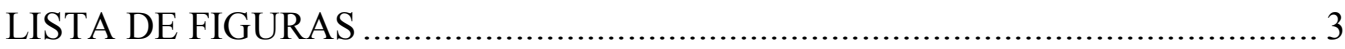

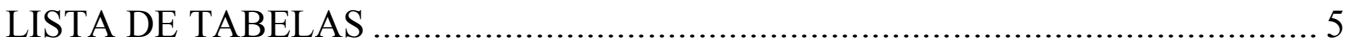

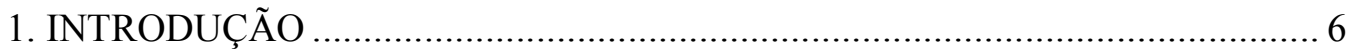

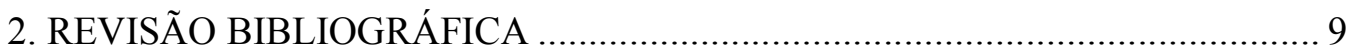

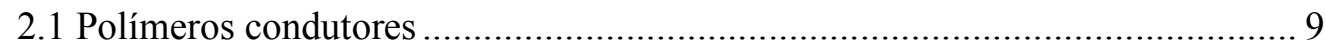

2.1.1. Polímeros conjugados .................................................................... 10

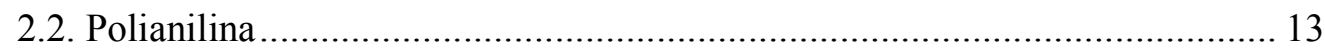

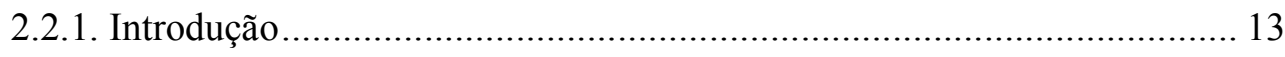

2.2.2. Estados de oxidação ………………………………………………... 13

2.2.3. Mecanismos de dopagem ................................................................... 15

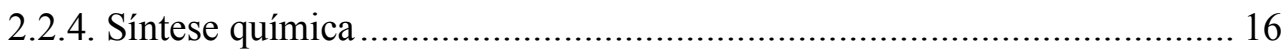

2.2.6. Reação da polianilina na presença de amônia. ........................................... 18

2.2.7. Reação da polianilina na presença de umidade. ......................................... 19

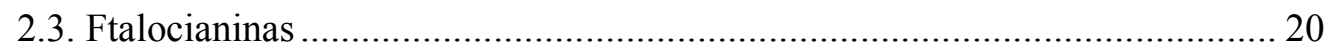

2.4. Técnica de deposição de filmes finos automontados ...................................... 24

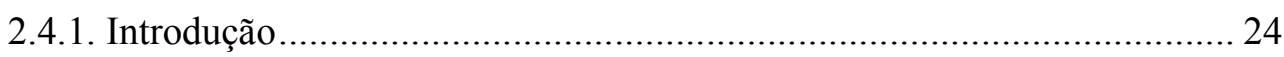

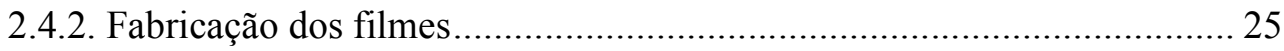

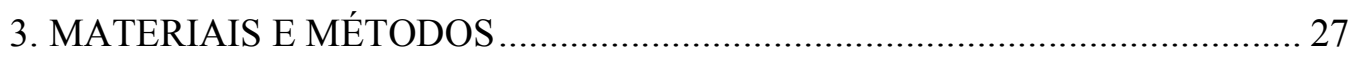

3.1. Etapa 1: Preparação dos materiais ………………………………………........ 27

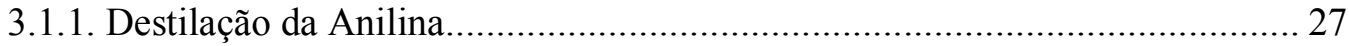

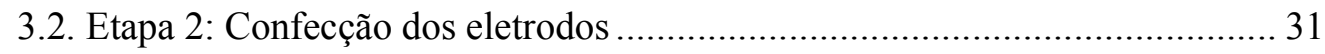

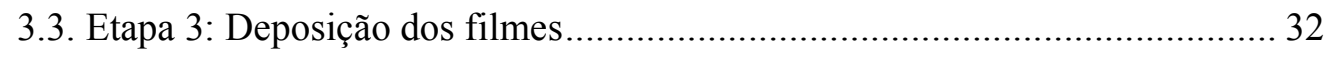

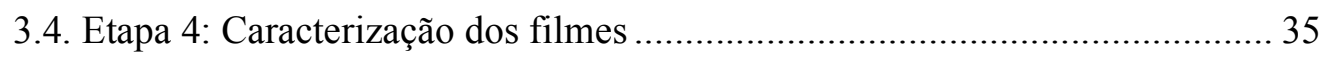

3.4.1. UV-vis : Espectroscopia de ultravioleta visível........................................ 35

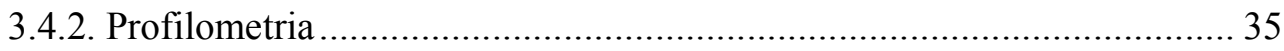


3.5. Etapa 5: Caracterização dos dispositivos ................................................ 36

3.5.1. Medida de resistência em corrente/tensão contínua................................ 36

3.5.2. Medida de resistência em corrente/tensão alternada.............................. 37

3.5.3. Medida de resistência em corrente/tensão alternada: resposta a variação de temperatura e umidade......................................................................... 38

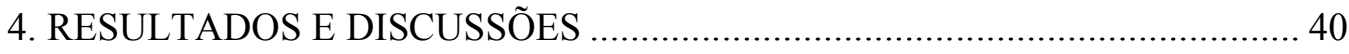

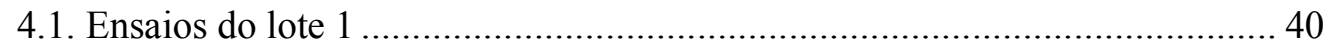

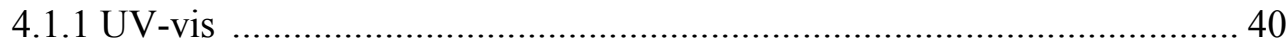

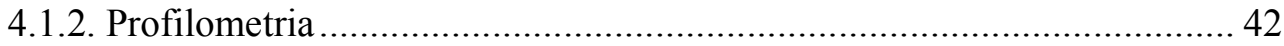

4.1.3. Comportamento elétrico dos dispositivos: ensaios em DC ................... 42

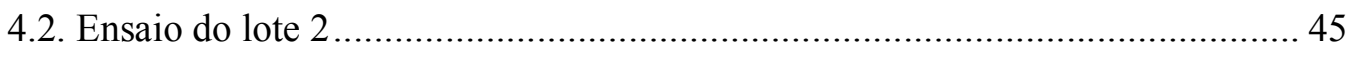

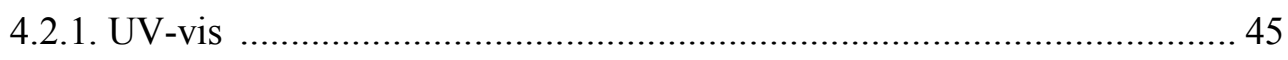

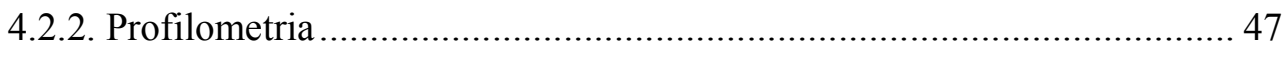

4.2.3. Comportamento elétrico dos dispositivos: ensaios em AC: .................. 47

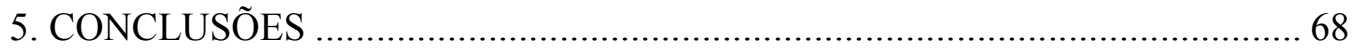

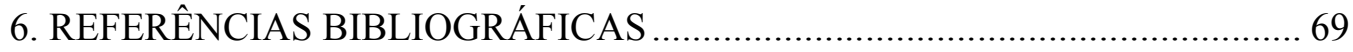




\section{LISTA DE FIGURAS}

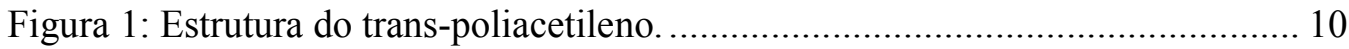

Figura 2: Formação do sóliton. ....................................................................... 11

Figura 3: PAni na forma de sal, totalmente oxidada e condutora.......................... 14

Figura 4: Fórmula gerâl"da polianilina. Configuração "não dopada, forma de base... 14

Figura 5: Protonação da polianilina. Conversão de isolante para condutor sem

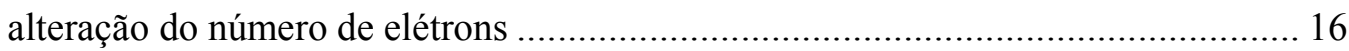

Figura 6: Processo de dopagem e desdopagem da PAni .........................................18

Figura 7: Ligação de hidrogênio entre Polianilina e a molécula da água ................. 19

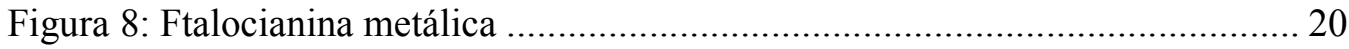

Figura 9: Representação estrutural da Ftalocianina de Cobre Tetrassulfonada......... 22

Figura 10: Esquema do aparato montado para destilação da anilina ...................... 28

Figura 11: Esquema da síntese química da Polianilina ....................................... 30

Figura 12: Diagrama esquemático dos eletrodos interdigitados de ouro e níquel

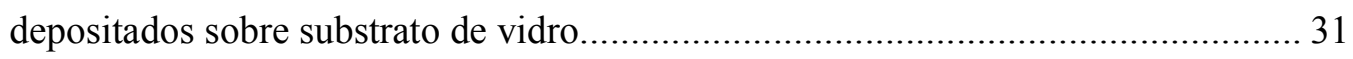

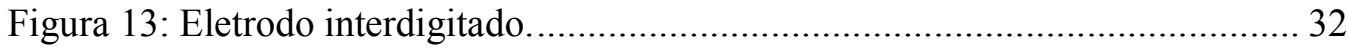

Figura 14: Esquema da deposição dos filmes poliméricos por automontagem......... 33

Figura 15: Eletrodos de ouro com filme de 40 bicamadas de PAni/ PVS. .............. 34

Figura 16: Esquema de montagem do aparato para ensaio dos sensores. ................ 37

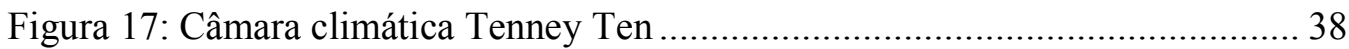

Figura 18: Esquema da montagem realizada para ensaio dos sensores sob variação

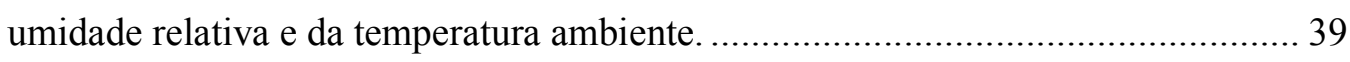

Figura 19: Caracterização por UV-vis dos nove diferentes sistemas...................... 41 Figura 20: Variação da corrente dos sensores PAni/CuTsPc 10 bicamadas, PAni/CuTsPc 20 bicamadas e PAni/PVS 10 bicamadas, alimentados em $2 \mathrm{~V}$ mediante variação da quantidade de amônia. 43

Figura 21: Variação da corrente do sensor de PAni/CuTsPc 40 bicamadas alimentado em 2 V mediante variação da quantidade de amônia............................................ 44

Figura 22: Caracterização por UV-vis dos filmes.............................................. 46 
Figura 23: Variação da resistência elétrica dos sensores de Pani/CuTsPC mediante variação da concentração de amônia.

Figura 24: Variação da resistência elétrica dos sensores de Pani/NiTsPC mediante variação da concentração de amônia.

Figura 25: Variação da resistência elétrica dos sensores de Pani/PVS mediante variação da concentração de amônia.

Figura 26: Sensibilidade mediante variação de concentração de amônia nos sensores de PAni/NiTsPc, PAni/CuTsPc e PAni/PVS......................................................... 57

Figura 27: Comparação entre sensores com mesmo número de bicamadas. ............ 58

Figura 28: Tempo de resposta dos sensores mediante 10 ppm de amônia............... 59

Figura 29: Comportamento dos sensores de PAni/ NiTsPc 20 bicamadas mediante variação de temperatura e umidade relativa.

Figura 30: Comportamento dos sensores de PAni/ CuTsPc 20 bicamadas mediante variação de temperatura e umidade relativa.

Figura 31: Comportamento dos sensores de PAni/ PVS 20 bicamadas mediante variação de temperatura e umidade relativa. 65

Figura 32: Comparação da sensibilidade dos diferentes sensores a $20^{\circ} \mathrm{C}, 25^{\circ} \mathrm{C}$ e $30^{\circ} \mathrm{C}$ considerando como resistência inicial os valores a $20 \%$ de umidade relativa. 67 


\section{LISTA DE TABELAS}

Tabela 1: Componentes dos dois lotes de sensores fabricados............................ 34

Tabela 2: Espessura dos nove diferentes filmes confeccionados. ......................... 42 


\section{LISTA DE SÍMBOLOS E ABREVIATURA}

CuTsPc - Ftalocianina tetrassulfonada de Cobre

LbL - Layer-by- layer

LB - Langmuir-Blodgett

NiTsPc - Ftalocianina tetrassulfonada de Níquel

PAni - Polianilina

PcM - Ftalocianinas metálicas

ppm - Partes por milhão

PVS - poli (ácido vinil sulfônico)

t-PA - Trans-poliacetileno

UV-vis : Espectroscopia na região do ultravioleta e do visível 


\section{INTRODUÇÃO}

A presença de gases no ambiente avícola é bastante comum. Vários gases são constantemente produzidos pelas próprias aves e outros por bactérias presentes em suas excreções [1]. Alguns desses gases, como a amônia, quando se acumulam no ambiente das aves, podem causar severas intoxicações [2]. A amônia atua principalmente como irritante para as mucosas do trato respiratório superior e olhos. Níveis de 25 ppm (partes por milhão) podem ser detectados pelo homem através de odor característico [3] e é considerada por alguns criadores de frangos como limite máximo permitido no criadouro [4]. Quando a quantidade de amônia inalada é superior a $60 \mathrm{ppm}$, a ave fica predisposta a doenças respiratórias, aumentando os riscos de infecções secundárias às vacinações [5]. A Sociedade Brasileira de Avicultura sugere que a quantidade máxima de amônia dentro do criadouro de frangos seja de no máximo 11 ppm (partes por milhão) [6], evitando assim eventuais danos à saúde dos animais e funcionários.

Diversos tipos de sensores de amônia estão disponíveis no mercado, baseados nas mais variadas tecnologias [7]. Ho e colaboradores [8] realizaram estudos chegando a conclusão de que para aplicações in-situ em geral, como no caso de criação de frangos, os sensores mais apropriados são os eletroquímicos, especificamente os sensores baseados em variação de condutividade, devido à sua robustez e simplicidade. Dentre os tipos de sensores de gases eletroquímicos que trabalham com variação de condutividade, estão os sensores baseados em semicondutores e os baseados em filmes poliméricos, como a polianilina (PAni). Os filmes poliméricos apresentam uma grande vantagem sobre os tradicionais sensores baseados em semicondutores inorgânicos, que é a possibilidade de trabalhar em temperatura ambiente, já que os sensores baseados em semicondutores inorgânicos requerem altas temperaturas para aumentar a sensibilidade dos materiais [9].

Entre os materiais que têm sido objeto de estudos para utilização em sensores de gases em geral estão também as ftalocianinas. Ftalocianinas metálicas (PcM, onde M pode ser Cobre, Zinco, Níquel, etc.) são semicondutores orgânicos que apresentam alta sensibilidade a gases como o cloro e a amônia. [10]. Assim como no caso dos 
filmes de PAni, a medida da variação da condutividade pode indicar a concentração de gás ao qual o material está sendo submetido [11].

Apesar de serem indicados para monitoração de gases nos mais variados ambientes [12], os sensores poliméricos são susceptíveis à variações de temperatura e umidade [13]. Além destes fatores, gases que são fortemente oxidantes ou redutores também afetam a condutividade do polímero, podendo comprometer a resposta do sensor [14], já que no ambiente da granja coexistem diversos gases.

Em busca de contribuir para um melhor desempenho de sensores baseados em materiais poliméricos, o presente trabalho visa estudar o comportamento elétrico de sensores fabricados com filmes de polianilina e ftalocianinas e eletrodos interdigitados de ouro depositados sobre substratos de vidro, para diferentes concentrações de amônia. Polianilina e ftalocianinas podem ser processadas na forma de filmes finos nanoestruturados, o que aumenta o controle de características necessárias para a confecção dos dispositivos, tal como a espessura. Desta maneira, foram fabricados três diferentes tipos de sistemas: Polianilina, polianilina/ftalocianina de níquel e polianilina/ftalocianina de cobre, sendo cada uma destas com três diferentes espessuras. Após a revisão bibliográfica, é apresentada a parte experimental composta por materiais e métodos utilizados e a caracterização por ultravioleta-visível dos filmes depositados. É estudada posteriormente a variação da resistência dos sensores mediante variação da quantidade de amônia. Separadamente é verificada a variação de resistência com relação à umidade e temperatura, a fim de analisar a influência destas duas variáveis nos dispositivos, verificando assim a viabilidade de cada sistema como sensor de amônia. 


\section{REVISÃO BIBLIOGRÁFICA}

Será apresentada neste capítulo uma breve revisão sobre polímeros condutores. Com maiores detalhes, serão abordadas também a Polianilina e as Ftalocianinas, mecanismos de condução, dopagem e desdopagem, aplicações em sensores de gases além de seus comportamentos mediante o gás de amônia e umidade. Além disso, será descrita a automontagem, método utilizado para deposição dos filmes deste trabalho. Desta maneira, as escolhas dos materiais dos filmes e do método de deposição serão justificadas.

\subsection{Polímeros condutores}

Polímeros são macromoléculas formadas por unidades químicas que se repetem, denominadas monômeros [15]. Os monômeros são geralmente hidrocarbonetos, ou seja, constituídos por ligações de carbono e hidrogênio, ou derivados, que formam a cadeia polimérica [16]. Diversos polímeros são encontrados na natureza e têm origem animal ou vegetal como por exemplo as proteínas, o DNA, e a madeira. Outros são obtidos sinteticamente como o PVC e o PET, que são amplamente utilizados devido as suas características mecânicas. Os polímeros apresentam originalmente característica elétrica isolante, porém, em meados da década de 50, surgiu o interesse em unir as propriedades mecânicas dos polímeros e as propriedades elétricas condutoras dos metais, incorporando-se cargas condutoras como negro de fumo aos polímeros, produzindo os chamados polímeros extrínsecos [17]. Posteriormente, uma outra classe de materiais condutores e semicondutores começou as ser estudada, os chamados polímeros intrínsecos, pois neste caso, os polímeros conduzem corrente elétrica sem a incorporação de portadores de carga elétrica [18].

As propriedades eletrônicas dos polímeros semicondutores começaram a ser descobertas e estudadas com mais ênfase a partir de 1977 quando foram produzidos acidentalmente filmes de trans-poliacetileno (t-PA) que apresentavam um brilho metálico bem diferente do que se conhecia até então. Quando este filme fora exposto ao iodo, o valor da condutividade elétrica obtida era bilhões de vezes maior que os 
filmes em condições originais [19]. Esta é uma das características dos polímeros semicondutores: a possibilidade de torná-los isolantes ou chegar à condutividade próxima dos metais. Esta classe de materiais é também chamada de metais sintéticos, justamente por apresentarem características mecânicas e de processabilidade dos polímeros convencionais e condutividade elétrica similar a dos metais.

\subsubsection{Polímeros conjugados}

A maioria dos polímeros semicondutores apresenta estrutura conjugada (com algumas exceções como a polianilina). A conjugação é a alternância de ligações simples e duplas dos átomos de carbono do polímero. Esta estrutura é possível devido à existência de átomos de carbono hibridizados na forma $\mathrm{sp}^{2}+\mathrm{pz}$. A estrutura eletrônica dos polímeros conjugados pode ser descrita em termos da sobreposição de orbitais pz provenientes da hibridização $\mathrm{sp}^{2}+\mathrm{pz}$. As ligações $\sigma$ (formadas pela sobreposição dos orbitais híbridos $\mathrm{sp}^{2}$ ) unem os átomos de carbono na cadeia polimérica principal (no plano da cadeia) e as ligações $\pi$ (formada pelas sobreposições dos orbitais pz, perpendiculares ao plano da cadeia principal) dão origem a orbitais ocupados $\pi$ e vazios $\pi^{*}$.

Para explicar o processo de condutividade desta classe de polímeros, o transpoliacetileno (t-PA) é o polímero constantemente utilizado por ser o polímero conjugado mais simples. No seu estado normal, ou seja, não dopado, ele é isolante.

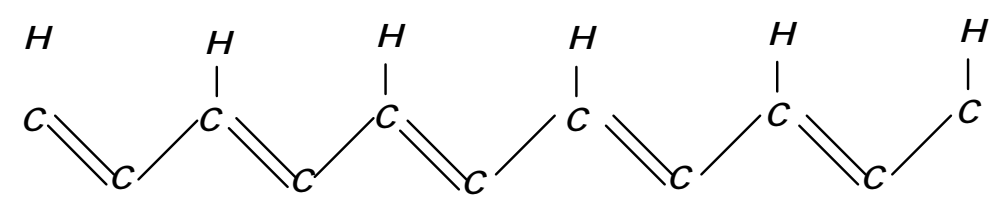

Figura 1: Estrutura do trans-poliacetileno.

Como pode ser visto na Figura 1, o t-PA tem carbonos ligados por ligações simples e duplas alternadamente, caracterizando a conjugação. As ligações simples de carbono $(\mathrm{C}-\mathrm{C})$ são mais longas que as ligações duplas de carbono $(\mathrm{C}=\mathrm{C})$, fato que origina orbitais ocupados $\pi$ e vazios $\pi^{*}$, análogos às conhecidas bandas de 
valência e condução, respectivamente, dos semicondutores inorgânicos. Isto porque esta diferença de comprimento gera uma diferença ou um gap de energia. Este fenômeno é chamado de dimerização, ou instabilidade de Peierls. Alguns estudos mostram que a diferença entre o comprimento das ligações simples e duplas dos átomos de carbono do trans-poliacetileno é de $0,1 \AA$. A formação deste gap pode explicar a característica semicondutora dos polímeros, porém, para explicar o comportamento das cargas, ou portadores, dentro do polímero, é necessário entender o que são sólitons, polarons, bipolarons e éxcitons. Para isso, utilizamos novamente o t-PA, ilustrado agora na Figura 2.

Existe a possibilidade de ocorrer duas ligações consecutivas $\mathrm{C}=\mathrm{C}$ ou duas $\mathrm{C}-\mathrm{C}$, ou seja, a cadeia ficaria dividida entre duas seqüências, uma de ligações simples e dupla (A) e outra de ligações dupla e simples (B). Com esta estrutura degenerada, e com a introdução de defeitos estruturais (não necessariamente este defeito seja uma quebra da molécula, mas sim uma deformação da cadeia), a cadeia polimérica pode adotar esta configuração que alternam duas seqüências, porém sem alterar sua energia. Estes defeitos são chamados de sólitons [20]. Neste caso, a energia é igual dos dois lados do defeito.

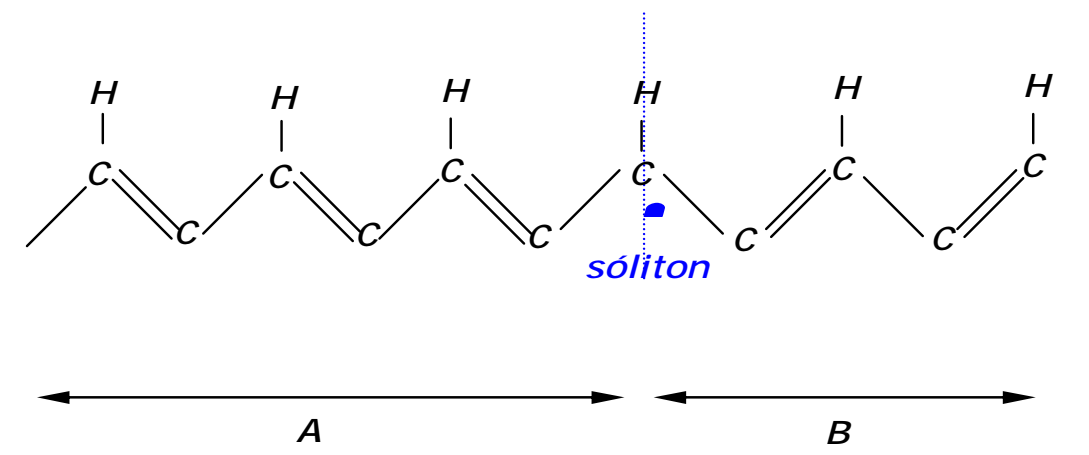

Figura 2: Formação do sóliton.

O sóliton é um defeito de carga elétrica neutra, mas pode existir no estado positivo e negativo, caso sejam adicionadas à cadeia espécies aceitadoras e doadoras. O sóliton não apresenta spin eletrônico, mas torna-se um portador de carga positivo quando um elétron é retirado ou negativo quando um elétron é adicionado. O t-PA, é 
o único polímero que apresenta degenerescência de estado. Todos os outros polímeros, quando separados por um defeito estrutural, ficam com duas regiões de energias diferentes. Neste caso, surge um anti-defeito, ou anti-sóliton, de forma que a seqüência de maior energia fique entre ele e o sóliton. Este par pode decair rapidamente, caso os defeitos sejam neutros, ou se estabelecerem, caso sejam negativos ou positivos. Estes são os chamados polarons, que podem ser negativos ou positivos. Se um sóliton e um anti-sóliton se combinam, surge um outro tipo de defeito denominado bipólaron.

Um critério importante na seleção de polímeros potencialmente condutores é a facilidade com que o sistema pode ser oxidado ou reduzido. Isto leva à escolha de polímeros com insaturações conjugadas que possuam baixo potencial de oxidação. Os elétrons das ligações $\pi$ podem ser facilmente removidos ou adicionados, para formar um íon polimérico, sem a destruição das ligações necessárias para a estabilidade da macromolécula [21]. 


\subsection{Polianilina}

\subsubsection{Introdução}

A polianilina é um polímero condutor, integrante da classe dos chamados metais sintéticos [22]. Esta classe de materiais tem sido objeto de diversas pesquisas [23-24], pois suas aplicações são promissoras em áreas como sensores, diodos emissores de luz, biossensores e baterias [25-26] entre outras [27].

Diversos polímeros condutores têm sido objeto de estudos como o polipirrol [28- 29], o politiofeno, polifenileno, além da polianilina, [30]. O primeiro polímero condutor, o poliacetileno, foi obtido em 1977 [19] com sua exposição a agentes dopantes, transformando-o de material isolante (condutividade da ordem de $10^{-}$ ${ }^{5} \mathrm{~S} / \mathrm{cm}$ ) em condutor elétrico (condutividade de $10^{2} \mathrm{~S} / \mathrm{cm}$ ). Todavia, mesmo com sua alta condutividade elétrica, características como instabilidade térmica e dificuldade de processamento fazem com que outros tipos de polímeros sejam estudados a fim de superar tais dificuldades. A polianilina (PAni) é um dos polímeros que vem sendo amplamente estudado, pois apresenta facilidade na polimerização e dopagem, boa estabilidade química ambiental e baixo custo. Desta maneira, várias aplicações tecnológicas têm se utilizado deste material para produzir sensores, entre outros dispositivos.

\subsubsection{Estados de oxidação}

A Figura 3 ilustra a PAni em forma de sal esmeraldina, quando é condutora. Já a polianilina quando na forma de base (não dopada e não condutora) está ilustrada na Figura 4. 


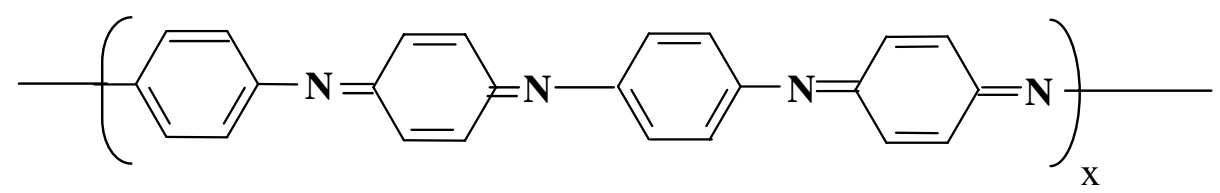

Figura 3: PAni na forma de sal, totalmente oxidada e condutora.

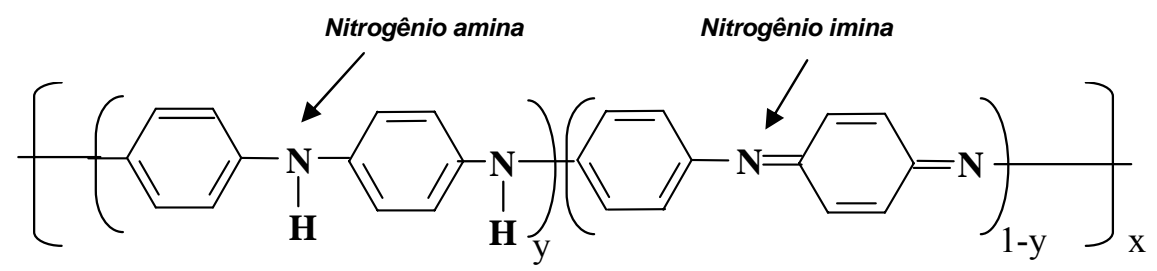

Figura 4: Fórmula geral da polianilina. Configuração não dopada, forma de base.

O valor de y pode variar entre 0 e 1, determinando assim o nível de oxidação da cadeia polimérica. No caso de y ser 1, o polímero encontra-se totalmente reduzido, contendo apenas nitrogênios amina, denominado assim de leucoesmeraldina. Quando y é 0, a polianilina encontra-se totalmente oxidada (Figura 3), contendo apenas nitrogênios imina, sendo então chamada de pernigranilina [referencia] Valores de y como $0.75,0.5$ e 0.25 implicam em estados de oxidação intermediários designados pelos termos protoesmeraldina, esmeraldina e nigranilina, respectivamente. $\mathrm{O}$ estado de oxidação esmeraldina é a forma na qual a polianilina, após a dopagem, atinge o maior valor de condutividade elétrica. 


\subsubsection{Mecanismos de dopagem}

A dopagem da polianilina se dá por protonação, ou seja, não há alteração no número de elétrons - redução ou oxidação - na cadeia polimérica [31,32]. Desta maneira, os nitrogênios imina da polianilina podem ser parcial ou totalmente protonados, transformando-a em sal, ou seja, dopada, gerando condução do tipo $p$ $[33,34]$. O grau de protonação depende do grau de oxidação em que o polímero foi sintetizado e do $\mathrm{pH}$ da solução dopante $[35,36]$. A dopagem química da polianilina no estado esmeraldina é feita por protonação em solução ácida aquosa, geralmente com acido clorídrico $(\mathrm{HCl})$ [22]. Desta forma, a base esmeraldina, que apresenta coloração azulada, tem sua condutividade aumentada cerca de 10 ordens de grandeza, mudando para uma coloração verde-escura. Na Figura 5 é apresentado um esquema genérico do mecanismo de dopagem da polianilina por $\mathrm{HCl}$.

No processo de dopagem, as moléculas de $\mathrm{HCl}$ se dessociam e os prótons $\mathrm{H}^{+}$ se ligam aos nitrogênios, provocando a quebra da ligação $\pi$ do nitrogênio imina, gerando bipolarons [22]. Dessa maneira, o anel quinóide se relaxa, restabelecendo-se em benzenóide. O radical cátion será neutralizado eletrostaticamente devido à presença do contra íon $\mathrm{Cl}^{-}$[37]. Após a relaxação e reorganização dos spins, a polianilina encontra-se dopada e condutora, com sua coloração verde-escura. Os demais polímeros condutores possuem em geral íons de carbono, porém, no caso da PAni, no estado sal esmeraldina, a carga positiva reside primordialmente no nitrogênio [43]. 

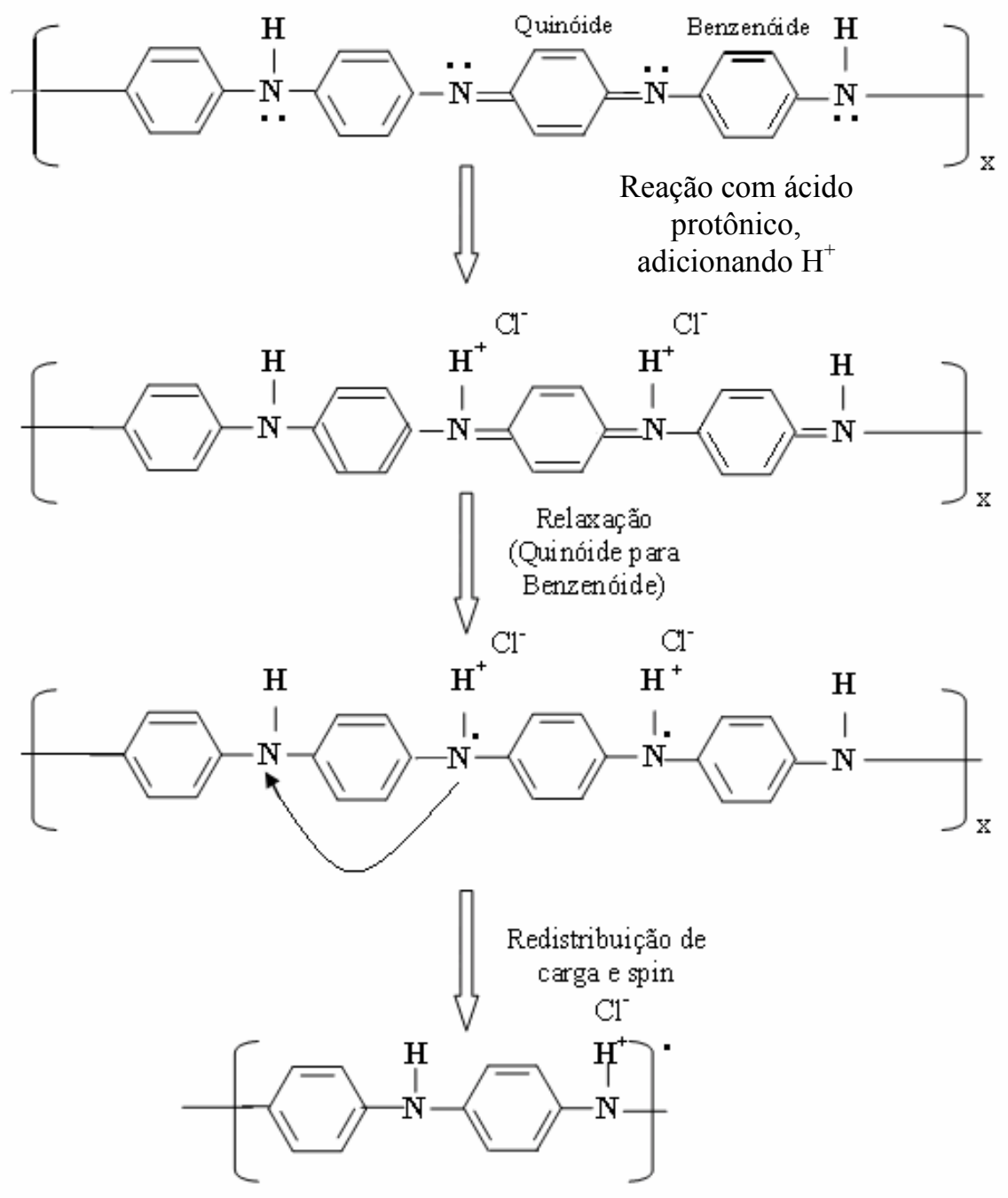

$\mathrm{x}$

Figura 5: Protonação da polianilina. Conversão de isolante para condutor sem alteração do número de elétrons [38].

\subsubsection{Síntese química}

A síntese química da PAni requer basicamente três componentes: o monômero anilina, um meio ácido (aquoso ou orgânico) e um agente oxidante. Os ácidos comumente usados são o ácido clorídrico $(\mathrm{HCl})$, e o ácido sulfúrico $\left(\mathrm{H}_{2} \mathrm{SO}_{4}\right)$. 
Já o persulfato de amônia $\left(\left(\mathrm{NH}_{4}\right)_{2} \mathrm{~S}_{2} \mathrm{O}_{8}\right)$, o dicromato de potássio $\left(\mathrm{K}_{2} \mathrm{Cr}_{2} \mathrm{O}_{7}\right)$, o iodeto de potássio $\left(\mathrm{KIO}_{3}\right)$ e o peróxido de hidrogênio $\left(\mathrm{H}_{2} \mathrm{O}_{2}\right)$ são utilizados como oxidantes [39]. Neste trabalho, o ácido utilizado é o $\mathrm{HCl}$ e o agente oxidante é o persulfato de amônia. As etapas e os detalhes da síntese encontram-se no item "metodologia".

\subsubsection{A utilização da Polianilina em sensores de gases}

Dentre os tipos de sensores de gases eletroquímicos que trabalham com variação de condutividade estão os sensores baseados em semicondutores e os baseados em filmes poliméricos. Este último apresenta uma grande vantagem sobre os tradicionais sensores baseados em semicondutores, que é a possibilidade de trabalhar em temperatura ambiente, o que não é possível com os sensores semicondutores, que requerem altas temperaturas [40]. O polipirrol foi um dos primeiros polímeros a ser utilizados como parte ativa de sensores de gás, porém apresentou baixa sensibilidade, alto tempo de resposta além de apresentar irreversibilidade devido à desabsorção parcial das moléculas dos gases [41]. Em 1991, Lubentsov colaboradores [42] investigaram os efeitos da amônia em camadas de filmes de PAni medindo sua variação de condutividade e dependência com a temperatura para desabsorção do gás. Comparada ao polipirrol, a PAni mostrou-se mais sensível a amônia, além de apresentar tempo de resposta muito menor. A PAni quando dopada por ácidos minerais como o ácido clorídrico $(\mathrm{HCl})$ torna-se condutora [43], porém, quando exposta ao gás de amônia, tem sua condutividade reduzida. Além disso, é verificada a reversibilidade da condutividade com a volatilização do gás de amônia. Devido a este comportamento, ao baixo custo, à facilidade de síntese, à versatilidade no processamento e à relativa estabilidade da condutividade elétrica [44], a PAni passou então a ser um dos polímeros mais pesquisados em aplicações para sensoriamento de amônia [45], além de gases como ácido sulfídrico, dióxido de nitrogênio e dióxido de enxofre [30]. 


\subsubsection{Reação da polianilina na presença de amônia.}

A amônia $\left(\mathrm{NH}_{3}\right)$ é um gás geralmente detectado por filmes finos de PAni. Isto é possível devido ao mecanismo de protonação e desprotonação dos átomos de nitrogênio, que permite a sensibilidade e a reversibilidade da PAni. As ligações entre os átomos de nitrogênio e hidrogênio se quebram, permitindo que nitrogênio da molécula de amônia estabeleça uma ligação com o orbital livre do próton dopante $\left(\mathrm{H}^{+}\right)$. Consequentemente, ocorre a desprotonação dos átomos de nitrogênio da PAni, envolvendo o desaparecimento dos portadores de carga (polarons), aumentando assim sua resistividade elétrica. A reversibilidade através da desprotonação ocorre com a volatilização do $\mathrm{NH}_{3}$ [46]. O diagrama esquemático da Figura 6 ilustra tal processo.

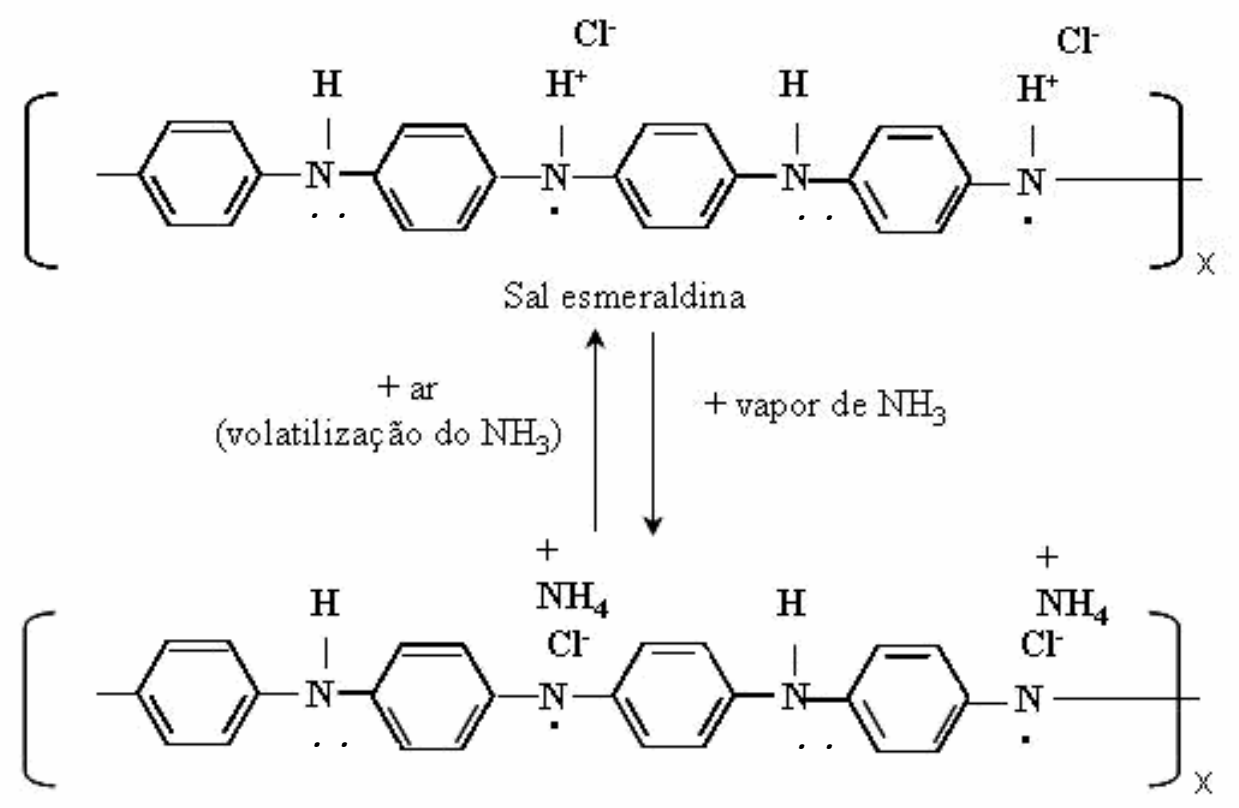

Figura 6: Processo de dopagem e desdopagem da PAni [46] 


\subsubsection{Reação da polianilina na presença de umidade.}

Pesquisas mais recentes sobre sensores de gases mostram que há uma busca constante por sensores com melhor estabilidade, seletividade e sensibilidade [4748]. Um dos fatores que pode influenciar na resposta de um sensor de gás baseado em PANi ou polímeros em geral é a presença de umidade [49]. A absorção de água na PAni é um processo volumétrico diretamente relacionado aos prótons que dopam o polímero [50]. Alguns estudos realizados com PAni sintetizada quimicamente [5152] sugerem que as moléculas de água formam ligações de hidrogênio com os centros ácidos da polianilina, e que possivelmente existam duas formas de adsorção para as moléculas de água na matriz polimérica. Uma mais fracamente ligada aos nitrogênios amina pode ser facilmente removida com fluxo de nitrogênio. A outra, mais fortemente ligada à cadeia polimérica nos nitrogênios imina, pode ser retirada apenas mediante aquecimento com elevadas temperaturas [34, 50-51]. As moléculas de água estariam ligadas ao polímero através de ligações de hidrogênio (Figura 7) que provocariam variações a conformações moleculares das cadeias poliméricas. A protonação causada pela presença de água nos átomos de nitrogênio resulta na formação de um policátion positivamente carregado $\left(-\mathrm{N}^{+} \mathrm{H}=\right)$, estabilizado entre a deslocalização $\pi$ ao longo da cadeia polimérica. Apesar disso, a força ácida da água não é suficiente para transformar o polímero de base em sal, mas estimula o processo de protonação aumentando a condutividade do mesmo.

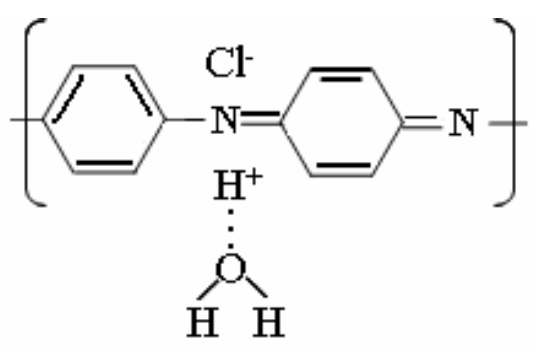

Figura 7: Ligação de hidrogênio entre Polianilina e a molécula da água [42]. 


\subsection{Ftalocianinas}

\subsubsection{Introdução}

As ftalocianinas, do grupo nafta e cianas são corantes conhecidos há muitos anos. As primeiras ftalocianinas foram produzidas acidentalmente em 1907 durante um estudo das propriedades das 1,2 cianobenzamida. Durante o aquecimento da solução alcoólica de benzamida formou-se um precipitado azul. Vinte anos depois, a ftalocianina de cobre foi obtida durante uma tentativa na reação de 1,2dicianobenzeno para dibromobenzeno e cianeto de cobre [11].

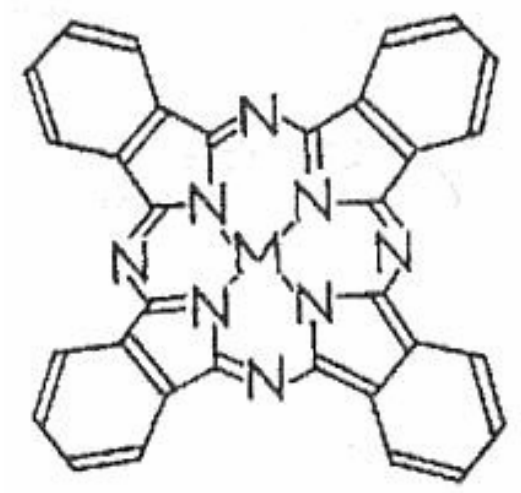

Figura 8: Ftalocianina metálica [11].

Além de sua utilização como pigmentos, as ftalocianinas metálicas, cuja estrutura está ilustrada na Figura 8, mostram uma variedade de propriedades especiais de grande interesse na área tecnológica [53]. Elas são facilmente cristalizadas e sublimadas, resultando em um material puro. Mostram também uma excepcional estabilidade térmica e química [54].

As ftalocianinas e seus derivados metálicos constituem moléculas planas e simétricas. Suas altas estabilidades químicas e térmicas favorecem sua utilização em aplicações tecnológicas, principalmente sob a forma de filme fino, em dispositivos sensoriais e eletrônica molecular [55]. Ftalocianinas metálicas são produzidas em larga escala na indústria, principalmente a ftalocianina de cobre.

A natureza do íon metálico "preso" na cadeia tem influência na propriedade fisioquímica da ftalocianina metálica $(\mathrm{PcM})$. O comportamento óxido-redutor da 
unidade molecular ou a natureza do estado fotoquímico excitado pode ser alterado pelo complexo do íon metálico.

A estrutura da maioria das PcMs são determinadas pela medida de difração do raio $\mathrm{X}$. Pelo menos três formas polimórficas conhecidas são designadas pelas letras $\alpha, \beta$ e X. [56]. A taxa de transformação da forma $\alpha$ para a forma $\beta$ é influenciada pela presença de álcool na atmosfera. A transformação $\alpha-\beta$ leva a diferentes morfologias do filme. Este é provavelmente um dos fatores que determina a sensibilidade para os gases das ftalocianinas de cobre ( $\mathrm{CuPc})$, ftalocianinas de níquel (NiPc), ftalocianinas de zinco $(\mathrm{ZnPc})$ e ftalocianinas de cobalto $(\mathrm{CoPc})$ [57]. Pizzini e colaboradores [58] verificaram que a morfologia e a estrutura interferem na sensibilidade dos filmes de ftalocianinas metálicas. Neste caso, os filmes $\beta$-Pc mostraram-se mais sensíveis ao dióxido de nitrogênio $\left(\mathrm{NO}_{2}\right)$. Verificaram também que a otimização destes dispositivos requer um cuidadoso controle de procedimento de preparação, já que estas condições influenciam diretamente na estrutura do filme e sua morfologia.

\subsubsection{A utilização das Ftalocianinas em sensores de gases}

As ftalocianinas tem sido objeto de estudos para utilização em sensores de componentes orgânicos voláteis com aplicação na indústria alimentícia [59] e como sensores de gases como cloro e amônia. A interação entre alguns componentes presentes no ambiente com filmes finos orgânicos ou inorgânicos pode causar variações nas propriedades físicas da camada que entra em contato com estes componentes [60]. As ftalocianinas metálicas ( $\mathrm{PcM}$, onde $\mathrm{M}$ pode ser $\mathrm{Cu}, \mathrm{Zn}, \mathrm{Ni}$, etc.) que são semicondutores orgânicos do tipo p, portadores de buracos [61], apresentam alta sensibilidade mediante moléculas aceitadoras de elétrons como o $\mathrm{NO}_{2}$ e doadoras de elétron como o $\mathrm{NH}_{3}$. [10].

A variação da condutividade elétrica provocada nos filmes finos de ftalocianinas mediante a presença de gases oxidantes ou redutores, tem levado a utilização deste tipo de material a ser utilizado em sensores de gases. Ftalocianinas como a de chumbo (PbPc) exibe alta sensibilidade, na ordem de partes por bilhão ao 
$\mathrm{NO}_{2}$. Em menor proporção, a ftalocianina de cobre $(\mathrm{CuPc})$ também apresenta sensibilidade, ao $\mathrm{NO}_{2}$ e ao $\mathrm{NH}_{3}$. As ftalocianinas apresentam características como alta estabilidade térmica, facilidade de sintetização, além de poder ser utilizada em técnicas que permitem a fabricação de filmes finos com controle molecular, como Langmuir-Blodgett (LB) e a automontagem [62]. Para a preparação dos filmes de ftalocianinas de cobre e níquel alternadas com a PAni, como os sensores propostos neste trabalho, é necessária a inserção de grupos sulfonados $\left(\mathrm{SO}_{3}{ }^{-}\right)$nas ftalocianinas, para proporcionar a interação eletrostática com a PAni. Desta maneira, a PAni, que é um polieletrólito catiônico, interage com a MTsPc (ftalocianina metálica tetrassulfonada) de carga elétrica negativa, cuja estrutura é representada na Figura 9. Além disso, a ftalocianina metálica tetrasulfonada é solúvel em água, permitindo a obtenção de filmes finos pelo método da automontagem.

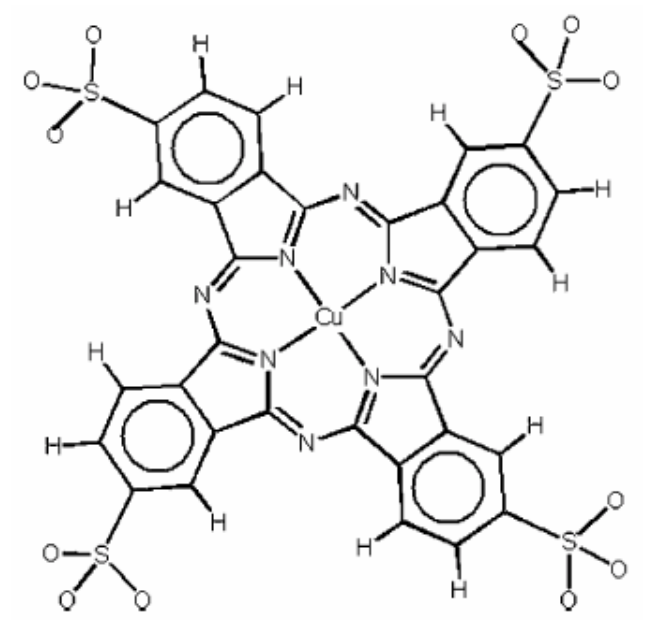

Figura 9: Representação estrutural da Ftalocianina de Cobre Tetrassulfonada [55].

Alguns sensores de amônia baseados em metais-ftalocianinas são encontrados na literatura. Estudos foram realizados sobre a sensibilidade de alguns tipos de ftalocianinas metálicas mediante a presença de amônia [57]. Verificou-se uma grande dependência dos valores não só da quantidade de amônia à qual os sensores eram submetidos, mas também uma dependência com relação à umidade relativa e a temperatura na qual os sensores eram ensaiados. Em [10] comentam sobre sensores de ftalocianinas de níquel (NiPc) e ftalocianinas de chumbo $(\mathrm{PbPc})$ sendo que ambos mostram sensibilidade à amônia e também à umidade. Entretanto, ao contrário do 
que ocorre com a PAni, as moléculas da água causam uma diminuição na condutividade elétrica do material, atuando como um efetivo doador de elétrons.

$\mathrm{O}$ efeito da umidade no comportamento do gás sensor de ftalocianina tem sido estudado para gases doadores de elétrons como o $\mathrm{NH}_{3}$, e para gases aceitadores de elétrons $\left(\mathrm{NO}_{2}\right)$. Vapor de água age como efetivo doador de elétrons até mesmo na presença de um forte doador como $\mathrm{NH}_{3}$. Neste caso, o vapor de água aumenta a sensibilidade do dispositivo, diminuindo o tempo de resposta e retorno ao estado inicial. Entretanto, o comportamento depende do histórico de exposição e a seqüência ao quais os gases são adsorvidos. 


\subsection{Técnica de deposição de filmes finos automontados}

\subsubsection{Introdução}

Vários estudos mostram que a sensibilidade e a seletividade dos sensores de gases baseados em filmes de PAni, podem variar com diversos parâmetros. Entre eles podemos citar a natureza dos dopantes, o método utilizado para deposição do filme e a espessura do filme [63], já que a estrutura e a morfologia dos filmes finos podem alterar suas características de sensibilidade a gases [64-65]. Diversos tipos de métodos de deposição de filmes poliméricos podem ser utilizados, entre eles o spin coating, dip-coating, evaporação térmica, Langmuir-Blodgett e automontagem ou LbL (Layer-by-Layer) [66-67] entre outros. Em especial, as duas últimas técnicas são de extrema importância no campo da Eletrônica molecular, pois permitem a fabricação de filmes ultrafinos com arquiteturas projetadas e alto grau de organização [68].

O método de automontagem, denominado em literaturas mais recentes como LBL, do inglês "layer-by-layer", baseia-se na propriedade que certos materiais apresentam de interagir entre si, proporcionando a obtenção de filmes que podem ser produzidos alternando a adsorção de materiais de cargas opostas [69]. Os filmes automontados são classificados de acordo com o mecanismo responsável pelo processo de adsorção. Basicamente, quatro tipos de filmes são identificados:

(i) multicamadas montadas eletrostaticamente por meio de polieletrólitos altamente carregados, onde as interações moleculares do filme fino são governadas pelas forças iônicas;

(ii) multicamadas montadas eletrostaticamente através de polieletrólitos fracos, parcialmente carregados. Neste caso, mesmo sendo a adsorção regida por interações iônicas, a quantidade de material adsorvido (e conseqüentemente a espessura de cada camada) pode variar consideravelmente com as condições de deposição, dependendo drasticamente do $\mathrm{pH}$ das soluções de polieletrólitos, que determina a densidade de carga das cadeias poliméricas;

(iii) multicamadas nas quais interações secundárias representam um papel importante nos processos de adsorção. Em especial, encontram-se os filmes depositados via 
interação de pontes de hidrogênio, tanto sozinho, como em conjunto com interações iônicas;

(iv) filmes automontados por mecanismos de interação muito específicos como a afinidade de ligação entre biotina-avidina. Neste caso, materiais de mesma carga podem formar o filme, pois a forte atração entre a biotina e a avidina supera a força eletrostática de repulsão.

O método de automontagem é amplamente utilizado para deposição de polímeros carregados com cargas opostas, porém tem sido também utilizado com outros tipos de materiais, como, por exemplo, nanocristais poliméricos, azo polímeros [70], polímeros emissores de luz [71-72], nanoparticulas metálicas e semicondutoras, entre outros. Além disso, este método tem sido utilizado para produzir camadas de componentes biológicos como proteínas, enzimas, DNA, e vírus.

A simplicidade da técnica é uma importante vantagem, particularmente em comparação com a técnica de Langmuir-Blodgett (LB). Até pouco tempo, a técnica LB era o único método para se obter filmes com multicamadas orgânicas com controle molecular. O próximo item detalhará a fabricação dos filmes automontados, demonstrando sua simplicidade.

\subsubsection{Fabricação dos filmes}

No processo de deposição dos filmes automontados a adsorção espontânea e seqüencial de materiais com cargas opostas é proporcionada através da diluição destes materiais, na maioria das vezes, em soluções a base de água. Basicamente, um substrato carregado é imerso alternadamente em soluções de um policátion e um poliânion. Atrações eletrostáticas ocorrem entre a superfície do substrato e as moléculas de cargas opostas da solução. Se a concentração de poliíons for suficiente, a adsorção ocorrerá até que a superfície do substrato fique carregada com a carga oposta ao que se encontrava originalmente, ou seja, carregado com as cargas do material da solução na qual foi imerso. O tempo de imersão é um importante parâmetro para as propriedades do filme. Após a adsorção da primeira camada, o substrato é lavado em uma solução aquosa para remover o material não adsorvido. $\mathrm{O}$ 
pH da solução de lavagem geralmente é o mesmo das soluções. Após a lavagem o filme pode ser secado em um jato de gás inerte, como o nitrogênio, o que contribui para a homogeneidade do filme. Uma bicamada é então completada imergindo o substrato na segunda solução, com carga oposta a da primeira. Dessa forma, as moléculas desta solução adsorvem na primeira camada depositada. Mais uma vez, o substrato é lavado e eventualmente seco. Repetindo-se os passos acima descritos, é possível obter o número de bicamadas que se desejar. Este procedimento foi realizado para a deposição dos filmes dos sensores utilizados neste trabalho e está esquematizado na Figura 14, do item Materiais e Métodos .

Filmes automontados podem ser produzidos apenas com beckers, porém, sistemas automáticos têm sido empregados em diversos lugares, com o intuito de facilitar a deposição de filmes com grande número de camadas. Com a minimização da manipulação humana, consegue-se obter uma melhor reprodutibilidade dos filmes. 


\section{MATERIAIS E MÉTODOS}

A metodologia que foi aplicada para o desenvolvimento deste trabalho segue as seguintes etapas, posteriormente detalhadas:

Etapa 1: Preparação dos materiais;

Etapa 2: Confecção dos eletrodos;

Etapa 3: Deposição dos filmes nos eletrodos;

Etapa 4: Caracterização dos filmes obtidos;

Etapa 5: Caracterização dos dispositivos.

\subsection{Etapa 1: Preparação dos materiais}

Antes da síntese da PAni, a anilina, adquirida comercialmente, passa pelo processo de destilação. Para obtenção da PAni com baixo peso molecular está sendo utilizado o método de síntese química conforme detalhado nos próximo itens. As ftalocianinas e o PVS (poli (ácido vinil sulfônico)) são da Aldrich, obtidos em forma de pó e posteriormente dissolvidos em água para serem processados na forma de filmes.

\subsubsection{Destilação da Anilina}

A anilina comercial, que apresenta uma coloração escura, deve ser destilada antes de ser utilizada. Após a destilação, ela apresenta-se praticamente incolor, levemente amarelada, devido às impurezas retiradas. $\mathrm{O}$ aparato utilizado para a destilação da anilina é ilustrada na Figura 10. 


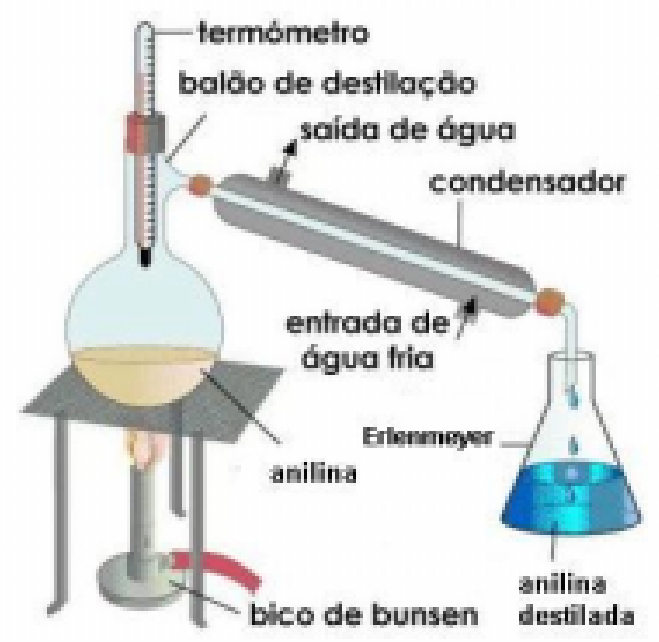

Figura 10: Esquema do aparato montado para destilação da anilina [73].

A anilina é colocada no balão volumétrico, juntamente com um agitador magnético (pulga), e aquecida em "banho Maria” em glicerina ou em óleo vegetal. Para melhores resultados este processo deve ser realizado lentamente. Dessa maneira utilizase glicerina ou óleo vegetal, que proporcionam um controle maior da evaporação da anilina, pois tanto a glicerina como o óleo, chegam ao ponto de ebulição mais lentamente, comparado, com a água. O controle da evaporação da anilina é a parte mais importante para o sucesso da destilação. Para isso, existe simultaneamente o controle da temperatura da glicerina, que fica em torno de $70^{\circ} \mathrm{C}$ a $120^{\circ} \mathrm{C}$, dependendo do vácuo e o controle da pressão do sistema, através de uma bomba de vácuo.

A anilina evaporada sobe através do tubo, envolta por papel alumínio que ajuda a distribuir melhor o calor no comprimento do tubo, que é protegida da luz por uma folha de alumínio, a fim de evitar sua degradação e alteração das propriedades da substância. Na parte superior do tubo ocorre a condensação através de um sistema de resfriamento promovido pelo gelo derretido que circula no tubo externo. A primeira parte da anilina destilada, aproximadamente $10 \%$ da quantidade total, e o final do resultado da destilação, devem ser descartados. 


\subsubsection{Síntese da Pani}

A polianilina utilizada foi sintetizada via reação química detalhada em [37]. Para tal, três reagentes são utilizados: anilina destilada, solução aquosa de acido clorídrico ( $\mathrm{HCl} 1 \mathrm{~mol} / \mathrm{l})$ e peroxidissulfato de amônia como agente oxidante. Primeiramente, diluímos em um becker 11,52g de peroxidissulfato de amônia $\left(\mathrm{NH}_{4} \mathrm{~S}_{2} \mathrm{O}_{8}\right)$ em $200 \mathrm{ml}$ de $\mathrm{HCl} 1 \mathrm{~mol} / \mathrm{l}$. Em outro becker, diluímos 20ml de anilina destilada em 300ml de $\mathrm{HCl} 1$ mol/l. Os beckers com as duas soluções são deixadas em repouso em banho de gelo até a estabilização das temperaturas. As soluções foram então misturadas, lentamente, sob agitação constante. Passadas duas horas, a solução obtida apresentou coloração verdeescura, característica de seu estado dopado e condutor. A solução foi posteriormente filtrada em um funil de Büchner, com papel filtro e lavada com acetona. O próximo passo foi a desdopagem da polianilina obtida. O pó obtido no processo anterior foi colocado sob agitação constante em uma solução de $1000 \mathrm{ml}$ de hidróxido de amônia $\mathrm{NH}_{4} \mathrm{OH} 1 \mathrm{~mol} / \mathrm{l}$ durante 16 horas com $\mathrm{pH}$ próximo de 10. Por último, o polímero obtido foi seco, sendo filtrado e espalhado sobre uma placa de Petry, deixado posteriormente sob vácuo de aproximadamente 10-2 Torr por 24 horas, tempo mínimo necessário. O polímero obtido em forma de pó apresentava coloração azulada, característica da base esmeraldina, desdopada e não-condutora. 


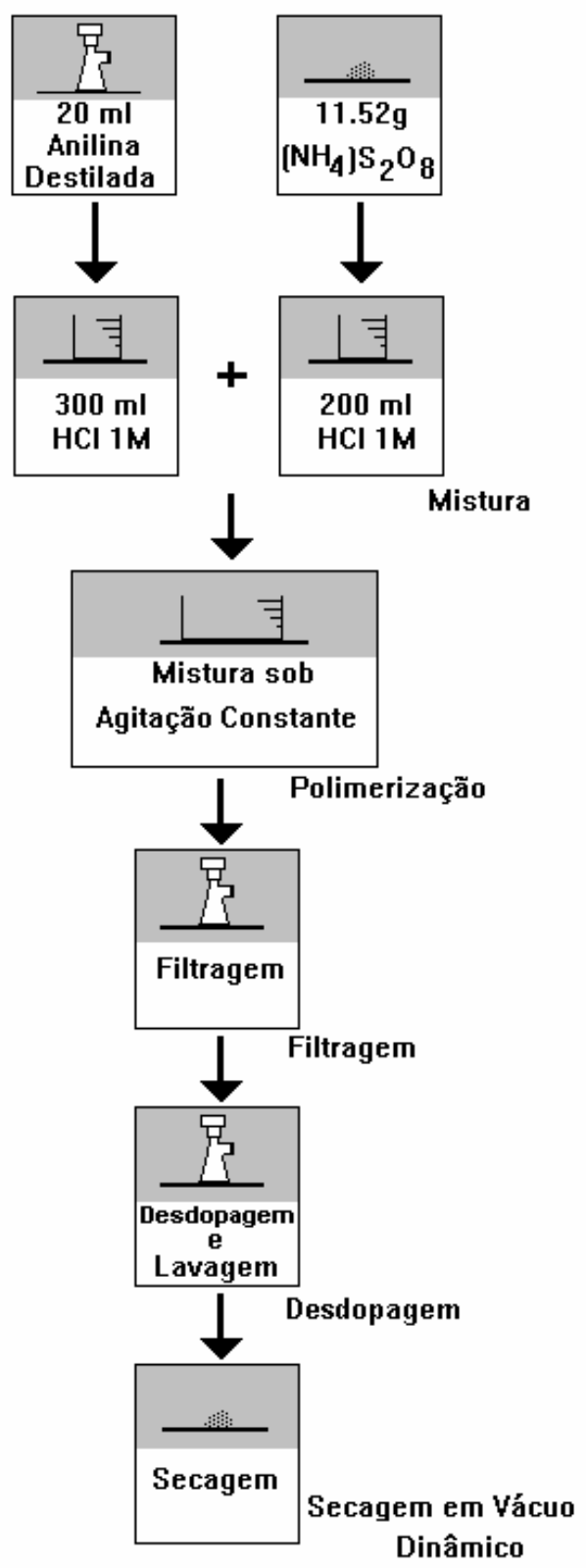

Figura 11: Esquema da síntese química da Polianilina [37]. 


\subsection{Etapa 2: Confecção dos eletrodos}

Os eletrodos interdigitados de ouro são obtidos sobre lâminas de vidro usando a técnica chamada Lift-off. Neste processo o metal é depositado sobre o substrato com fotorresiste revelado, fixando-se sobre as zonas livres de resina e sobre a resina resultante do processo de fotogravação. A deposição foi efetuada por bombardeamento iônico, conhecido como sputtering. Este processo foi realizado na metalizadora Sputron 2, modelo BA510A, do Laboratório de Microeletrônica da Escola Politécnica da Universidade de São Paulo (LME- EPUSP). Antes da deposição da camada de 100nm de ouro, uma camada de níquel-cromo com espessura de $25 \mathrm{~nm}$ foi depositada com o intuito de melhorar a adesão do ouro ao substato de vidro. Após a deposição, o metal depositado sobre a resina é removido pela dissolução da resina que o suporta [74]. Um esquema ilustrativo do eletrodo encontra-se na Figura 12 e uma fotografia é mostrada na Figura 13.

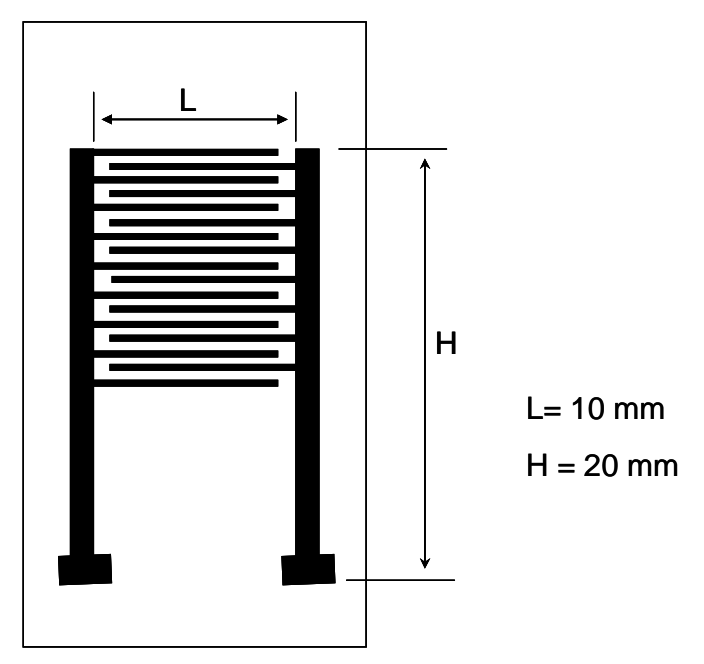

Figura 12: Diagrama esquemático dos eletrodos interdigitados de ouro e níquel depositados sobre substrato de vidro. A espessura dos dedos é de $0,1 \mathrm{~mm}$ assim como a distância entre eles. 


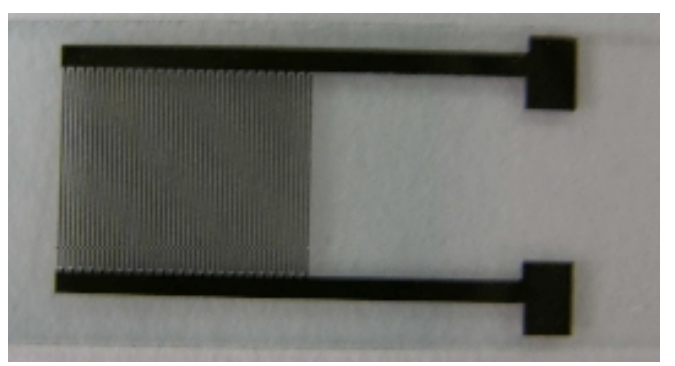

Figura 13: Eletrodo interdigitado.

\subsection{Etapa 3: Deposição dos filmes}

Para a deposição dos três tipos de filmes, foi utilizada a técnica da automontagem, que baseia-se na tendência que polieletrólitos com cargas elétricas contrárias têm de formar complexos [75] . No caso, a PAni foi utilizada como solução catiônica (cargas elétricas positivas) e o PVS e as ftalocianinas como soluções aniônicas (cargas elétricas negativas) [62]. Para a obtenção de uma bicamada é realizada a deposição de duas monocamadas, conforme etapas mostradas na Figura 14. A primeira monocamada é obtida deixando o substrato imerso na solução catiônica do béquer 1 por três minutos. Após lavagem do substrato em água ultra-pura de $\mathrm{pH} 2.8$ no béquer 2 , o substrato é então submerso na solução aniônica do béquer 3 por mais três minutos. Para finalizar o primeiro ciclo correspondente a confecção de uma bicamada, o substrato é lavado na solução do béquer 4 (água ultra-pura com pH corrigido para 2,8). Esta seqüência foi repetida conforme o numero de bicamadas que se desejava, no caso, 10, 20 e 40 para os três tipos de filmes, ou seja, PAni com PVS, PAni com ftalocianina de cobre e PAni com ftalocianina de níquel, resultando assim em nove diferentes combinações de materiais e espessuras. 


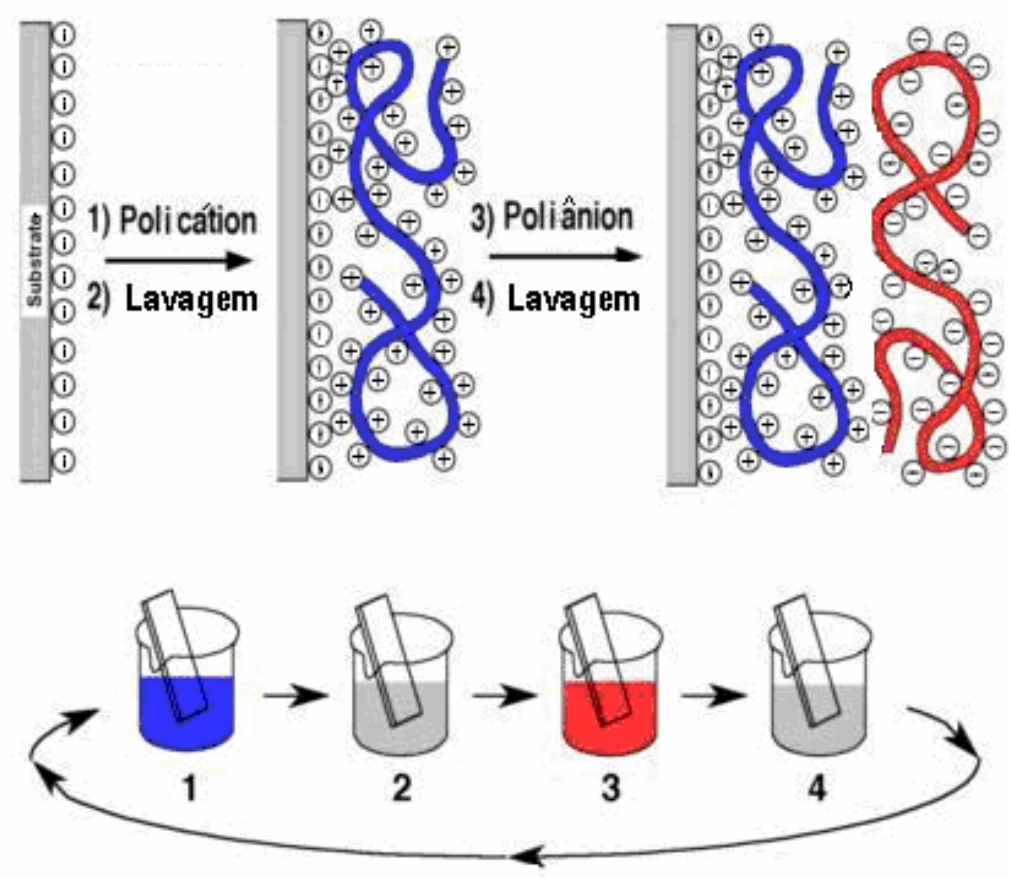

Figura 14: Esquema da deposição dos filmes poliméricos por automontagem.

A solução de PAni utilizada na automontagem foi preparada a partir de polianilina na forma de base esmeraldina obtida por síntese detalhada em [37] diluída em DMAc (Dimetil-acetamida) na razão 0,02g/ml. As soluções de PVS e ftalocianinas foram obtidas diluindo-as em água ultra-pura nas proporções $4 \mathrm{mg} / \mathrm{ml} \mathrm{e} 0,5 \mathrm{mg} / \mathrm{ml}$ respectivamente. Em todos os casos, o valor do $\mathrm{pH}$ das soluções foi acertado para 2,8 através de adição de $\mathrm{HCl} 1 \mathrm{~mol} / \mathrm{l}$.

Com o intuito de avaliar o desempenho dos sensores, foram fabricados dois diferentes lotes. O primeiro lote contém sensores com filmes de ftalocianina de cobre com PAni, ftalocianina de níquel com PAni e finalmente PAni com PVS, cada um destes com 10, 20 e 40 bicamadas, totalizando nove diferentes sensores. Posteriormente um segundo lote foi fabricado, desta vez com três sensores de mesmo tipo e quantidade de bicamadas, totalizando 27 sensores. A Tabela 1 resume os componentes de cada lote. A Figura 15 ilustra um dos eletrodos com filme já depositado. 
Tabela 1: Componentes dos dois lotes de sensores fabricados.

Lote 1

\begin{tabular}{|c|l|}
\hline Quant. & Tipo \\
\hline 1 & PAni/ NiTsPc 10 bicamadas \\
\hline 1 & PAni/ NiTsPc 20 bicamadas \\
\hline 1 & PAni/ NiTsPc 40 bicamadas \\
\hline 1 & PAni/ CuTsPc 10 bicamadas \\
\hline 1 & PAni/ CuTsPc 20 bicamadas \\
\hline 1 & PAni/ CuTsPc 40 bicamadas \\
\hline 1 & PAni/ PVS 10 bicamadas \\
\hline 1 & PAni/ PVS 20 bicamadas \\
\hline 1 & PAni/ PVS 40 bicamadas \\
\hline
\end{tabular}

Lote 2

\begin{tabular}{|l|l|}
\hline Quant. & tipo \\
\hline 3 & PAni/ NiTsPc 10 bicamadas \\
\hline 3 & PAni/ NiTsPc 20 bicamadas \\
\hline 3 & PAni/ NiTsPc 40 bicamadas \\
\hline 3 & PAni/ CuTsPc 10 bicamadas \\
\hline 3 & PAni/ CuTsPc 20 bicamadas \\
\hline 3 & PAni/ CuTsPc 40 bicamadas \\
\hline 3 & PAni/ PVS 10 bicamadas \\
\hline 3 & PAni/ PVS 20 bicamadas \\
\hline 3 & PAni/ PVS 40 bicamadas \\
\hline
\end{tabular}

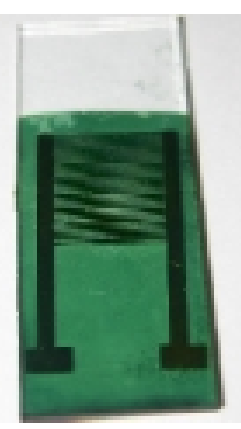

Figura 15: Eletrodos de ouro com filme de 40 bicamadas de PAni/ PVS. 


\subsection{Etapa 4: Caracterização dos filmes}

Os filmes de todos os sensores foram analisados por espectroscopia de absorção no ultravioleta-visível e por profilometria para determinação de espessura. Abaixo segue uma breve descrição dos equipamentos utilizados.

\subsubsection{UV-vis : Espectroscopia na região do ultravioleta e do visível.}

Todos os filmes fabricados foram submetidos a medidas de absorção na região do ultravioleta visível. Através destas medidas é possível a analise das propriedades ópticas dos materiais depositados. O equipamento utilizado foi o modelo Cary 500 da marca Varian do Instituto de Física da USP - São Paulo.

Quando a radiação ultravioleta visível atravessa o material do filme, uma parcela desta radiação é absorvida pelo composto. A quantidade de radiação obsorvida depende da estrutura do composto e do comprimento de onda da radiação. Os elétrons absorvem energia da radiação e saem dos orbitais de menor energia para os orbitais de maior energia. A posição da absorção corresponde ao comprimento de onda da radiação necessária para esta transição e a intensidade da absorção depende da probabilidade de interação entre a radiação e o sistema eletrônico [73]. Além disso, a quantidade de radiação absorvida é diretamente proporcional à quantidade de material absorvente.

\subsubsection{Profilometria}

As espessuras dos filmes foram obtidas através da técnica denominada profilometria. Para tal, foi utilizado o profilômetro do LME-EPUSP, modelo Alfa Step 500, da Tencor Instruments.

O profilômetro faz uma análise topográfica do filme, permitindo a obtenção de sua espessura, medindo o perfil deste filme. Isto é possível através de uma pequena agulha acoplada mecanicamente ao núcleo de um transformador. Esta agulha, conforme percorre o perfil do filme, move-se provocando variações do campo eletromagnético no núcleo do transformador. Estas variações são convertidas em dados gráficos e tabelas, fornecendo então a espessura do filme analisado. 


\subsection{Etapa 5: Caracterização dos dispositivos}

Para analisar o comportamento elétrico dos dispositivos sensores, foram realizados três tipos de ensaios, cujos equipamentos e aparatos montados são descritos a seguir.

\subsubsection{Medida de resistência em corrente/tensão contínua}

Para estudar as características dos dispositivos, os sensores do primeiro lote foram ensaiados individualmente dentro de um tubo de ensaio de $75 \mathrm{ml}$ vedado com um septo de borracha, utilizado como câmara. A amônia era inserida no tubo com o auxílio de uma seringa, com capacidade de $1 \mathrm{ml}$. Conforme o incremento da quantidade de amônia, os sensores respondiam com a variação da corrente, medida através do equipamento HP4156A - Precision Semiconductor Parameter Analyzer do laboratório do LME EPUSP. 


\subsubsection{Medida de resistência em corrente/tensão alternada}

Para análise da variação de resistência elétrica dos sensores, quando submetidos a variação de amônia, foi utilizado o equipamento HP4263 LCR meter, do LME. Porém, ao contrário do HP4156A, o HP4263 fornece tensão alternada, com opção de cinco freqüências diferentes.

Para este ensaio, foi criada uma câmara de inox com volume de $500 \mathrm{ml}$, na qual os sensores foram ensaiados individualmente. Para a inserção do gás na câmara, foi utilizada uma outra seringa, cuja escala é na ordem de dezenas de microlitros. O gás era inserido na câmara através de uma pequena entrada na tampa da câmara, fechada com um tubo de borracha. Para a aquisição automática das medidas feitas na HP4263, foi utilizado um computador ligado ao equipamento, provido de um software desenvolvido pela Embrapa (CNPDIA - São Carlos-SP), do laboratório do LME para que fosse acompanhada assim a variação de seus valores de resistência elétrica. O esquema da montagem é ilustrado na Figura 16.

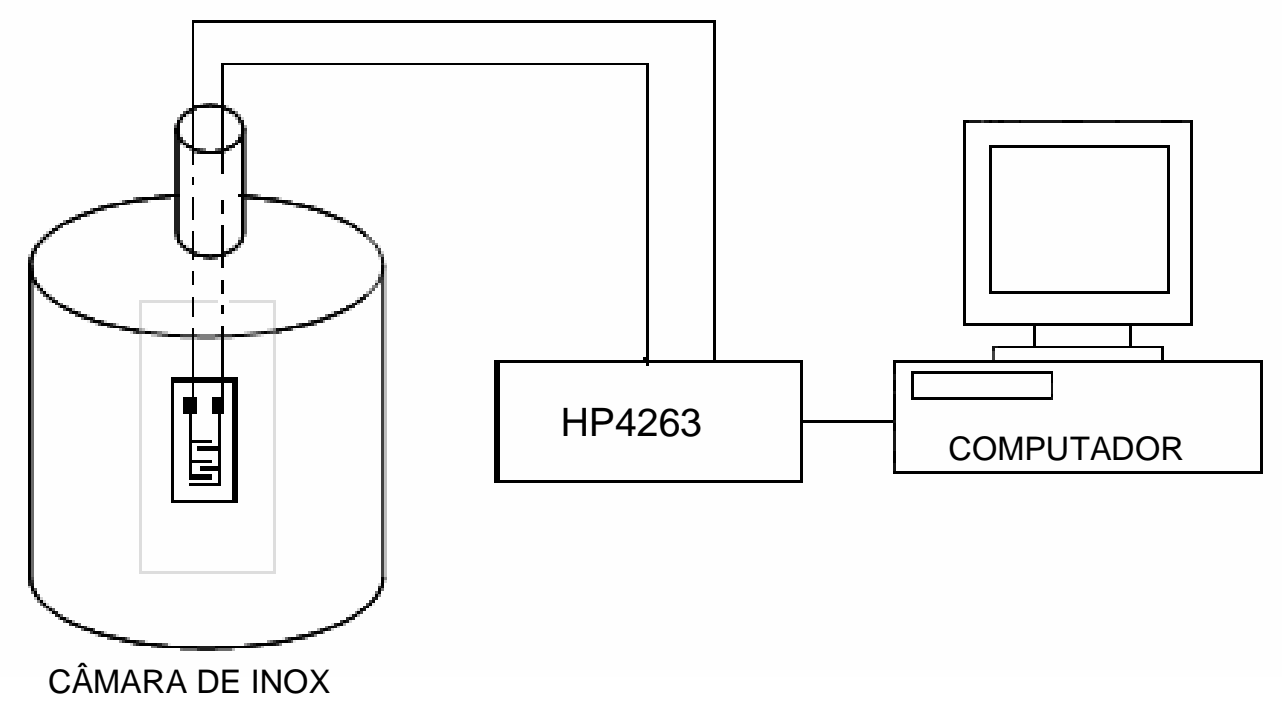

Figura 16: Esquema de montagem do aparato para ensaio dos sensores. 
3.5.3. Medida de resistência em corrente/tensão alternada: resposta a variação de temperatura e umidade.

Parte dos sensores foi ensaiada mediante variação de temperatura e umidade. Os sensores foram submetidos simultaneamente a tais variações através da câmara climática Tenney Ten, ilustrada na Figura. A medida da variação da resistência elétrica também foi realizada com o equipamento HP4263 LCR meter, e a aquisição dos dados feita pelo programa da Embrapa citado no item anterior. Porém, como vários sensores foram medidos simultaneamente, foi utilizado um multiplexador de 10 canais da Embrapa entre o equipamento de medição e o computador e uma "cabeça sensora", para interligar os cabos dos seis sensores ao multiplexador. Esta montagem está esquematizada na Figura 18.

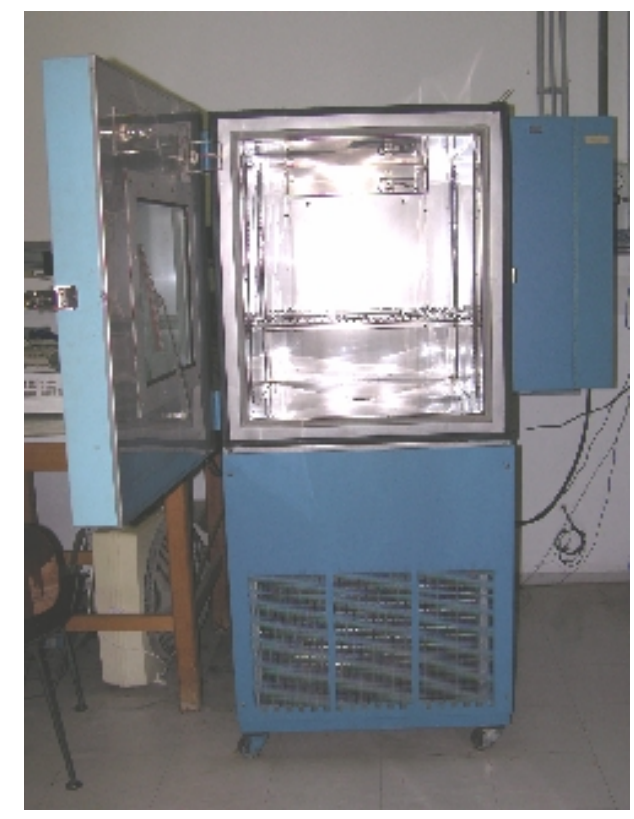

Figura17: Câmara climática Tenney Ten [76]. 


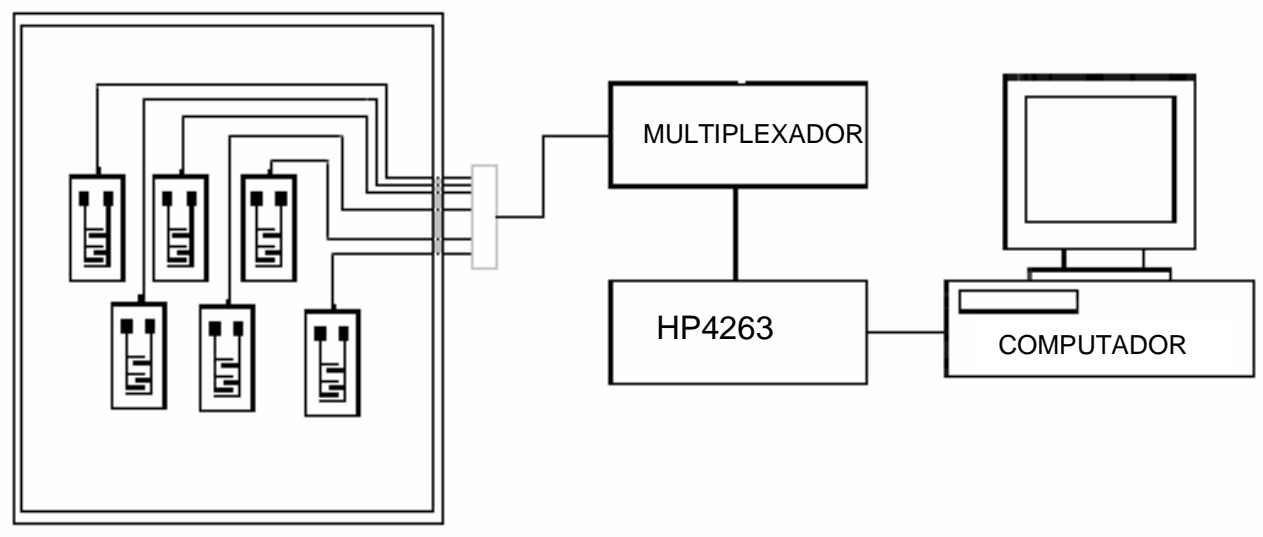

Figura 18: Esquema da montagem realizada para ensaio dos sensores sob variação da umidade relativa e da temperatura ambiente. 


\section{RESULTADOS E DISCUSSÕES}

\subsection{Ensaios do lote 1}

Os filmes das nove amostras do lote 1 foram inicialmente analisados por UV-vis , para análise do crescimento do filme e quantidade de material, além de verificação de suas espessuras por profilometria. Posteriormente foi realizado o ensaio de comportamento elétrico do dispositivo, analisando-se a variação da condutividade mediante variação da quantidade de amônia ao qual os sensores estavam sendo submetidos.

\subsubsection{UV-vis}

A caracterização dos filmes via espectroscopia ultravioleta visível (UV-vis ) foi realizada nos nove sensores, cujos espectros encontram-se a na Figura 19:

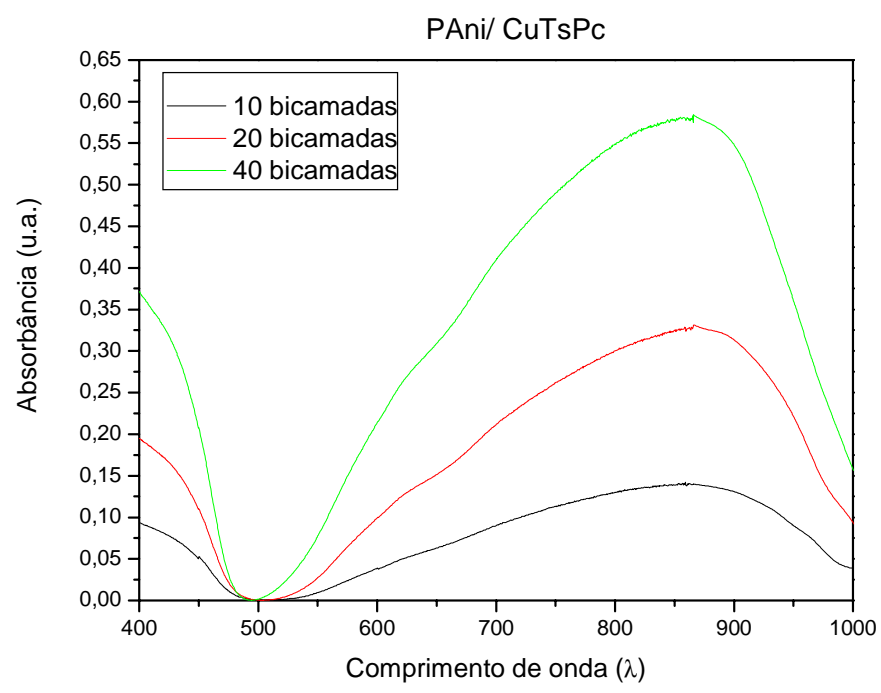

(a) 


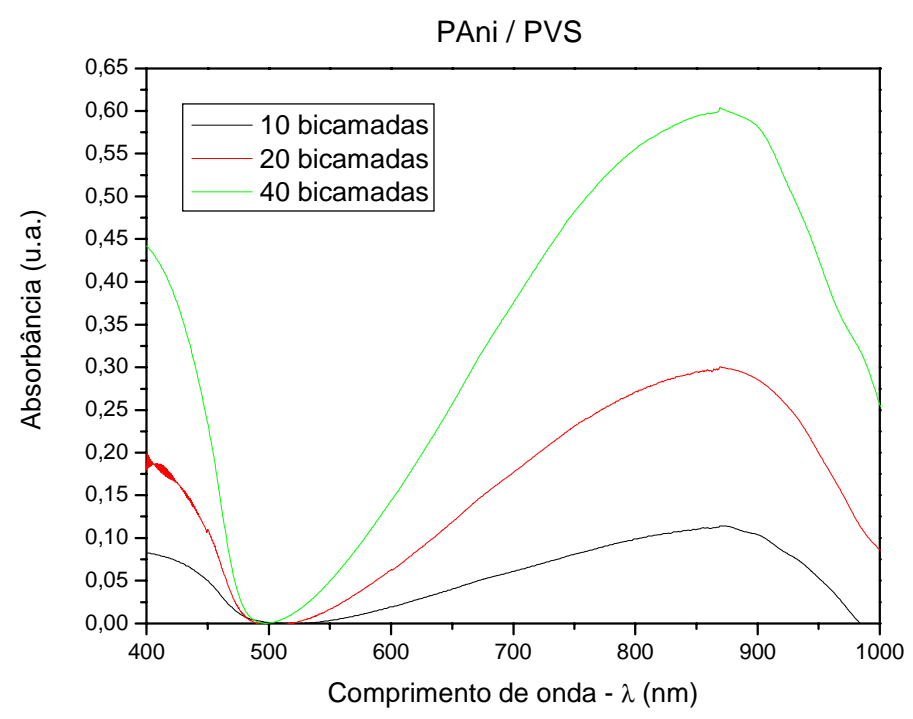

(b)

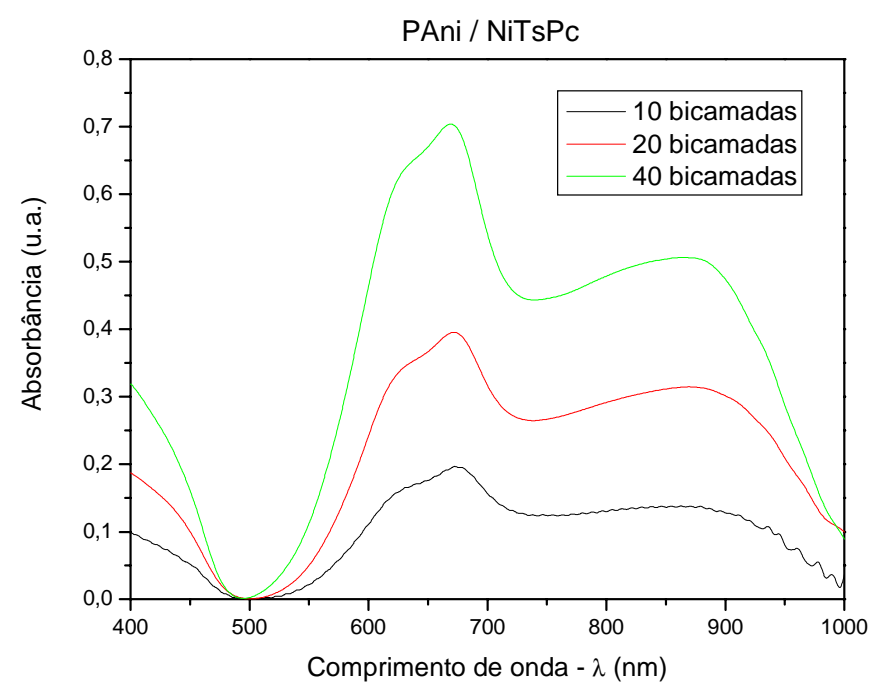

(c)

Figura 19: Caracterização por UV-vis dos nove diferentes filmes compostos por:

a) PAni/CuTsPc, (b) PAni/PVS e (c) PAni/NiTsPc.

Para os três tipos de filmes, podemos observar que a absorbância é praticamente proporcional ao numero de bicamadas do filme, o que indica que houve um crescimento 
linear da espessura do filme com o aumento do número de bicamadas. Este fato foi confirmado com a análise posterior através de profilometria.

\subsubsection{Profilometria}

A profilometria é uma técnica utilizada para medida de espessura de filmes finos. A Tabela 2 apresenta as espessuras dos nove diferentes filmes.

Tabela 2: Espessura dos nove diferentes filmes confeccionados.

\begin{tabular}{|c|c|c|c|}
\cline { 2 - 4 } \multicolumn{1}{c|}{} & \multicolumn{3}{c|}{ Espessura do filme (nm) } \\
\hline $\begin{array}{l}\text { Número de } \\
\text { bicamadas }\end{array}$ & PAni/ CuTsPc & PAni/ NiTsPc & PAni/PVS \\
\hline 10 & 41,1 & 50,1 & 52,9 \\
\hline 20 & 102,4 & 84,9 & 78,2 \\
\hline 40 & 200 & 193 & 141,1 \\
\hline
\end{tabular}

Analisando as espessuras obtidas podemos verificamos que o crescimento dos filmes foi praticamente linear e aumentou proporcionalmente com o número de bicamadas, sendo que apenas as espessuras dos filmes de 20 bicamadas apresentaram um pequeno desvio com relação aos demais. A espessura é um dos parâmetros de grande importância no desempenho de um sensor. Desta maneira, a técnica de automontagem demonstra-se apropriada na deposição de filmes finos para sensores de gases, permitindo alto controle do parâmetro espessura.

\subsubsection{Comportamento elétrico dos dispositivos: ensaios em DC}

Para estudar a variação da resistência dos sensores mediante a amônia, o primeiro lote de sensores foi ensaiado variando-se a concentração da amônia, num tubo de ensaio de $75 \mathrm{ml}$ vedado com tampa de borracha, deixando de fora um par de fios através do qual o sensor era ligado à HP4156A, ajustada para fornecer 2VDC. A amônia 
era inserida no tubo através de uma seringa, em passos de 0,1ml. A Figura 2020 ilustra alguns dos resultados obtidos.

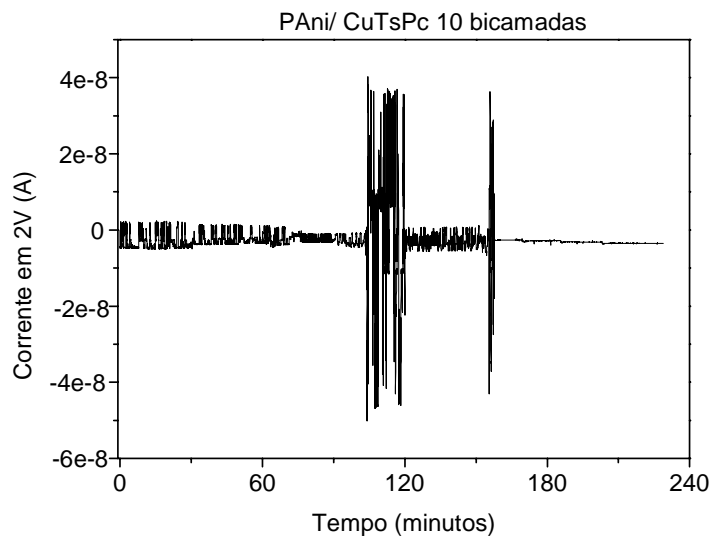

(a)

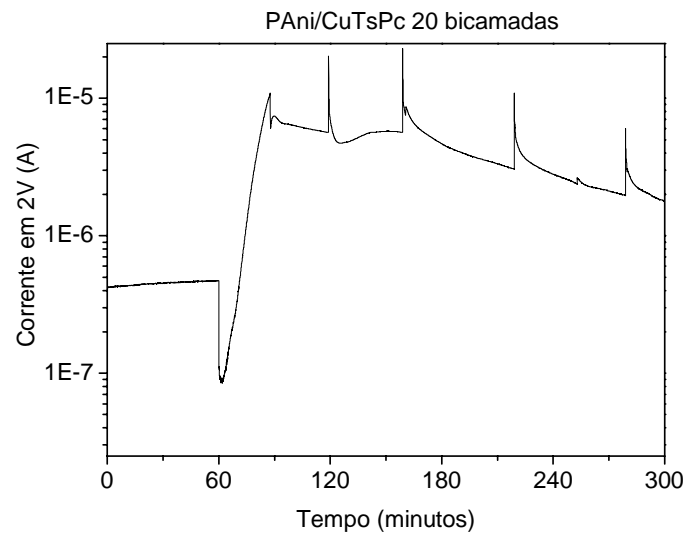

(b)

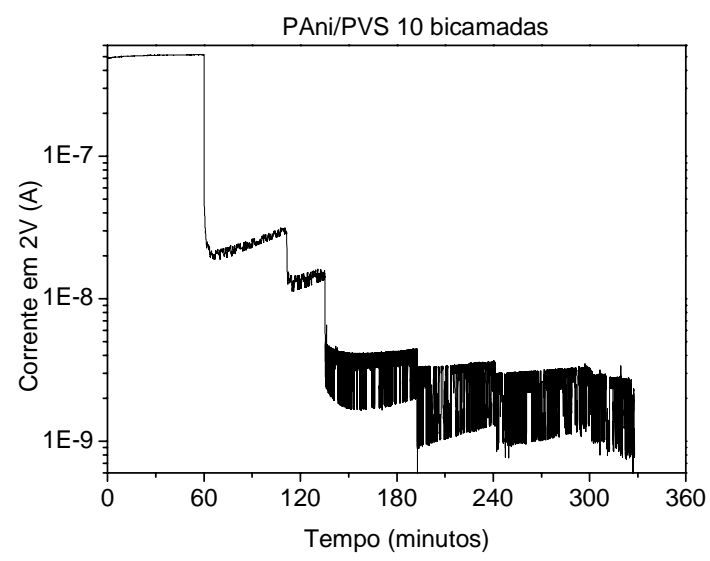

(c)

Figura 20: Variação da corrente dos sensores (a) PAni/CuTsPc 10 bicamadas, (b)

PAni/CuTsPc 20 bicamadas, (c) PAni/PVS 10 bicamadas, alimentados em 2 V mediante variação da quantidade de amônia.

Parte dos sensores ensaiados não demonstrou o comportamento esperado, ou seja, não apresentou variação de corrente, apenas em alguns momentos, mas devido a ruídos por deslocamento dos cabos de alimentação ou vibração da mesa onde o sistema estava montado, que é o caso da amostra de Pani/CuTsPc ilustrada na Figura 2020 a . Já 
os demais sensores que responderam à variação da concentração de amônia, não tiveram os valores de corrente estabilizados, aumentando de valor durante todo o ensaio, diminuindo apenas no momento da inserção da amônia, mas voltando a aumentar rapidamente, como acorrido com a amostra das Figuras 20.b e c. Tal comportamento pode ser explicado pelo fato de que as propriedades elétricas de um filme de polímero condutor podem ser alteradas irreversivelmente pelo deslocamento de espécies ionizadas para o seu interior, bem como por polarização permanente do filme, quando este é submetido à corrente contínua [77]. Por outro lado, as medidas em corrente alternada devem impedir tais efeitos. Além disso, a literatura tem mostrado que a sensibilidade e a seletividade de sensores de gases podem ser otimizadas quando alimentados por corrente alternada, variando de acordo com a freqüência utilizada [78]. Desta maneira, os demais testes foram realizados com os sensores alimentados em corrente alternada. Apenas a amostra de Pani/CuTsPc 40 bicamadas, como ilustra a Figura 21, apresentou um comportamento satisfatório aplicação em sensor de gás, com a diminuição e estabilização da corrente elétrica conforme aumento da quantidade de amônia. Este é o comportamento esperado já que tanto as ftalocianinas como a polianilina têm suas resistências aumentadas quando submetidas à presença de amônia.

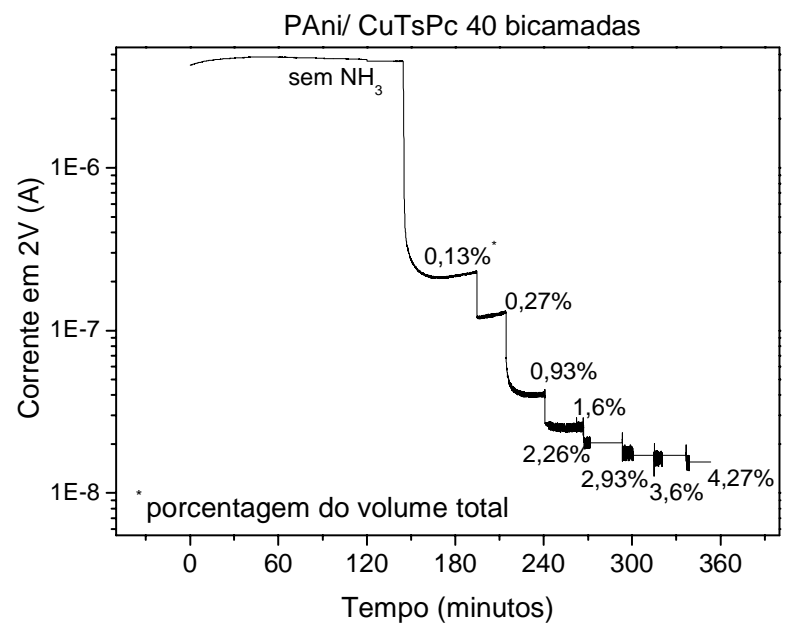

Figura 21: Variação da corrente do sensor de PAni/CuTsPc 40 bicamadas alimentado em 2 V mediante variação da quantidade de amônia. 


\subsection{Ensaio do lote 2}

Os filmes das 27 amostras do lote 2 foram analisados por UV-vis e suas espessuras medidas por profilometria. Os resultados de ambos são mostrados abaixo:

\subsubsection{UV-vis}

O UV-vis das amostras de mesmo material foram representadas em um mesmo gráfico. Em geral, elas apresentam grande similaridade, indicando quantidade de material depositado semelhante para as três amostras, conforme visto na figura 22 .

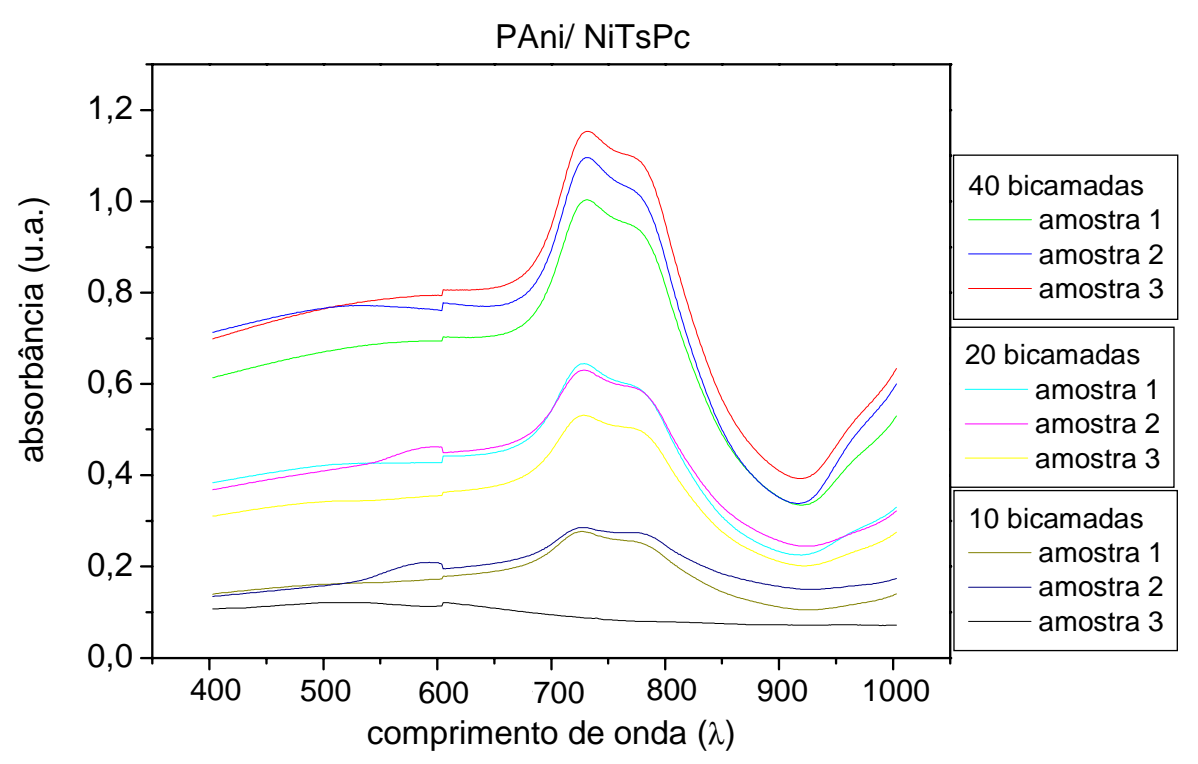

(a) 


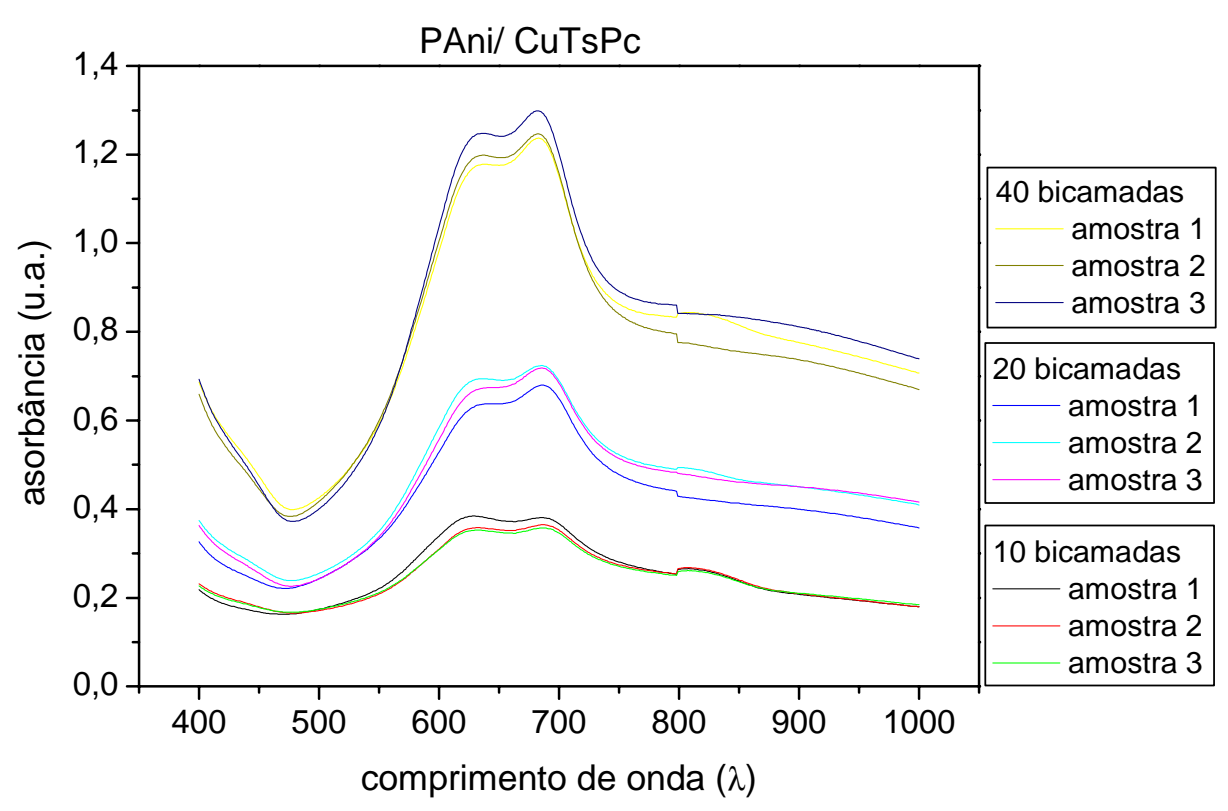

(b)

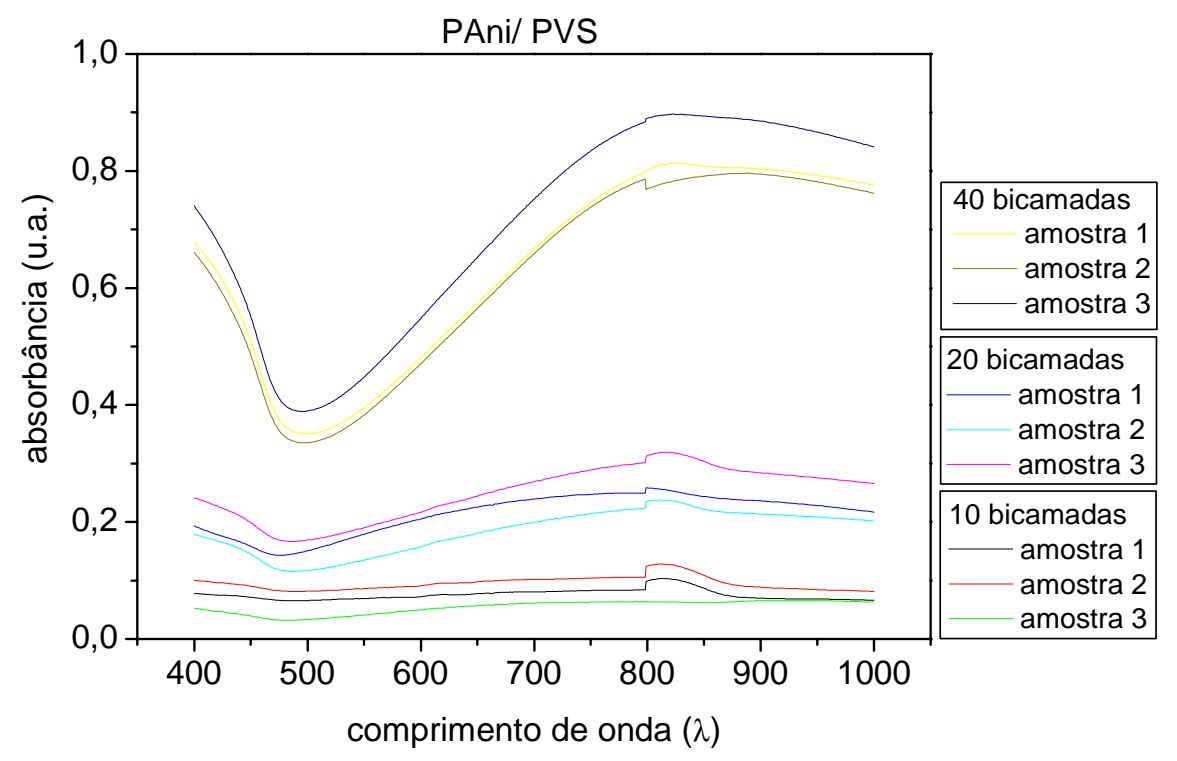

(c)

Figura 22: Caracterização por UV-vis dos filmes de PAni/NiTsPc (a), PAni/CuTsPc (b) e filmes de PAni/PVS (c). 


\subsubsection{Profilometria}

Através dos dados mostrados na tabela 2, podemos também verificar que os filmes de mesmo material apresentaram espessuras similares. Isto indica novamente uma boa reprodutibilidade no que diz respeito a espessura, que é proporcionada pela técnica da automontagem. Além disso, como no lote 1, percebe-se que houve praticamente um crescimento linear da espessura proporcional ao aumento do número de bicadas.

Tabela 2: Espessura obtida por profilometria dos 27 filmes.

\begin{tabular}{|c|c|c|}
\hline \multirow{2}{*}{ Tipo } & $\begin{array}{c}\text { No. } \\
\text { Bicamadas }\end{array}$ & Espessura (nm) \\
\hline \multirow{3}{*}{ PAni/ PVS } & 10 & $72,6+/-2,2 \%$ \\
\cline { 2 - 3 } & 20 & $125,9+/-11,5 \%$ \\
\cline { 2 - 3 } & 40 & $230,4 \pm 5,5 \%$ \\
\hline PAni/ CuTsPc & 10 & $40,8 \pm 0,7 \%$ \\
\cline { 2 - 3 } & 20 & $109,6 \pm 5,4 \%$ \\
\cline { 2 - 3 } & 40 & $188,3 \pm 9,3 \%$ \\
\hline PAni/ NiTsPc & 10 & $33,9 \pm 3 \%$ \\
\cline { 2 - 3 } & 20 & $88,0 \pm 2,8 \%$ \\
\cline { 2 - 3 } & 40 & $156,5 \pm 7,3 \%$ \\
\hline
\end{tabular}

\subsubsection{Comportamento elétrico dos dispositivos: ensaios em AC:}

Devido ás respostas não satisfatórias nos ensaios em DC, os sensores do segundo lote foram ensaiados em AC, na câmara de inox. Para tal, os sensores foram testados individualmente e submetidos a uma tensão de $0,250 \mathrm{~V}$ em $1000 \mathrm{~Hz}$. Neste ensaio, a resistência dos sensores foi medida primeiramente no ambiente sem amônia e posteriormente com o gás de amônia inserido em doses de 10, 20, 30 e 40 ppm, resultando valores de resistência bem distintos para cada concentração. A figura 23 ilustra os resultados dos sensores de PAni/CuTsPc, a figura 24 ilustra os resultados dos sensores de PAni/NiTsPc e a figura 25 ilustra a dos sensores de PAni/PVS. 

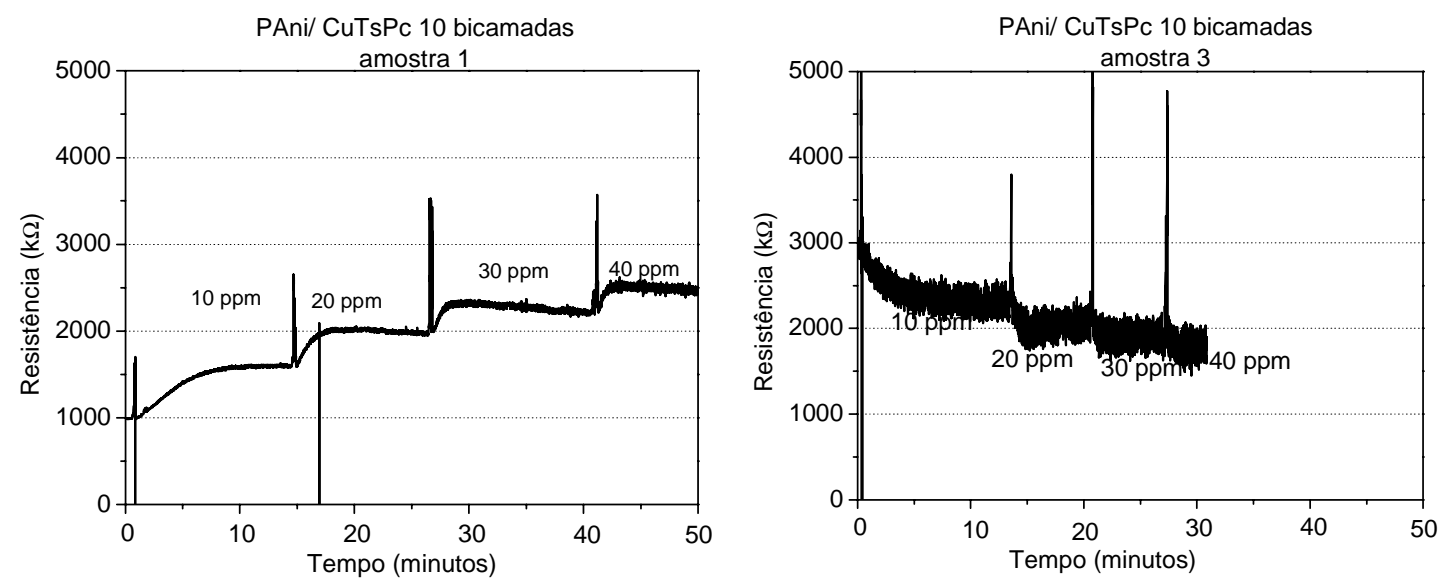

(a)
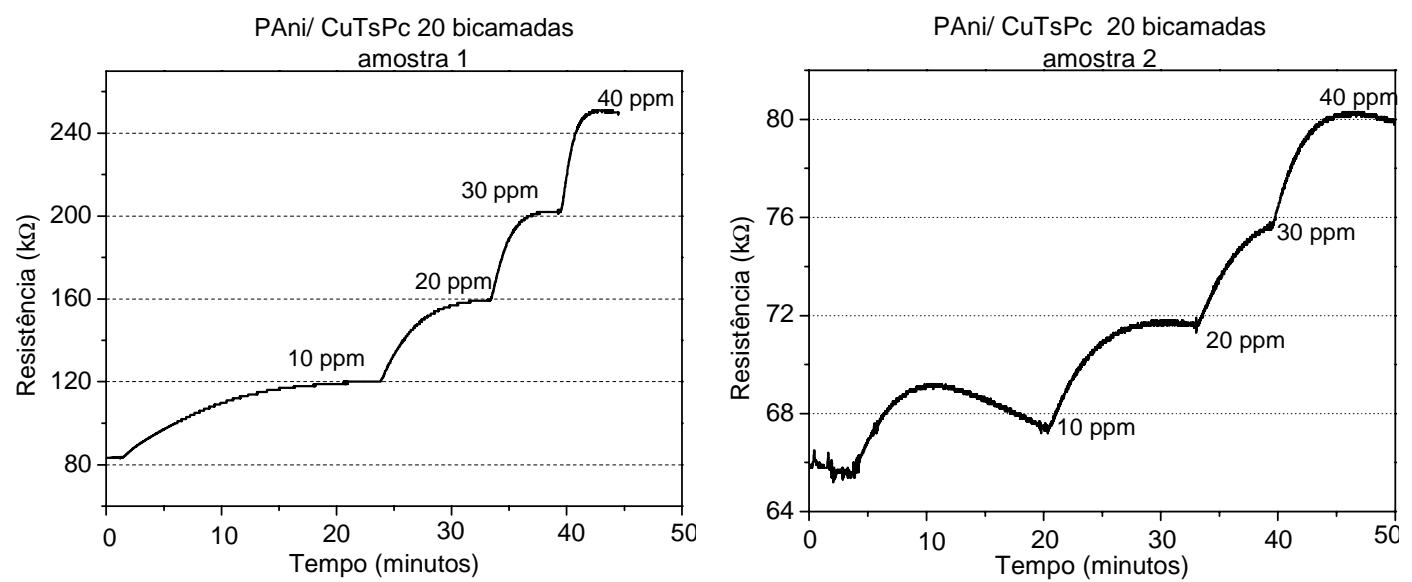


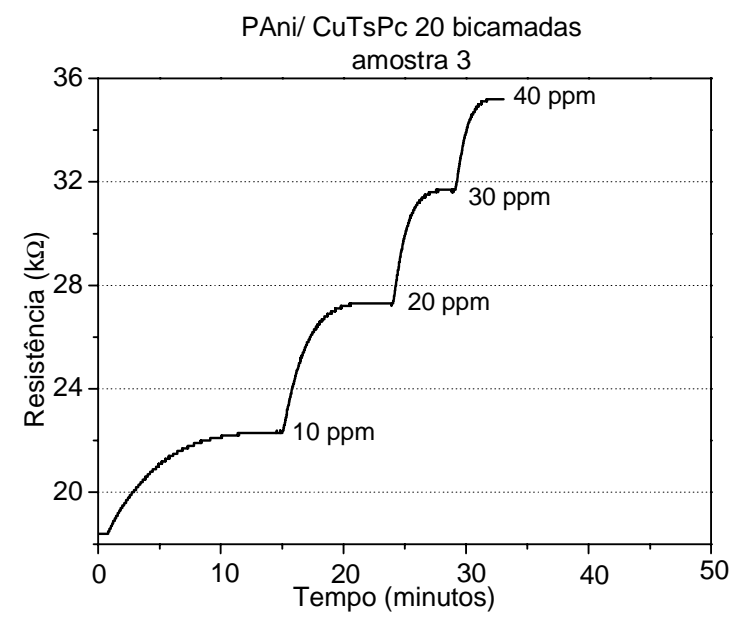

(b)
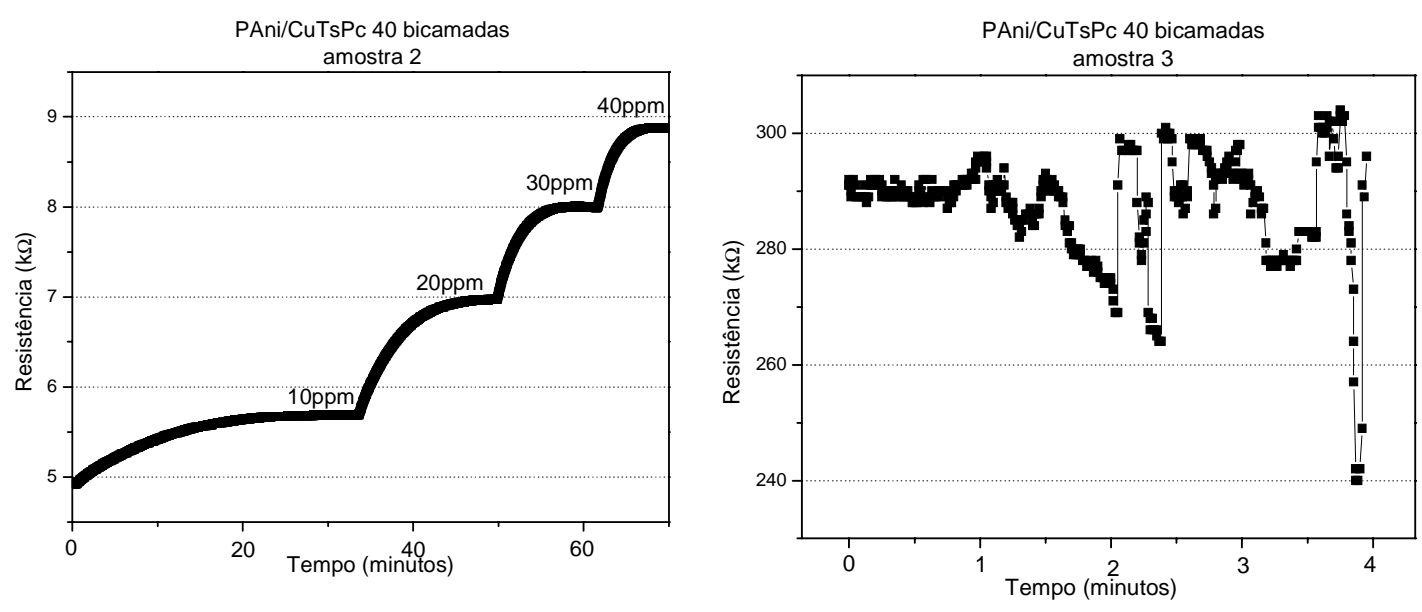

(c)

Figura 23: Variação da resistência elétrica dos sensores de Pani/CuTsPC de (a)10 bicamadas, (b) 20 bicamadas e (c) 40 bicamadas, mediante variação da concentração de amônia. 

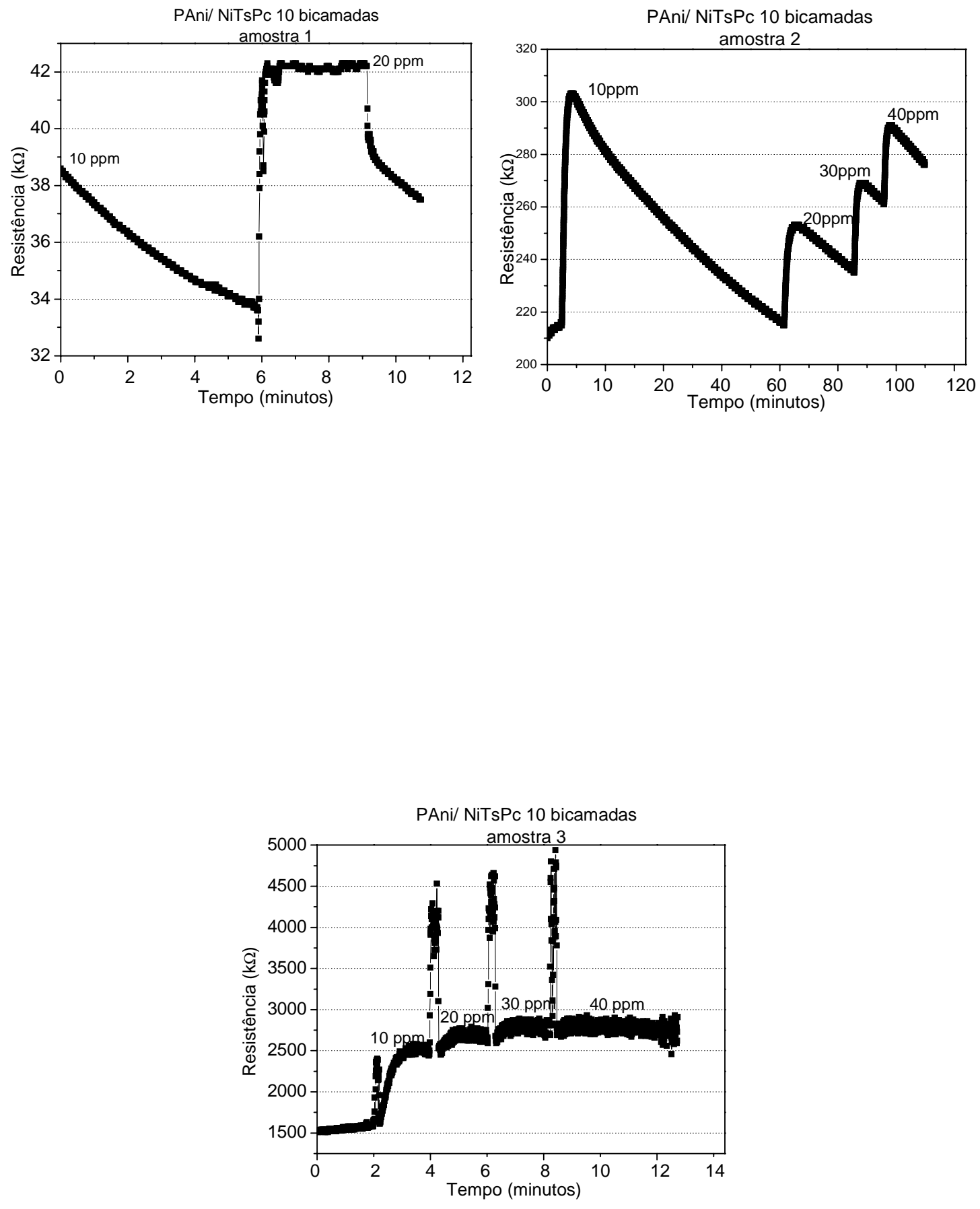

(a) 

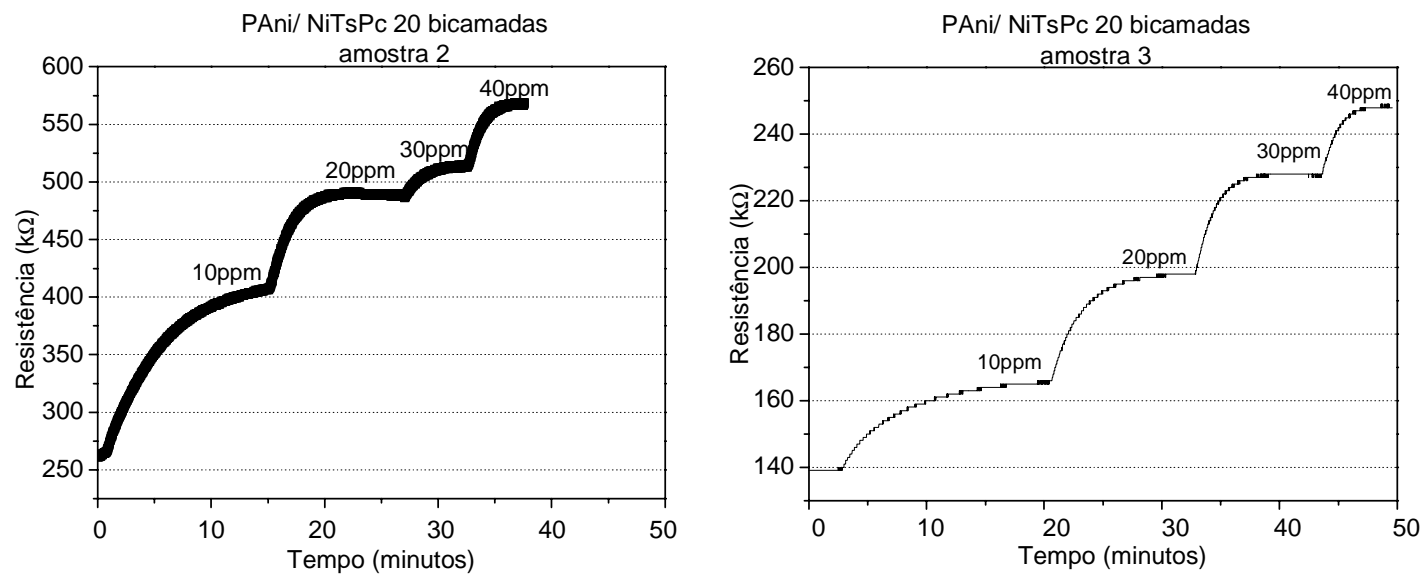

(b)
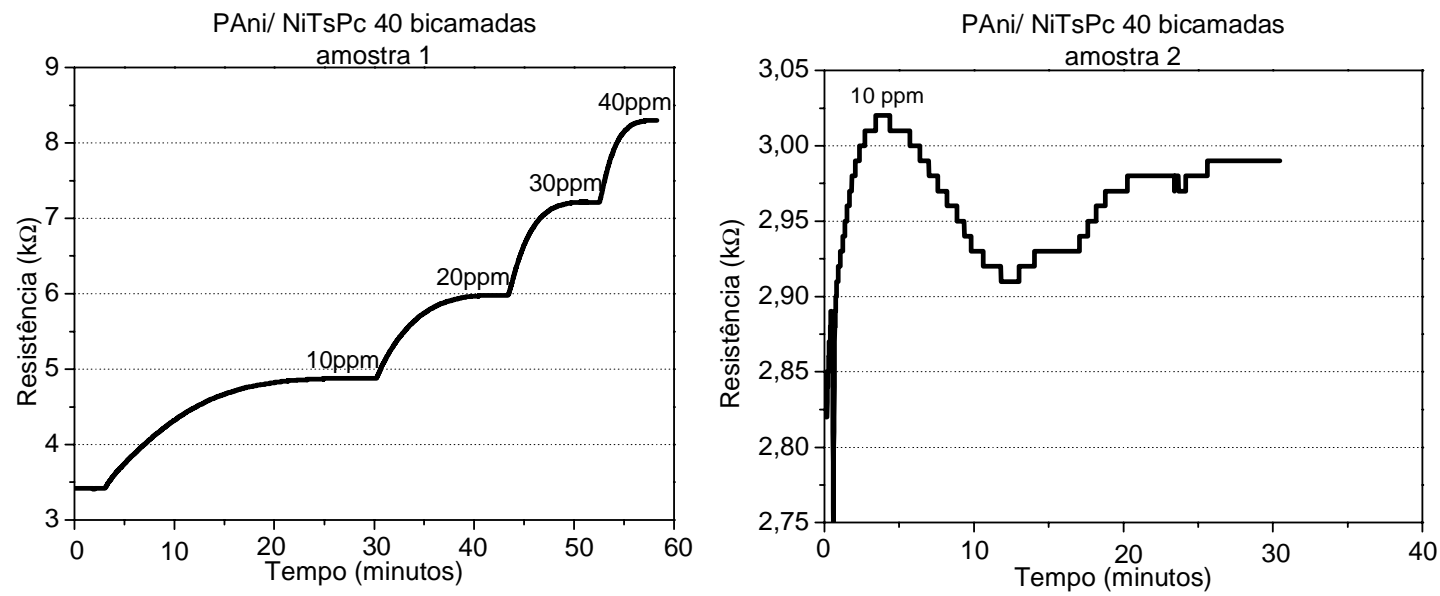


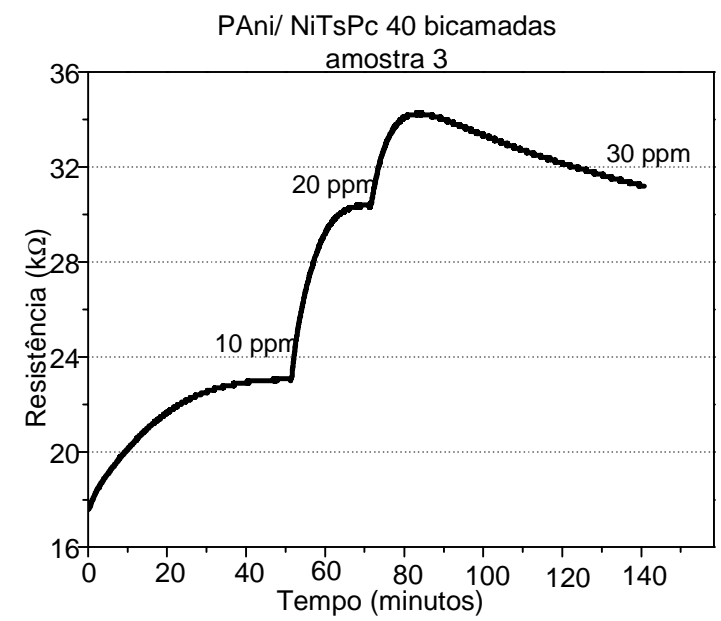

(c)

Figura 24: Variação da resistência elétrica dos sensores de Pani/NiTsPC de (a) 10 bicamadas, (b) 20 bicamadas e (c) 40 bicamadas, mediante variação da concentração de amônia.
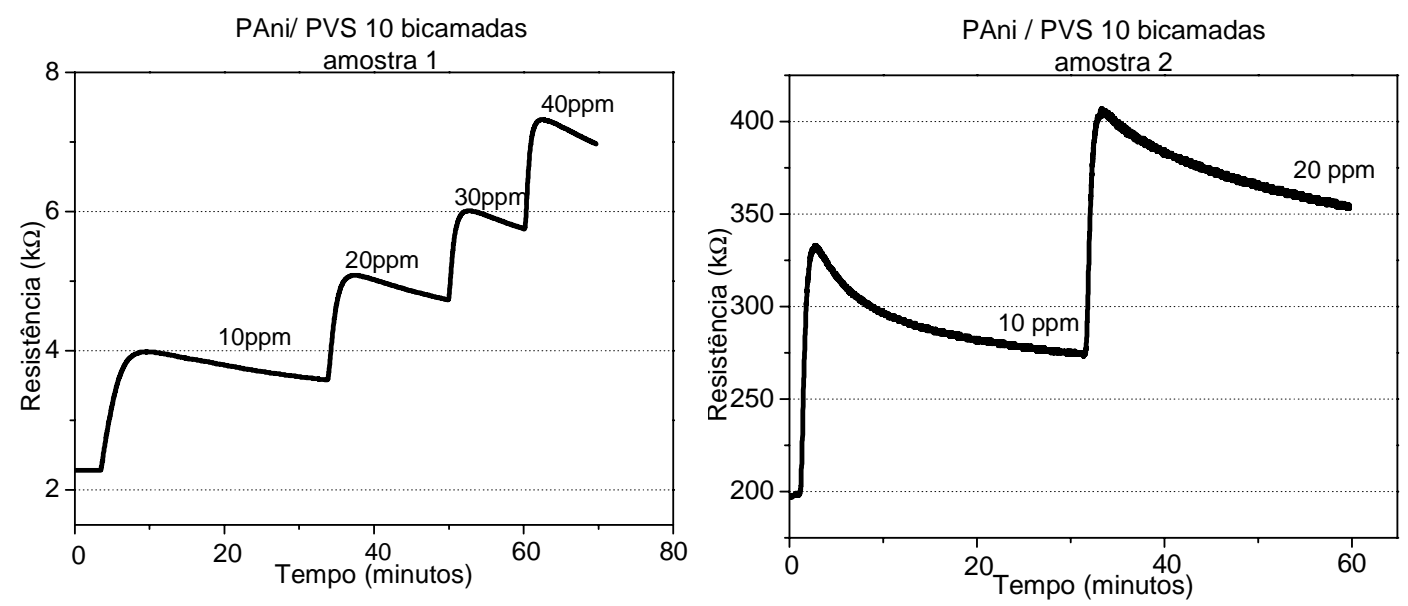


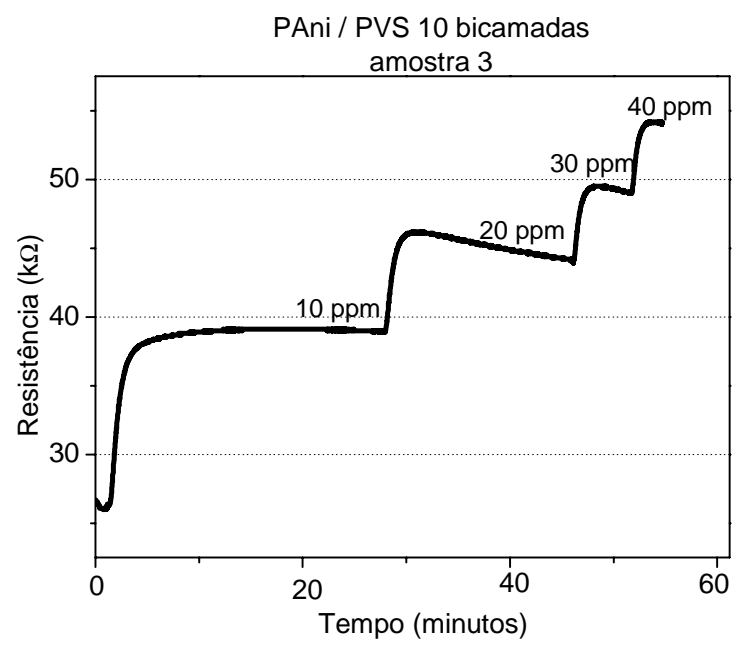

(a)
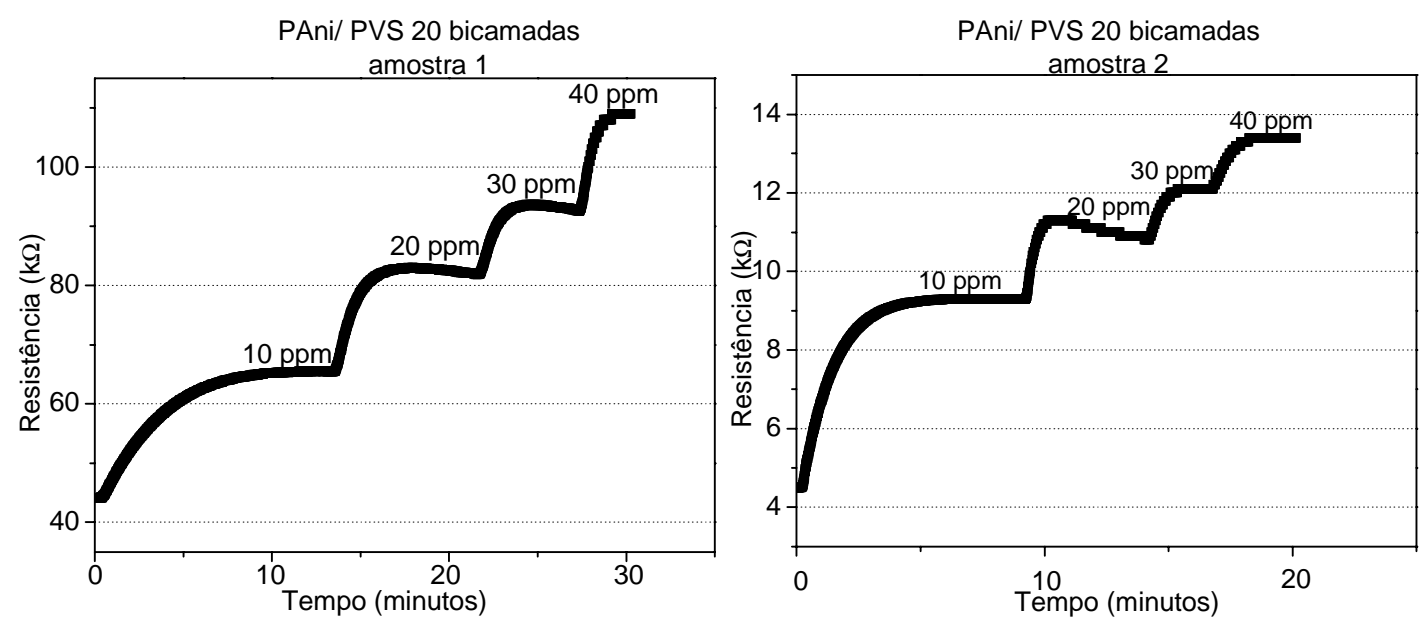


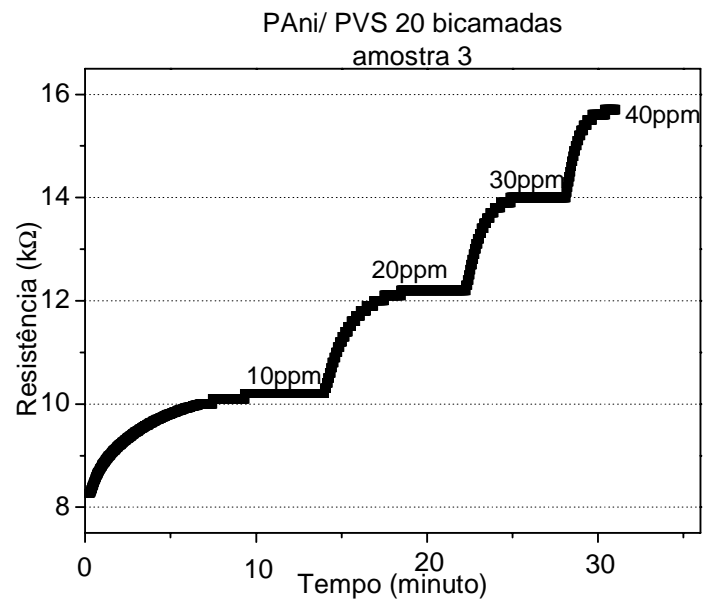

(b)
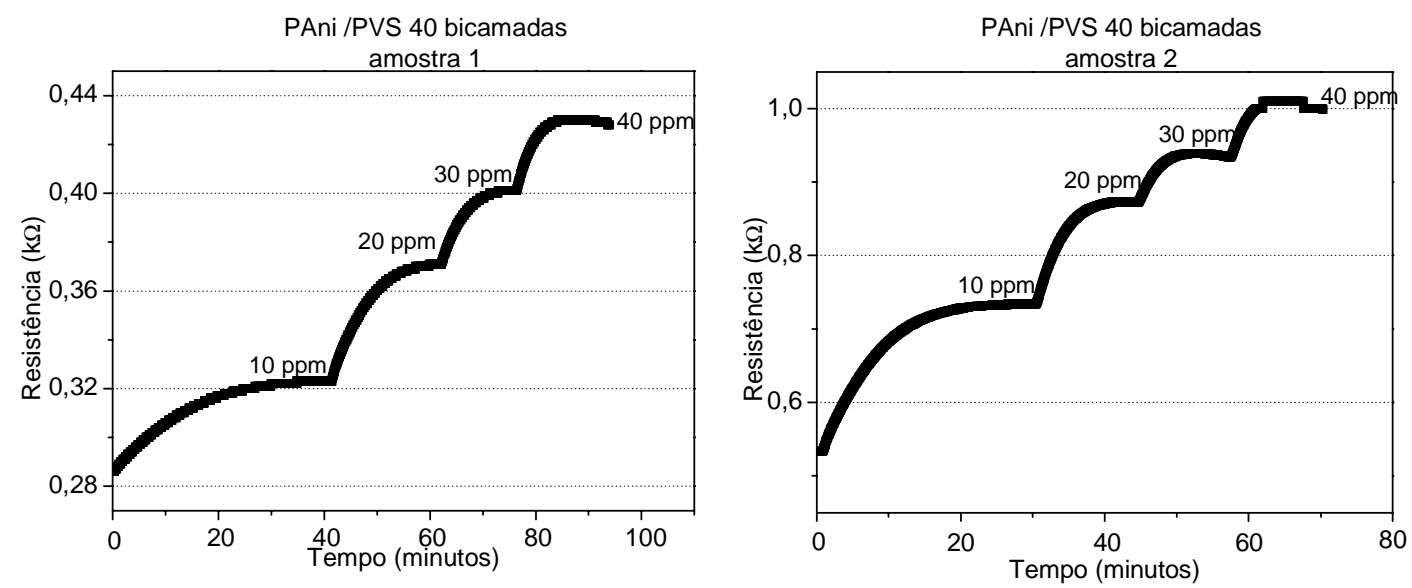


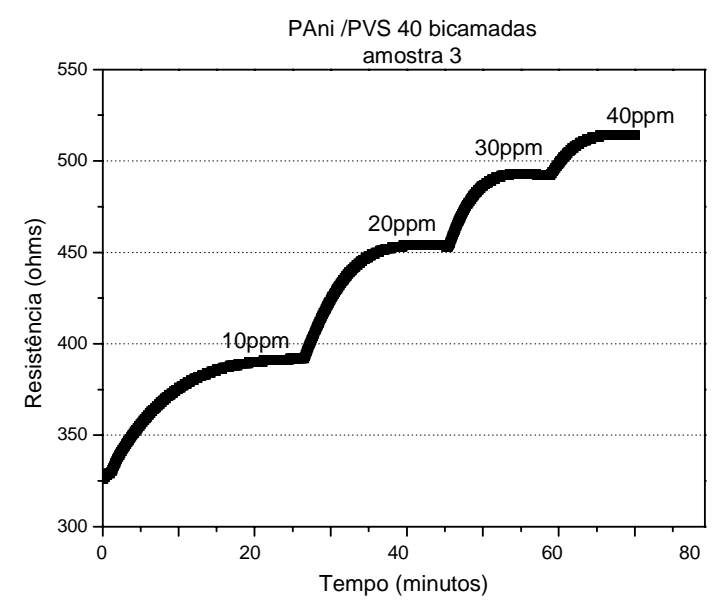

(c)

Figura 25: Variação da resistência elétrica dos sensores de Pani/PVS de (a) 10 bicamadas, (b) 20 bicamadas e (c) 40 bicamadas mediante variação da concentração de amônia.

Em alguns casos, os valores de resistência não se estabilizaram, mesmo após longos períodos (nestes casos os gráficos não foram apresentados). Verificou-se também que os valores de resistência elétrica foram diferentes para o mesmo tipo de sensor. Isso mostra que apesar de terem espessuras parecidas, as características elétricas não são similares, provavelmente pelo grau de dopagem não ser igual em todas as amostras. Além disso, os eletrodos também podem influenciar significamente nos resultados.

Com exceção dos sensores de PAni/CuTsPc 10 bicamadas e de PAni/NiTsPc 10 bicamadas, que não responderam satisfatoriamente aos ensaios, praticamente todos os sensores quando expostos à amônia, apresentaram aumento da resistência. A única exceção foi a amostra 3 da Pani/CuTsPc de 10 bicamadas. Neste caso, o efeito presenciado foi oposto aos demais sensores, já que a resistência diminuiu com a inserção da amônia. Provavelmente a influência da umidade na PAni pode ter prevalecido sobre as demais interações, resultando no aumento da condutividade do sistema. Além disso, observamos que os sensores de 10 bicamadas de PAni/CuTsPc e 
amostra 3 de PAni/NiTsPc mostraram-se bem sensíveis a ruídos externos. Os picos observados em seus gráficos ocorreram no momento da inserção da amônia, devido à leve movimento dos cabos. Com relação ao tempo de resposta, de modo geral, com o aumento da concentração de amônia o tempo de resposta e estabilização do sensor, além da variação da resistência diminui, caminhando assim para a saturação do sensor.

Um dos parâmetros de grande importância para avaliação do desempenho de sensores é a sensibilidade. A sensibilidade expressa a variação da resistência em relação à resistência inicial, ou diferença fracionária [75], [79] na forma percentual [(R$\left.\left.\mathrm{R}_{0}\right) / \mathrm{R}_{0}\right]^{*} 100$, onde $\mathrm{R}$ é a resistência do sensor quando exposto à amônia e $\mathrm{R}_{0}$ a resistência antes de ser submetido ao gás. O comportamento desejado de um sensor é que sua sensibilidade seja proporcional à variação da concentração de amônia dentro de certo intervalo, já que a partir de certo momento o sensor tende à saturação. Baseandose neste critério, dentre os sensores ensaiados foram escolhidas as melhores amostras de cada sistema e número de bicamadas para se realizar a analise da sensibilidade. Os gráficos seguintes mostram os resultados com relação à sensibilidade deste grupo de sensores. Nos gráficos da Figura 2626, observamos que os sensores com filmes mais finos se mostraram, na grande maioria dos casos, mais sensíveis. Filmes mais finos, apresentam menor condutividade e demonstram ser mais sensíveis provavelmente devido a rugosidade em suas superfícies, permitindo que a amônia penetre com maior facilidade [80].

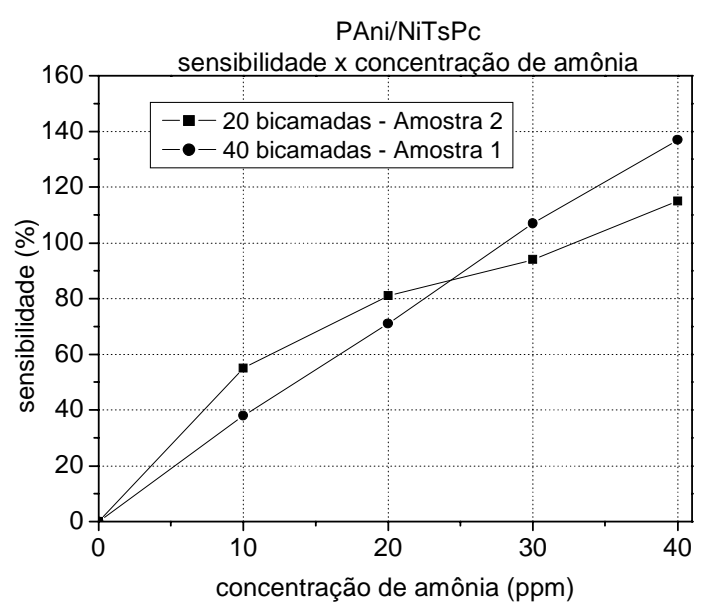

(a)

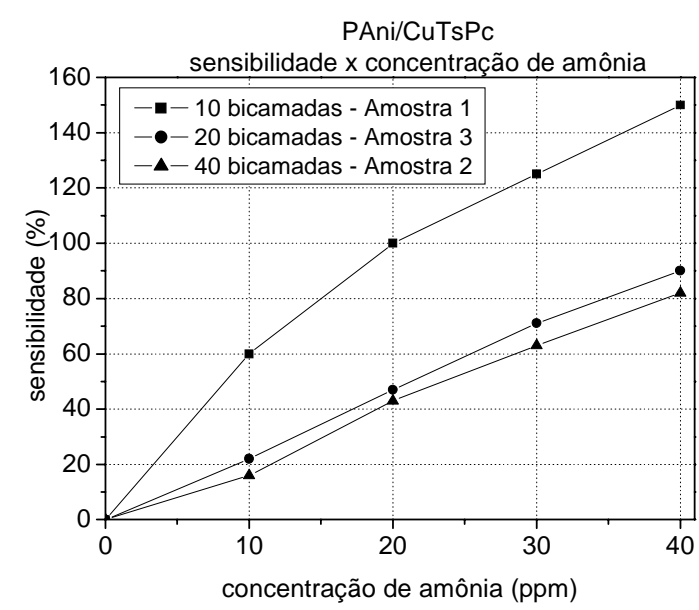

(b) 
PAni/ PVS

sensibilidade $x$ concentração de amônia

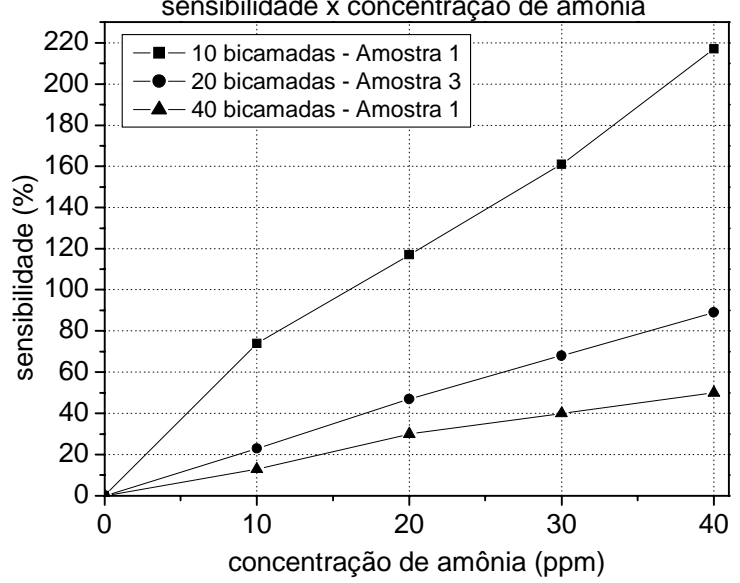

(c)

Figura 26: Sensibilidade mediante variação de concentração de amônia nos sensores de (a) PAni/NiTsPc; (b)PAni/CuTsPc e (c) PAni/PVS. Os sensores com filmes mais finos são os mais sensíveis.

Comparando os três tipos de sensores com o mesmo número de bicamadas, podemos verificar que o sensor de PAni/ NiTSPc é o mais sensível entre os sensores de 20 e 40 bicamadas. A figura 27 ilustra esta comparação.

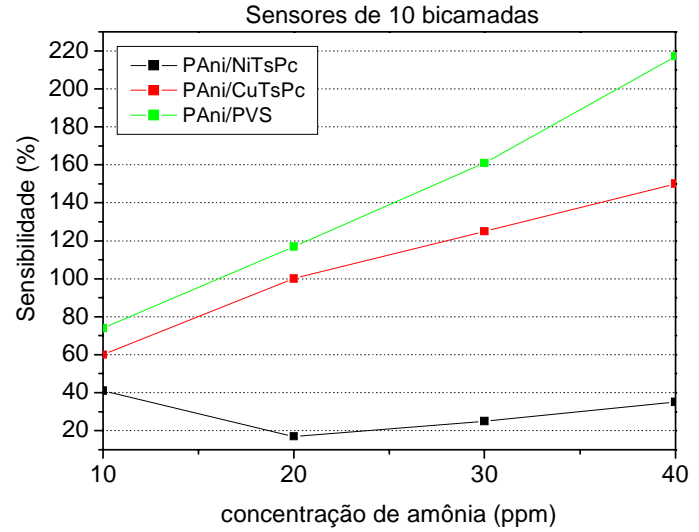

(a)

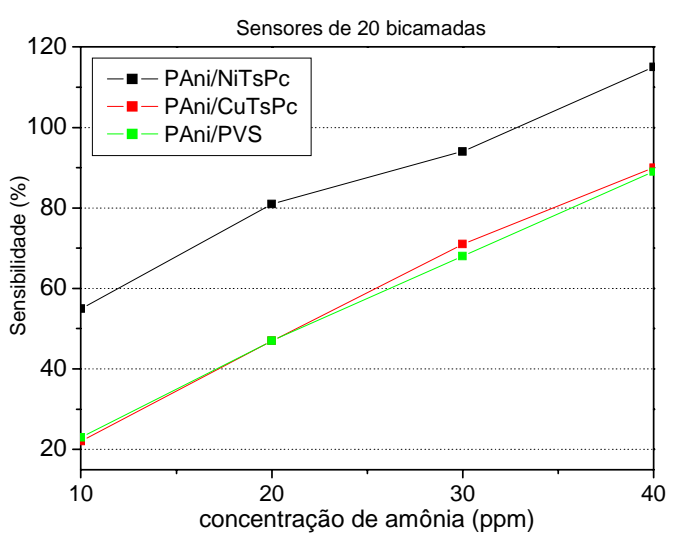

(b) 


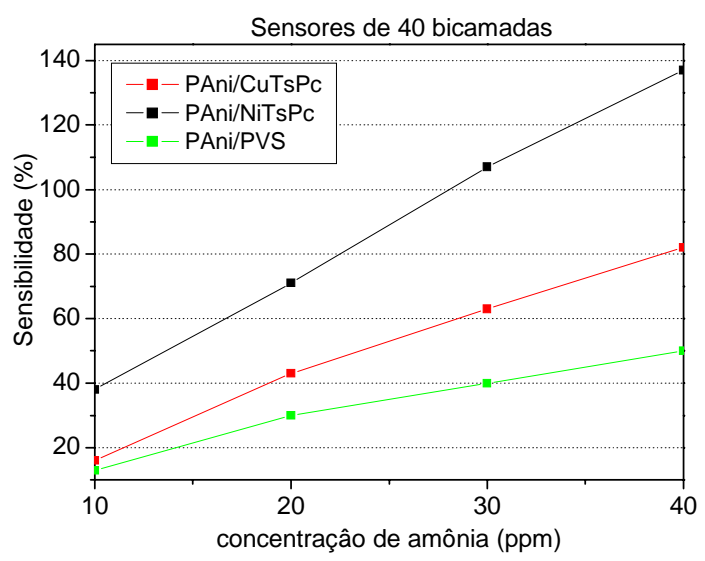

(c)

Figura 27: Comparação entre sensores com mesmo número de bicamadas. O sensor de PAni/NiTsPc mostrou-se mais sensível entre os de 20 e 40 bicamadas.

Comparando a sensibilidade destes sensores com outros sensores baseados em polianilina encontrados na literatura, podemos considerar que os três sistemas propostos apresentam alta sensibilidade à amônia. Matsuguchi e colaboradores [14] observaram a sensibilidade de sensores de amônia baseados em filmes de PAni com blendas de PSt (Poliestireno) e PMMA (poli(metil metacrilato)), além de filme apenas de PAni. Ensaiados em ar com umidade relativa de 33\%, quando expostos à 100ppm de amônia, estes sensores apresentaram sensibilidade de 13\%, 28\% e 17\% respectivamente (PAni-PSt, PAni-PMMA e PAni). Já Kukla e colaboradores [81] estudaram o comportamento de sensores baseados em um chip de silício e filme de polianilina como elemento sensível. Neste caso, a $37^{\circ} \mathrm{C}$ de temperatura ambiente, o sensor submetido a 100 ppm de NH3 apresentou sensibilidade de $90 \%$.

O tempo de resposta do sensor e consecutiva estabilização do valor da sensibilidade também se mostram variável de acordo com o número de bicamadas do filme polimérico, sendo que quanto maior este número, maior o tempo de resposta e estabilização, conforme Figura. Filmes mais finos 
apresentam menor tempo de resposta devido a maior proporção entre a superfície, e seu volume [29].

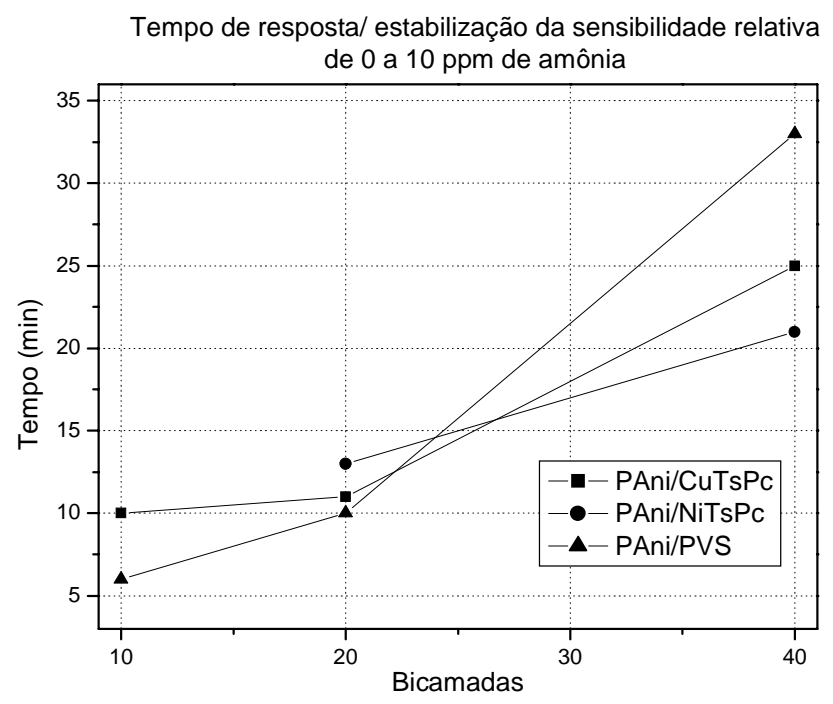

Figura 28: Tempo de resposta dos sensores mediante 10 ppm de amônia.

\subsubsection{Comportamento elétrico dos dispositivos: ensaios em AC-Variação de}

umidade e temperatura

Após os ensaios dos 27 sensores na presença de amônia, verificamos através dos gráficos comportamentos distintos. Apesar dos sensores de 10 bicamadas mostrarem-se resposta mais rápida na presença do gás, eles também se mostraram menos estáveis. Já os sensores de 20 e 40 bicamadas apresentaram respostas mais estáveis e comportamentos similares. Como os sensores de 20 bicamadas demandam metade do tempo para serem confeccionados e respondem à amônia mais rapidamente quando comparados aos sensores de 40 bicamadas, estes foram os escolhidos para serem ensaiados na câmara climática. Porém, nem todos os sensores de 20 bicamadas apresentaram desempenho satisfatório no ensaio sob amônia. Desta maneira, foram escolhidos apenas os 2 melhores sensores dentre os 3 de mesmo tipo, sendo que no total 6 sensores foram submetidos ao ensaio sob variação de temperatura e umidade. Os sensores foram submetidos a umidades relativas de $20 \%, 30 \%$ e $40 \%$, às temperaturas de $20^{\circ} \mathrm{C}, 25^{\circ} \mathrm{C}$ e $30^{\circ} \mathrm{C}$ na câmara climática. Ensaios em faixas de temperatura e umidade 
maiores não foram possíveis de serem realizados devido a limitações do equipamento. A medida da variação da resistência elétrica também foi realizada com o equipamento HP4263 LCR meter em 0,250V/ 1000Hz. As respostas encontram-se nos gráficos da Figura 29, Figura 30 e Figura 31.

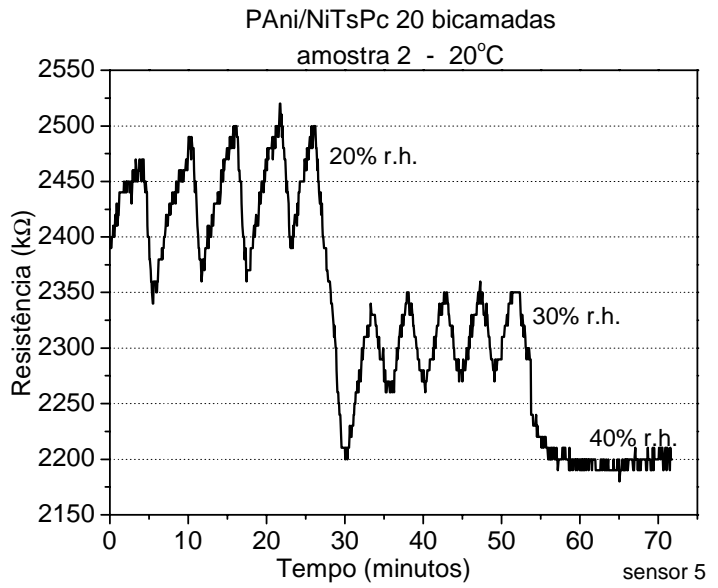

(a)

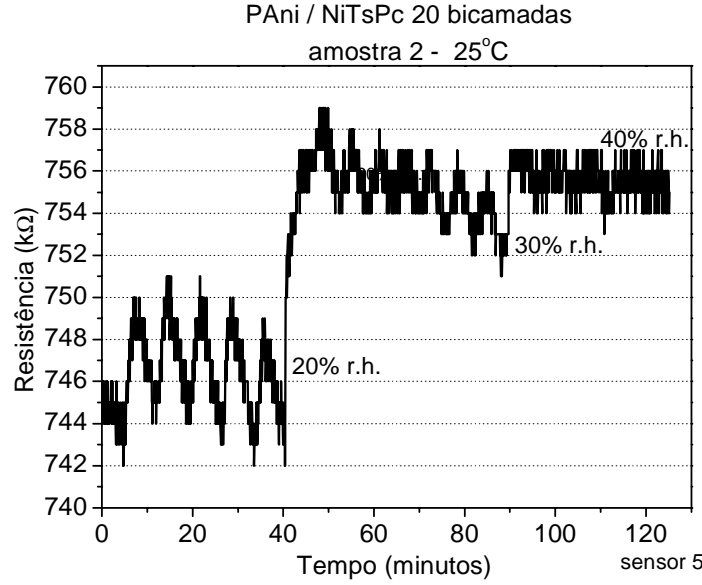

(b)

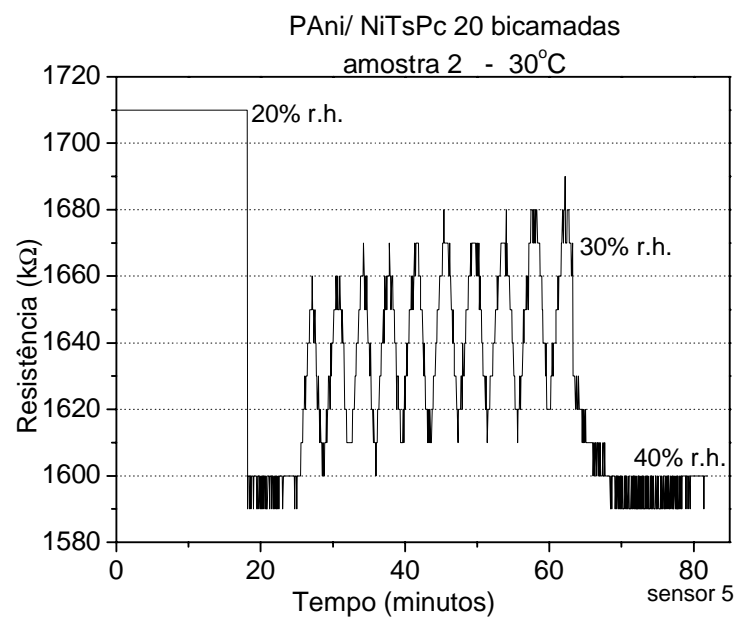

(c) 


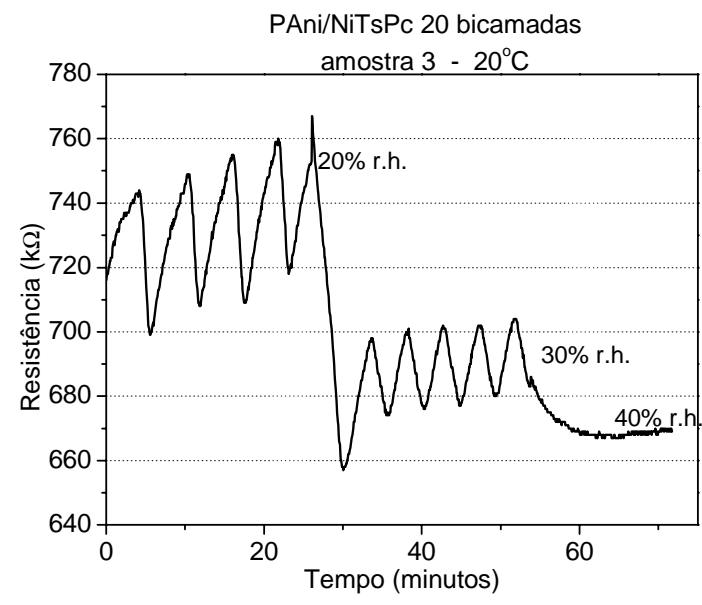

(d)

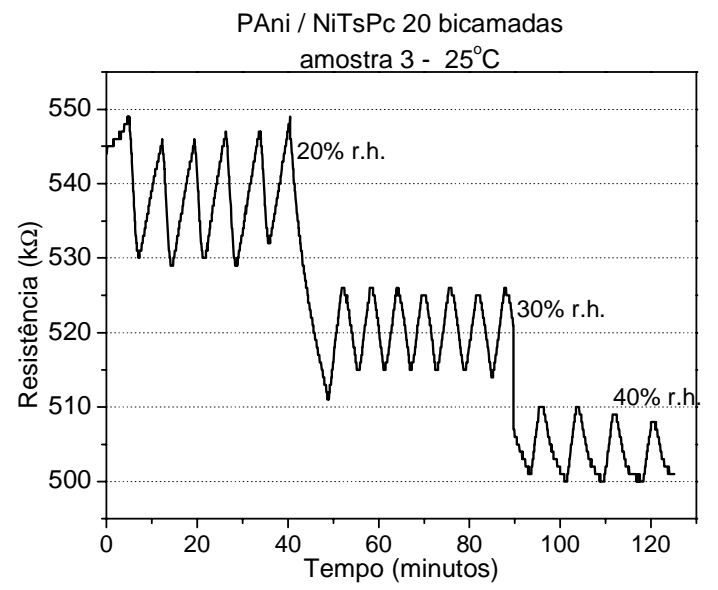

(e)

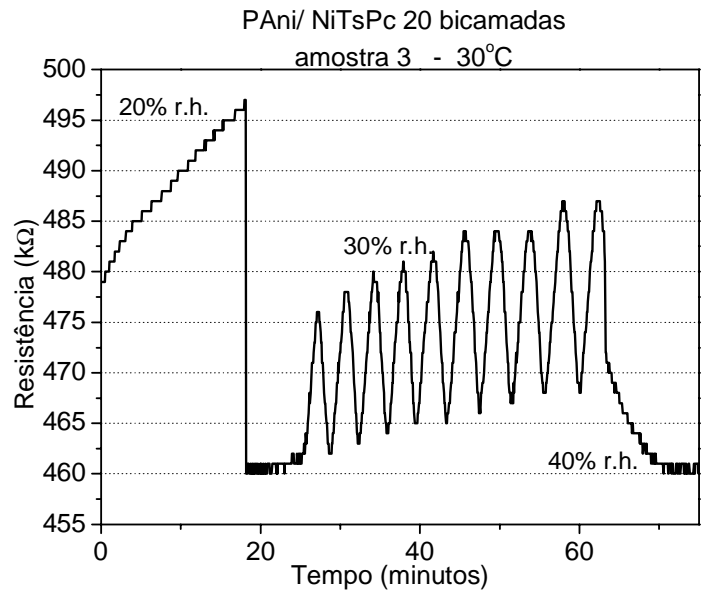

(f)

Figura 29: Comportamento dos sensores de PAni/ NiTsPc 20 bicamadas mediante variação de temperatura e umidade relativa. 


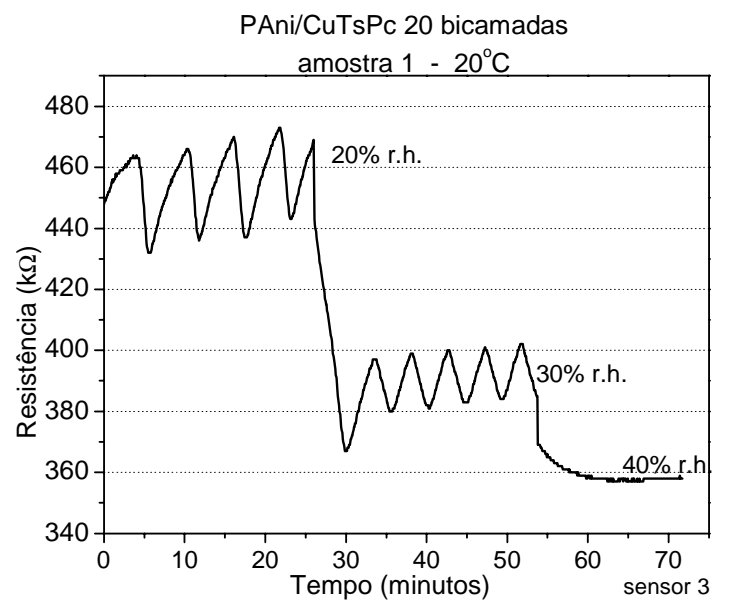

(a)

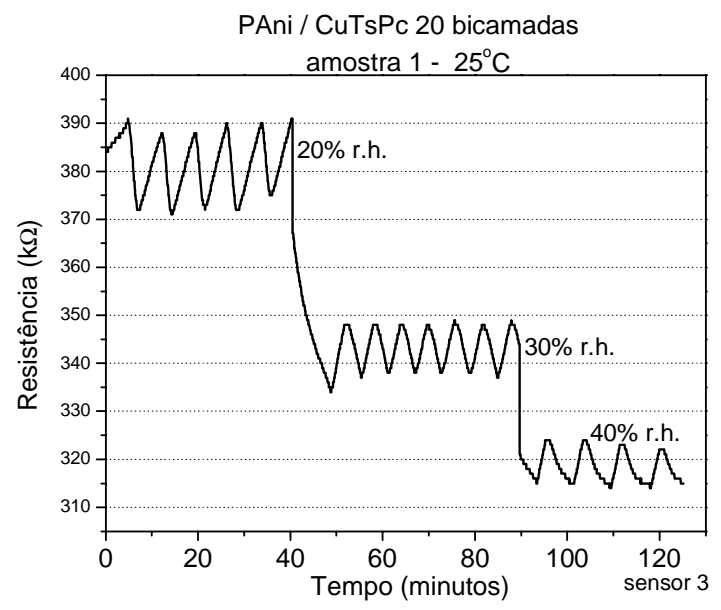

(b)

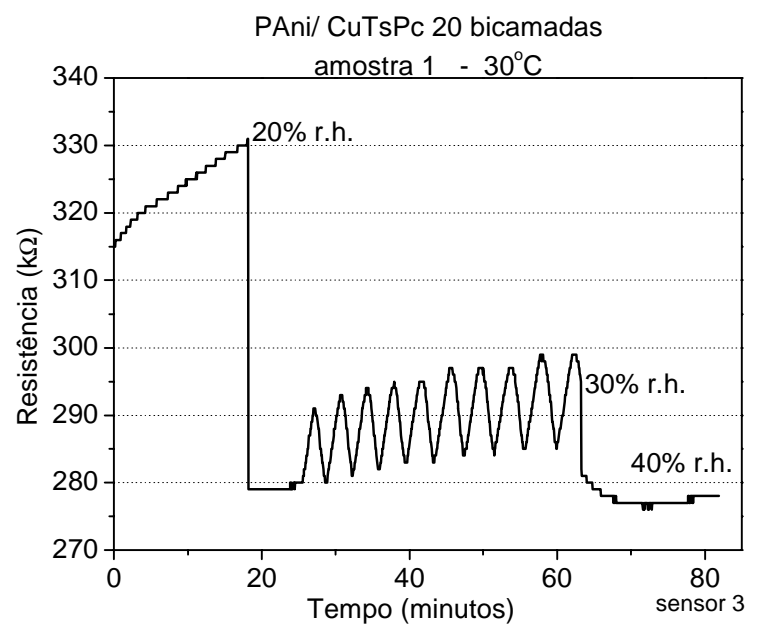

(c) 


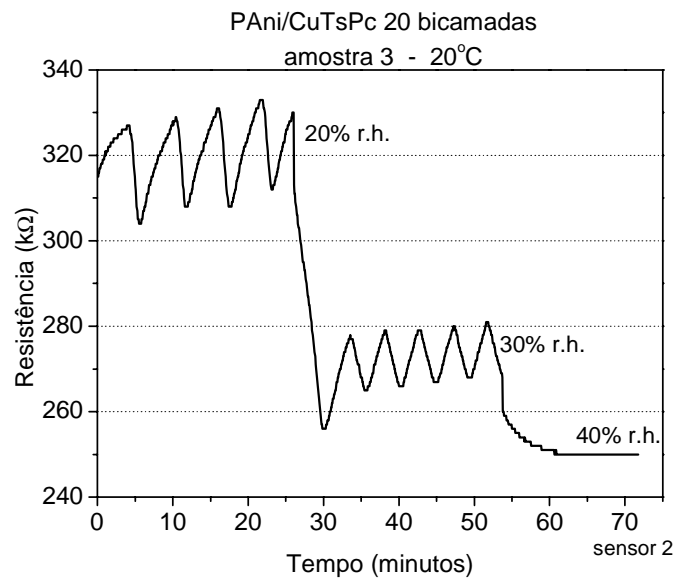

(d)

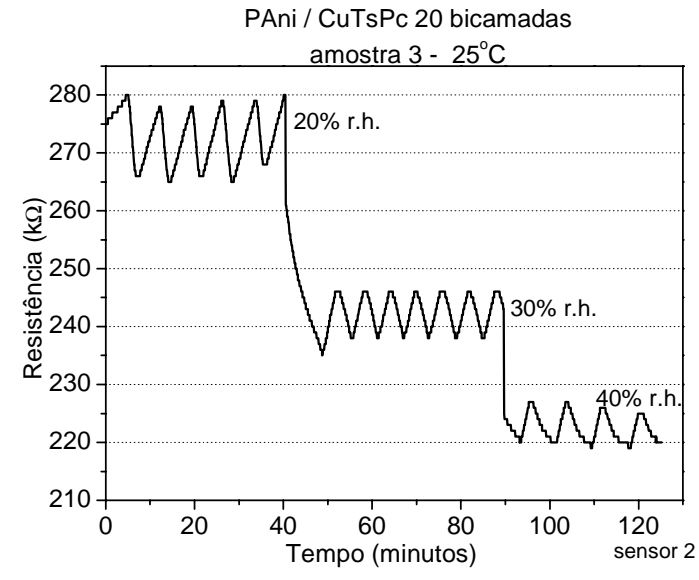

(e)

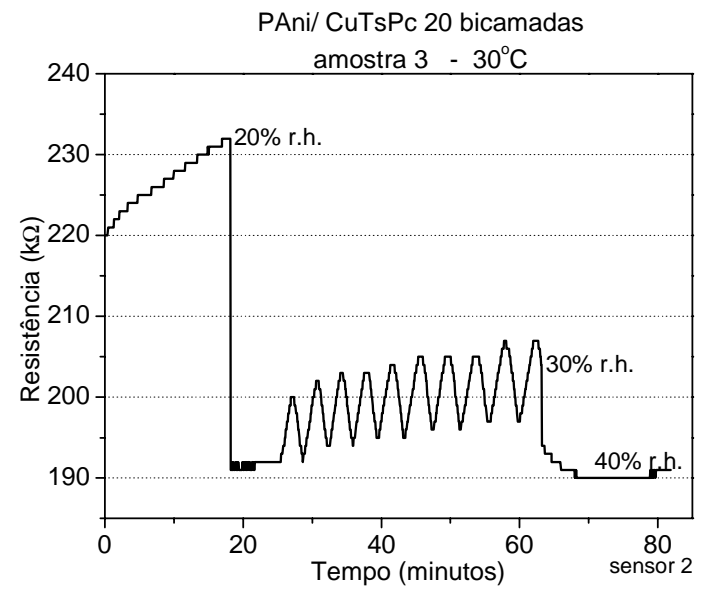

(f)

Figura 30: Comportamento dos sensores de PAni/ CuTsPc 20 bicamadas mediante variação de temperatura e umidade relativa. 


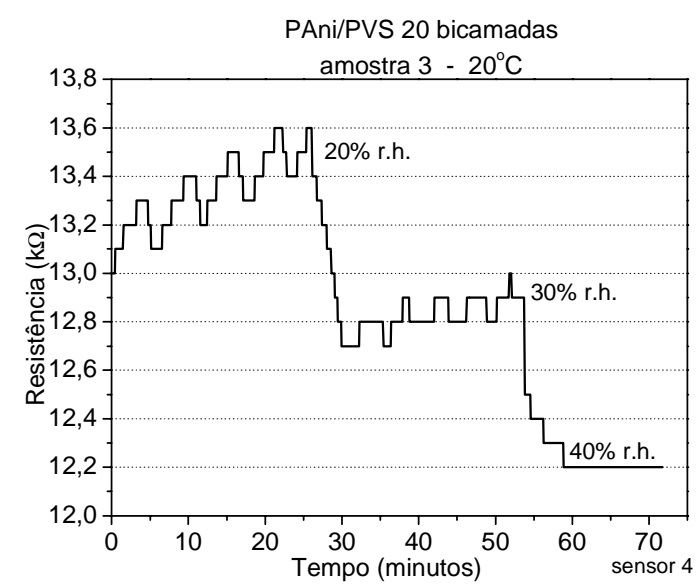

(a)

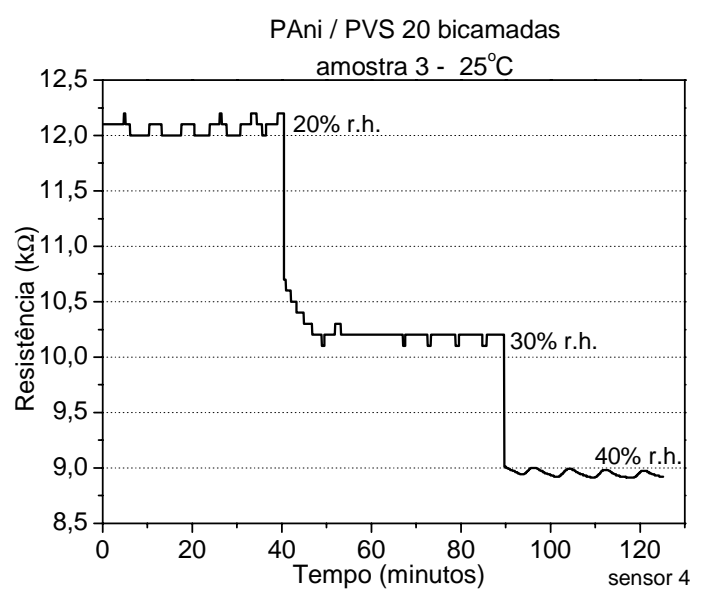

(b)

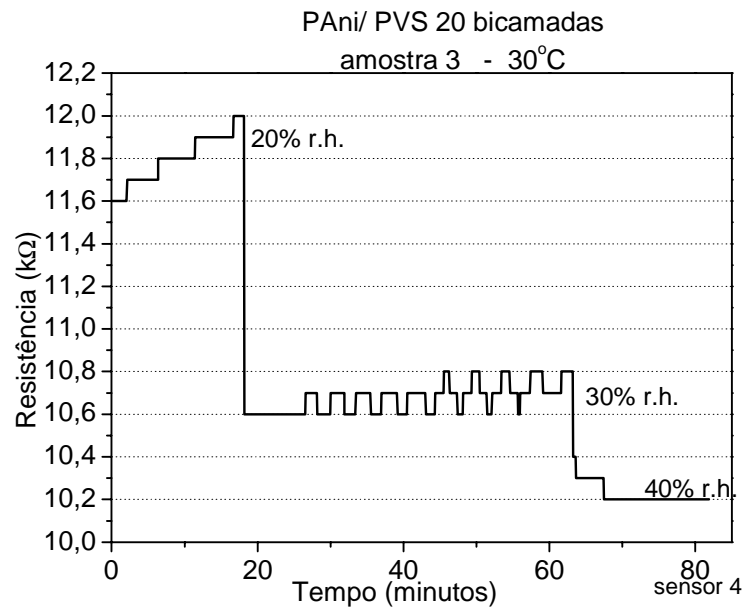

(c) 


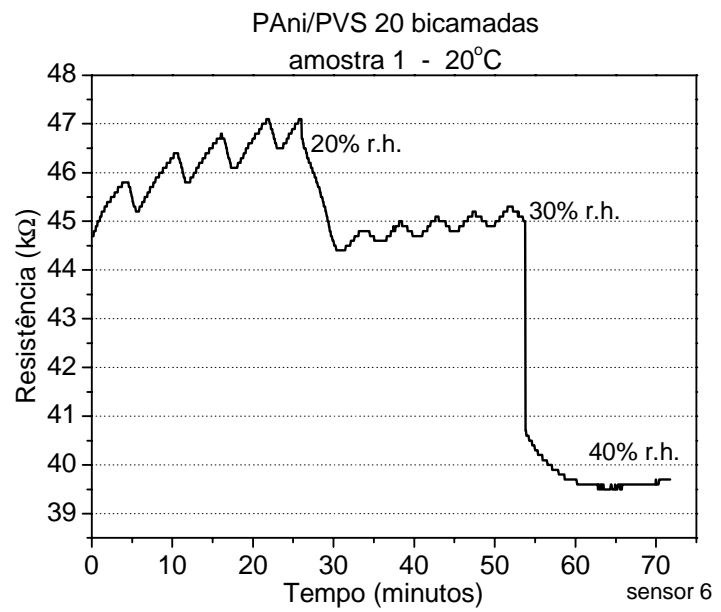

(d)

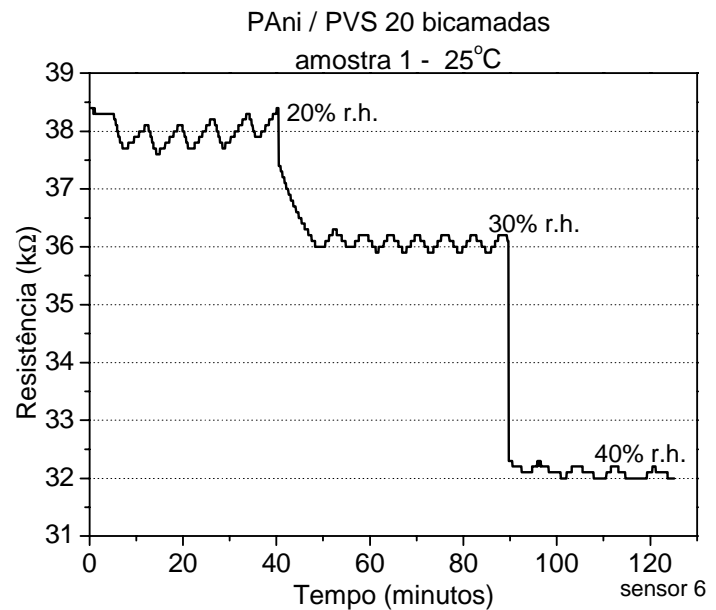

(e)

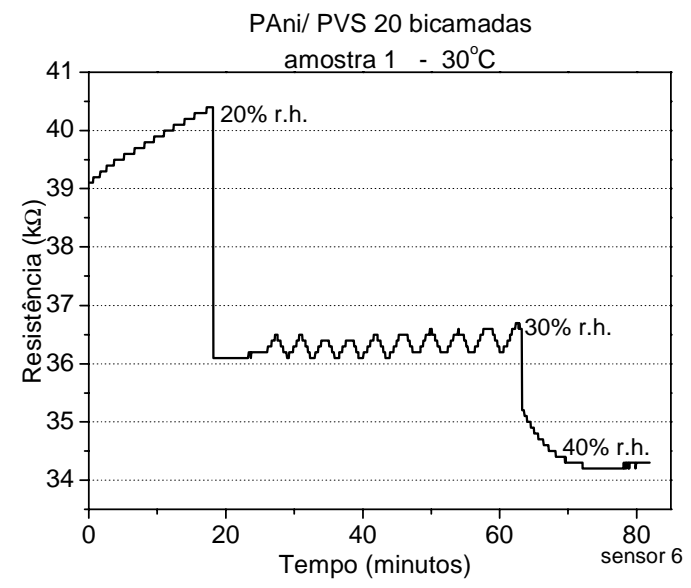

(f)

Figura 31: Comportamento dos sensores de PAni/ PVS 20 bicamadas mediante variação de temperatura e umidade relativa.

Nos gráficos apresentados, podemos verificar que a variação de temperatura entre $20^{\circ} \mathrm{C}$ e $30^{\circ} \mathrm{C}$ não apresentou grande influência nos resultados, apesar de notarmos uma diminuição da resistência elétrica com o aumento da temperatura.

Com relação à umidade relativa, notamos um aumento da sensibilidade dos sensores. Em todos os casos o comportamento da PAni prevaleceu sobre a das 
ftalocianinas, já que nas ftalocianinas a água atua como um gás doador de elétrons, diminuindo a condutividade desta. Além disso, os sensores mostraram uma rápida resposta a variação da umidade. As ondas tipo "serra" resultam da variação da umidade da câmara climática que controlada por um controlador lógico programável, variava em torno do valor de umidade selecionado.

Tomando-se como parâmetro de analise a sensibilidade dos sensores novamente como sendo $\left|\left[\left(R-R_{0}\right) / R_{0}\right] * 100\right|$, obtemos os gráficos da figura 32. Através deles podemos visualizar que os sensores de PAni/ NiTsPc apresentam a menor sensibilidade na presença de umidade, o que significa que o parâmetro umidade influencia menos na leitura do sensor de amônia, fato logicamente desejável. Este resultado pode ser explicado devido ao fato das ftalocianinas de níquel apresentar grande sensibilidade à água, como mostram alguns estudos [10]. Porém, neste caso, a sensibilidade que resultaria no aumento da resistência elétrica, se opôs ao comportamento da PAni, resultando na relativa baixa sensibilidade do sistema.
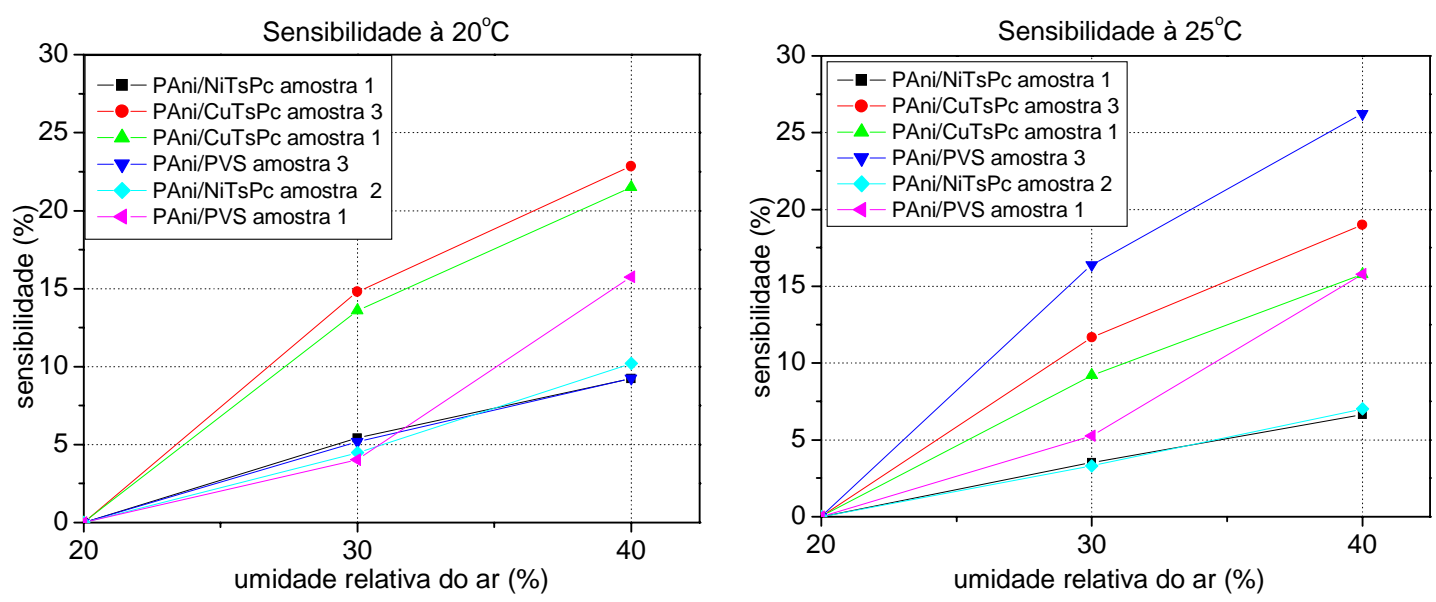


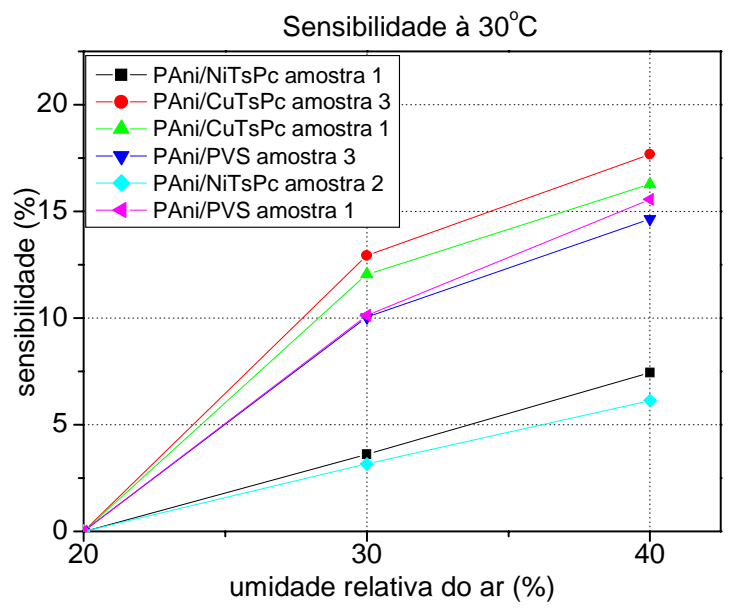

Figura 32: Comparação da sensibilidade dos diferentes sensores a (a) $20^{\circ} \mathrm{C}$, (b) $25^{\circ} \mathrm{C} \mathrm{e}$ (c) $30^{\circ} \mathrm{C}$ considerando como resistência inicial os valores a $20 \%$ de umidade relativa. 


\section{CONCLUSÕES}

Sensores de amônia baseados em filmes finos de PAni/PVS, PAni/NiTsPc e PAni/NiTsPc com três diferentes número de bicamadas foram confeccionados. Seus comportamentos elétrico quando submetidos à amônia e separadamente em relação a variação de temperatura e umidade foram observados. Seus filmes foram caracterizados por UV-vis e por profilometria, mostrando o crescimento linear dos filmes depositados pelo método da automontagem, com o aumento do número de bicamadas. Observamos que os ensaios realizados nos sensores alimentados em tensão continua não foram satisfatórios, já que os valores de corrente não se estabilizaram e que a alimentação em corrente alternada é mais apropriada para ensaios deste tipo de sensores. Este fato pode ser explicado com a possibilidade dos filmes serem polarizados quando alimentados em corrente continua.

Com relação ao número de bicamadas, podemos observar que os sensores de 10 bicamadas, são os mais sensíveis e apresentam menor tempo de resposta. Este fato pode dever-se ao fato de que em filmes mais finos é maior a proporção entre a superfície e seu volume. Porém, apesar de serem os mais sensíveis, não apresentaram desempenho satisfatório, não estabilizando seus valores de resistência, mostrando-se muito sensíveis a ruídos externos. Além disso, em filmes mais finos a rugosidade começa a afetar a condutividade do polímero, tornando-os assim mais difíceis de adquirir amostras reprodutivas [82]. Dessa maneira, os sensores com filmes de 20 bicamadas mostraramse mais adequados para a continuação do trabalho, pois apresentaram os melhores resultados nos ensaios, são mais sensíveis e demandam menos tempo de fabricação que os de 40 bicamadas.

No que diz respeito à combinação de materiais, os sensores de PAni/NiTsPc mostraram-se os mais apropriados para a detecção de amônia, já que apresentaram-se o de maior sensibilidade em relação à amônia e os menos sensíveis a umidade. O objetivo da combinação dos materiais PAni com ftalocianinas parece ter sido atingida, já que ambos são sensíveis a amônia, apresentando comportamento similar, ou seja, apresentam aumento da resistência elétrica quando expostos a este gás. Desta maneira, observou-se uma espécie de "soma" dos efeitos destes dois materiais. Por outro lado, com relação à umidade, estes materiais apresentam comportamentos opostos, sendo que 
a umidade aumenta a condutividade da PAni e diminui a das ftalocianinas. Novamente observou-se uma "soma" de efeitos opostos, resultando filmes de PAni/NiTsPc menos sensíveis a umidade do que os outros dois tipos de sistema. Uma possível explicação para o porquê o sensor com ftalocianina de cobre não apresentou este mesmo comportamento, pode ser o fato das ftalocianinas de níquel apresentarem grande sensibilidade à água, como mostram alguns estudos [10]. Porém, neste caso, a sensibilidade que resultaria no aumento da resistência elétrica, se opôs ao comportamento da PAni, resultando na relativa baixa sensibilidade do sistema.

Verificamos que a reprodutibilidade dos sensores não foi obtida, já que entre sistemas de mesmo tipo e mesmo numero de bicamadas obtivemos valores muito diferentes de resistividade elétrica. Este fato pode ser explicado devido a níveis de dopagem diferentes, à influência dos eletrodos e ao processo manual de deposição dos filmes. Além disso, alguns sensores baseados em filmes finos de ftalocianina encontrados na literatura apresentam a característica de serem diferentes com relação à morfologia e a estrutura, mesmo quando fabricados simultaneamente, nas mesmas condições ambientais. Estas diferenças por sua vez, causam variações no comportamento elétrico destes sensores.

Como trabalho futuro, a reprodutibilidade dos sensores pode ser abordada, na tentativa de melhorar este aspecto, já que neste trabalho os sensores aparentemente idênticos mostraram ser eletricamente diferentes. Uma tentativa é após a confecção dos sensores, a desdopar os filmes e posteriormente dopa-los novamente com gás de $\mathrm{HCl}$, na tentativa de uniformizar a dopagem proporcionando valores similares de resistência elétrica.

Parte dos resultados do presente trabalho, mostrando o potencial dos filmes finos de PAni/NiTsPc para utilização em sensores de amônia, foi reportado no trabalho apresentado no congresso internacional de Microelectronics Technology and Devices SBMicro 2006, ocorrido em Ouro Preto - M.G. 


\section{REFERÊNCIAS BIBLIOGRÁFICAS}

[1] HERNANDES,R. ; CAZETTA, J.O. Método simples e acessível para determinar amônia liberada pela cama aviária. Rev. Brás. Zootec., v.30, n.3, p. 824-829, 2001.

[2] RITZ, C.W., et al. Litter quality and broiler performance. Cooperative Extension Service/ The university of Georgia College of Agricultural and Enviromental Sciences. 2005. Disponível em: <http://pubs.caes.uga.edu/caespubs/pubs/PDF/B1267.pdf> Acesso em: 17 de abril de 2006.

[3] AVICULTURA INDUSTRIAL. LOCAL. DATA. Disponível em: $<$ http://www.aviculturaindustrial.com.br/site/dinamica.asp?id=1803\&tipo_tabela=cet\&a tegoria=nutricao $>$. Acesso em: 16 de abr. 2005.

[4] CARLILE, F.S. Ammonia in poultry houses: a literature review. World Poult. Science J., v.40, p.99-133, 1984

[5] OLIVEIRA, M.C. et al. Teor de matéria seca, $\mathrm{pH}$ e amônia volatilizada da cama de frango tratada ou não com diferentes aditivos. Revista Brasileira de Zootécnica v.32, n.4, p.951-954, 2003.

[6] SNA 2002. Sociedade Nacional de Avicultura. Artigo "Biosegurança e cuidados sanitários para frangos". Site da Internet http://biblioteca.sna.agr.br/artigos/artitecfrangos.htm

[7] TIMMER, B. et al. Ammonia sensor and their applications - a review.Sensors and actuators B., v.107, p. 666-677, 2005.

[8] HO, C.K et al. Review of chemical sensors for in-situ monitoring of volatile contaminants. Sandia Report 2001 SAND2001-0643. 
[9] DICKINSON, T.A. et al. Current trends in "artificial-nose" technology. Tibtech, v16, p.250-258, 1998

[10] BELGHACHI, A. ; COLLINS, R.A.. The effects of humidity on phthalocyanine $\mathrm{NO}_{2}$ and $\mathrm{NH}_{3}$ sensors. J. Phys. D : Appl. Phys. v23, p223-227, 1990.

[11] GUILLAUD, G. et al. Metallophthalocyanines gas sensor, resistors and field effect transistors. Coordination chemistry reviews. 178-180 (1998) 14331484

[12] GERARD, M.; CHAUBEY, A.; MALHOTRA, B.D. Application of conducting polymers to biosensors - review. Biosensors and Bioelectronics, v17, p345-359, 2002.

[13] PARTRIDGE, A.C.; JANSEN, M.L.; ARNOLD,W.M. Conducting polymer-based sensors. Materials science and engineering C, v.12, p.37-42, 2000.

[14] MATSUGUCHI,M.; OKAMOTO,A.; SAKAI,Y. Effect of humidity on NH3 sensitivity of polyaniline blend films. Sensors and Actuators B, V.94, p46-52, 2003

[15] MANO, E.B. Introdução a polímeros, Editora Edgard Blücher Ltda, 1988.

[16] WIKIPÉDIA. A enciclopédia livre. 26 de março de 2007. Monômero. Disponível em <http://pt.wikipedia.org/wiki/Mon\%C3\%B4mero $>$. Acesso em: 20 de maio de 2007.

[17] SANTOS, M.A. et al. Compósitos de borracha natural com compostos condutivos à base de negro de fumo e polímero condutor. Polímeros: Ciência e Tecnologia, v.11, $\mathrm{n}^{\mathrm{o}}$ 3, p. 126-134, 2001.

[18] FAEZ, R. et al. Polímeros condutores. Química nova na escola, v.11, p.13-18, 2000.

[19] CHIANG, C.K. et al. Electrical conductivity in doped polyacetylene. Physical Review Letters, v.39, p.1098-1101, 1977. 
[20] FARIA, R.M. ; OLIVEIRA, O.N. Exploiting the electrical properties of thin films of semiconducting polymers. Brazilian Journal of Physics, v.29, p.360-370, 1999.

[21] MATTOSO, L.H. Polianilinas:síntese, estrutura e propriedades. Química Nova, v.19 (4), p. 388-399, 1996.

[22] MACDIARMID, A.G. Synthetic Metals: a novel role for organic polymers. Synthetic Metals, v.125, p. 11-22, 2002.

[23] OKABAYASHI, K. el al. Electrochemical studies of polyaniline and its applications. Synthetic Metals, v. 18, p.365-370 , 1987.

[24] WATANABE, A. et al. Electrochromism of polyaniline film prepared by electrochemical polymerization. Macromolecules, v.20, p.1793-, 1987.

[25] MACDIARMID, A.G. et al. Polyaniline: Electrochemistry and application to rechargeable batteries. Synthetic Metals, v.18, p.393-398, 1987.

[26] GENIES, E.M., et al. Polyaniline, spectroelectrochemistry, display and battery Synthetic Metals, v18, p.631-636, 1987.

[27] ROTH, S.; GRAUPNER,W. Conductive polymers: Evaluation of industrial applications. Synthetic Metals, v.57, p.3623-3631, 1993.

[28] SOUZA, J.E.G. et al. Polypyrrole based aroma sensor. Synthetic Metals, 102, p. 1296-1299, 1999.

[29] SOUZA, J.E.G. et al. Free-grown polypyrrole thin films as aroma sensors. Sensors and Actuators B, 88, p. 246-259, 2003.

[30] AGBOR, N.E. et al. Polyaniline thin films for gas sensing. Sensors and Actuators B, v28, p173-179, 1995. 
[31] WUDL, F. et al. Poly-p-phenyleneamineimine: synthesis and comparison to polyaniline. Journal of the American chemical society. V109, p.3677-3684, 1987.

[32] CAO, Y. et al. Counter-ion induced processibility of conducting polyaniline and of conducting polyblends of polyaniline in bulk polymers. Synthetic Metals , v.48, p-9197, 1992.

[33] WU, S. et al. Ammonia sensitivity of polyaniline films via emulsion polymerization. European Polymer Journal, v.36, p.679-683, 2000.

[34] CHABUSKSWAR, V.V. et al. Acrylic acid doped polyaniline as an ammonia sensor. Sensors and actuators B, v77, p.657-663, 2001.

[35] ALBUQUERQUE, J.E. et al. A simple method to estimate the oxidation state of polyanilines. Synthetic metals, v.113, p.19-22, 2000.

[36] NATH, A. et al. In-situ measurement of $\mathrm{pH}$ in the interior of conducting polymer microtubules. Journal of Electroanalytical Chemistry v.557, p.119-125, 2003.

[37] BIANCHI, R.F. Aplicações do modelo de distribuição aleatória de barreiras de energia livre em mecanismos de condução iônico ou eletrônico em sistemas desordenados: polianilinas, ormolytes e perovskitas tipo $\operatorname{SrTi}(1-\mathrm{x}) \mathrm{RuxO}_{3}$, Dissertação de Mestrado, IFSC ,1997.

[38] HEEGER, A.J. Semiconducting and metallic polymers: the fourth generation of polymeric materials. Synthetic metals, v.125, p.23-42, 2002.

[39] MALINAUSKAS, A. Chemical deposition of conducting polymers Polymer, v.42, p-3957-3972, 2001.

[40] DICKINSON, T.A. et al. Current trends in "artificial-nose" technology. Tibtech, v16, p.250-258, 1998 
[41] BLANC, J.P. et al. Study of the action of gases on a polypyrrole film. Sensor and Actuators B, v1, p. 130-133, 1990.

[42] LUBENTSOV, B.Z. et al. Conducting polymer interaction with gaseous substances. Synthetic Metals, v45, p.235-240, 1991.

[43] MATTOSO, L.H.C. Revisão: Polianilinas - síntese, estrutura e propriedades. Química nova, v 19 (4), p.388-399, 1996.

[44] LI, D. et al. Self-assembly of polyaniline ultrathin films based on doping-induced deposition effect and applications for chimical sensors. Sensors and Actuators B, v66, 125-127, 2000.

[45] HARSÁNYI, G. Polymers films in sensor applications: a review of present uses and futures possibilities. Sensor review, v.20, p.98-150, 2000.

[46] DEBARNOT, D.N.; EPAILLARD, F.P. Polyaniline as a new sensitive layer for gas sensors. Analytica Chimica Acta, v475, p1-15, 2003.

[47]ADHIKARI, B. ; MAJUMDAR, S. Polymers in sensor applications. Progress in Polymer Science, v.29, p. 699-766, 2004.

[48] BARKER, PS. et al. Vapour recognition using organic films and artificial neural networks. Sensors and Actuators B, v.17, p.143-147, 1994.

[49] BUCHLER, M.G.; RYAN, M.A. Temperature and humidity dependence of a polymer-based gas sensor. Microdevices Laboratory - California Institute of Technology. Disponível em: <http://enose.jpl.nasa.gov/publications/sensors/970482.pdf $>$. Acesso em: 16 de maio de 2007.

[50] ALIX, A. et al. Water absorption study in polyaniline. Synthetic Metals, v.29, p 457-462, 1989. 
[51] MATVEEVA, E.S.; CALLEJA, R.D.; PARKHUTIK,V.P. Thermogravimetric and calorimetric studies of water absorbed in polyaniline. Synthetic Metals, v.72, p 105-110, 1995.

[52] MATVEEVA, E.S. Residual water as a factor influencing the electrical properties of polyaniline. The role of hydrogen bonding of the polymer with solvent molecules in the formation of a conductive polymeric network. Synthetic Metals, v.79, p 127-139, 1996.

[53] KHARISOV, B. et al. Técnicas para la obtención de las ftalocianinas. Ingenierias, v.VII, no22, p.71-84, 2004.

[54] EL-NAHASS, M.M. et al. Optical properties of copper phthalocyanine thin films. Egypt. J.Sol, v.24, n ${ }^{\circ} 1$, p.11-19, 2001.

[55] TOMA, H. E. et al. Da cor à cor inexistente: uma reflexão sobre espectros eletrônicos e efeitos cromáticos. Química Nova, v28, no 5, p897-900, 2005.

[56] IWATSU, F. et al. Solvent effect on crystal growth and transformation of zinc phthalocyanine. The journal of physical chemistry, v.84, p.3223-3230, 1980.

[57] COLLINS, R.A.; MOHAMMED, K.A. Gas sensitivity of some metal phthalocyanines. Journal of Physics. D, Applied Physics, v.21, p.154-161, 1988.

[58] PIZZINI, S. et al. Influence of the structure and morphology on the sensitivity to nitrogen oxides of phthalocyanine thin-film resistivity sensors. Sensors and Actuators, v.17, p.481-491, 1989.

[59] GUTIERREZ, N. et al. Array of sensors based on lanthanide bisphthalocyanine Langmuir-Blodgett films for the detection of olive oil aroma. Sensors and actuators B, v.77, p.437-442, 2001. 
[60] SPADAVECCHIA, J. et al. Metallophthalocyanines thin films in array configuration for electronic optical noise applications. Sensors and actuators B, V.96, p.489-497, 2003.

[61] FAASSEN, E. van; KERP. H. Explanation of the low oxygen sensitivity of thin films phthalocyanine gas sensor. Sensors and actuators B, V.88, p.329-333, 2003.

[62] ZUCOLOTTO, V., et al. Nanoscale processing of polyaniline and phthalocyanines for sensing applications. Sensors and Actuators B, v. 113, p809-815, 2006.

[63] XIE, D. et al. Fabrication and characterization of polyaniline-based gas sensor by ultra-thin film technology. Sensors Actuators B, v81, p158-164, 2002.

[64] JONES, T.A et al. Fast response metal phthalocynanine-based gas sensors. Sensors and Actuators, v.17, p.467-474, 1989.

[65] MOCKERT, $\mathrm{H}$. et al. Lead phthalocyanine $(\mathrm{PbPc})$ as a prototype organic material for gas sensors: comparative electrical and spectroscopic studies to optimize $\mathrm{O} 2$ and $\mathrm{NO}_{2}$ sensing. Sensors and Actuators, v. 19, p. 159 -176, 1989.

[66] KIM, Y.H. et al. Electrochemistry of Langmuir-Blodgett and self-assembled monolayers of pyrrole derivatives. Thin Solid Films, v. 352, p138-144, 1999

[67] DECHER,G.; LVOV,Y.; SCHMITT, J. Proof of multilayer structural organization in self-assembled polycation-polyanion molecular films. Thin Solid Films, v. 244, p772-777, 1994.

[68] MATTOSO, L.H. Polianilinas:síntese, estrutura e propriedades. Química Nova, v.19 (4), p. 388-399, 1996.

[69] OLIVEIRA, O.N. et al. LBL polyelectrolyte-based thin films for electronic and photonic applications. ". Handbook of polyelectrolytes and their applications. Volume 1. American Scientific Publishers. 2002. 
[70] BALASUBRAMANIAN, S. et al. Azo chromophore-functionalized polyelectrolytes. 2. Acentric self-assembly through a layer-by-layer deposition process. Chem. Mater. v.10, p.1554-1560,1998.

[71] FOU, A.C. et al. Fabrication and properties of light-emitting diodes based on selfassembled multilayers of poly(phenylene vinylene) J. Appl. Phys. ,v.79, p.7501 - 7509, 1996.

[72] WU, A. et al. Solid state light-emitting devices based on the tris-chelated Ru (II) complex: 3. High efficiency devices via a layer-by-layer molecular-level blending approach. J. Am. Chem. Soc., v.121, p.4883-4891 ,1999.

[73] SANTOS, A.F.F. Estudo da tecnologia de impressão por jato de tinta para deposição de filmes finos poliméricos. Dissertação de mestrado, EPUSP (2005).

[74] JUNIOR, N.P.F. Caracterização e otimização de processos de fotolitografia aplicados na fabricação de dispositivos micrométricos MOS e microssistemas. Dissertação de mestrado, UNICAMP (2004).

[75] SAKURAI, Y. et al. Novel array-type gas sensors using conducting polymers, and their performance for gas identification. Sensor and Actuators B, v.83, p.270-275, 2002.

[76] REGAÇO, M.P.Sensor de amônia baseado em filmes finos de polianilina para criadouros de frangos de corte. Dissertação de mestrado, EPUSP2006.

[77] WIZIACK, N.K.L. Estudo do desempenho de uma língua eletrônica baseada em materiais nanoestruturados. Dissertação de mestrado, EPUSP 2005.

[78] MUSIO, F. ; FERRARA, M.C. Low frequency a.c. response of polypyrrole gas Sensors. Sensors and Actuators B, v.41, p.97, 1997.

[79] SOUZA, J.E.G. et al. Polypyrrole thin films gas sensors. Synthetic Metals , v119, p383-384, 2001. 
[80] BRIE, M. et al. The effect of initial conductivity and doping anions on gas sensitivity of conducting polypyrrole films to NH3. Sensors and actuators B, 37, p.119$122,1996$.

[81] KUKLA, A.L. et al. Ammonia sensors based on sensitive polyaniline films. Sensors and Actuators B, V.37, p. 135-140, 1996.

[82] STUSSI, E. et al. Chemoresistive conducting polymer-based odour sensors: influence of thickness changes on their sensing properties. Sensors and Actuators B, v.43, p. 180-185, 1997. 